\title{
TRADUÇÃO, ADAPTAÇÃO CULTURAL E VALIDAÇÃO DA ESCALA DE ATITUDES FRENTE AO ÁlCOOL, AO ALCOOLISMO E AO ALCOOLISTA- EAFAA - VERSÃO ESPANHOL.
}

\author{
Versão corrigida da Dissertação apresentada ao \\ Programa de Pós-Graduação em Enfermagem da \\ Escola de Enfermagem da Universidade de São Paulo \\ para obtenção do título de Mestre em Ciências \\ Área de concentração: Cuidado em \\ Saúde/Enfermagem Psiquiátrica
}

Orientador: Prof. Dr. Divane de Vargas

\section{VERSÃO CORRIGIDA}

A versão original encontra-se disponível na Biblioteca da Escola de Enfermagem da Universidade de São Paulo e na Biblioteca Digital de Teses e Dissertações da Universidade de São Paulo.

\section{São Paulo}

2015 
AUTORIZO A REPRODUÇÃO E DIVULGAÇÃO TOTAL OU PARCIAL DESTE TRABALHO, POR QUALQUER MEIO CONVENCIONAL OU ELETRÔNICO, PARA FINS DE ESTUDO E PESQUISA, DESDE QUE CITADA A FONTE.

Assinatura:

Data:

\section{Catalogação na Publicação (CIP)}

Biblioteca "Wanda de Aguiar Horta"

Escola de Enfermagem da Universidade de São Paulo

León Ramírez, Erika Gisseth

Tradução, adaptação cultural e validação da escala de atitudes frente ao álcool, ao alcoolismo e ao alcoolista EAFAA - versão espanhol / Erika Gisseth León. São Paulo, 2015.

$109 \mathrm{p}$.

Dissertação (Mestrado) - Escola de Enfermagem da Universidade de São Paulo.

Orientadora: Prof. Dr. Divane de Vargas

Área de concentração: Cuidado em Saúde / Enfermagem Psiquiátrica

1. Atitudes do pessoal de saúde. 2. Testes psicológicos. 3. Alcoolismo. 4. Alcoolista. 5. Enfermagem psiquiátrica. 


\section{Folha de aprovação de Mestrado}

Nome: Erika Gisseth León Ramírez

Título: Tradução, adaptação cultural e validação da escala de atitudes frente ao álcool, ao alcoolismo e ao alcoolista- EAFAA - versão espanhol.

Dissertação apresentada ao Programa de Pós-Graduação em Enfermagem da Escola de Enfermagem da Universidade de São Paulo para obtenção do título de Mestre em Ciências.

Aprovado em:

Banca Examinadora

Prof. Dr. Divane, de Vargas

Instituição: Escola de Enfermagem Universidade de São Paulo

Julgamento:

Assinatura:

Prof. Dra. Luz Patrícia Diaz Heredia

Instituição: Facultad de Enfermeria Universidad Nacional de Colombia.

Julgamento: Assinatura:

Prof. Dra. Margarita Villar Luis

Instituição: Escola de Enfermagem Universidade de São Paulo Ribeirão Preto Julgamento: Assinatura: 


\section{DEDICATÓRIA}

Aos meus pais, que me ensinaram que é possível ter sonhos, e lutar com perseverança para consegui-los, e porque apesar da distância sempre manifestaram seu apoio incondicional. Essa vitória é também de vocês....

Ao meu irmão por ser um motor em minha vida, sinônimo de paz e alegria, que com suas particularidades faz de mim um melhor ser humano a cada dia. 


\section{AGRADECIMENTOS}

Agradeço em primeiro lugar a Deus, por ter me permitido concluir essa etapa satisfatoriamente. Por todas as vitórias e perdas, que deixaram em mim um grande aprendizado.

Ao professor Divane de Vargas, meu orientador, por ter depositado sua confiança em mim desde o primeiro momento; pelos conhecimentos compartilhados e pelo seu apoio $e$ preocupação constante durante a elaboração desse trabalho.

Aos funcionários do Departamento de Enfermagem Materno infantil e psiquiátrica, pelo acolhimento e apoio administrativo durante o Mestrado.

A Mily Moreno, companheira em todos os momentos, pelo apoio e compreensão durante todo o caminho percorrido até a finalização desse trabalho.

Aos meus colegas, amigos e cúmplices, Janaina, Bruna, Caroline, Marina, Fernanda, Talita, Simone, Carol, Felipe, Margarita, Inês, Rejane, William, Andrea, Carolina, por estarem junto comigo nos momentos de dificuldade e alegria, servindo de inspiração para continuar trabalhando pela sociedade.

\section{À Fundação de Amparo à Pesquisa do Estado de São}

Paulo pela bolsa de Mestrado concedida sob processo. No. 2013/24983-3 e pelo apoio financeiro para a realização desta pesquisa.

A todas as pessoas que fizeram suas contribuições diretas e indiretas neste processo, muito obrigada. 
"Cada dia que amauhece assemelha-se a uma página em branca, na qual grawamos as nossos pensamentos, açöes e atitudes. Na essência, cada dia é a preparaçãa do nossa própria amaukã"

$$
\text { Chica Xavier }
$$


León EG. Tradução, adaptação cultural e validação da Escala de atitudes frente ao álcool, ao alcoolismo e ao alcoolista versão espanhol. [Dissertação]. São Paulo: Escola de Enfermagem, Universidade de São Paulo; 2015.

\section{RESUMO}

O presente estudo objetivou traduzir, adaptar e validar a Escala de Atitudes frente ao álcool, ao alcoolismo e ao alcoolista - EAFAA para língua espanhola. Método. Estudo metodológico, que seguiu as diretrizes internacionais para tradução e adaptação de escalas de mensuração. A escala original foi adaptada para o idioma espanhol na cultura colombiana. A validade de construto da versão traduzida e adaptada foi realizada por meio da teoria clássica do teste representada pela análise fatorial confirmatória. A confiabilidade da versão em Espanhol da EAFAA foi testada pelo coeficiente de Alfa de Cronbach e Ômega de Mc Donald. Resultado. A validação de conteúdo, indicou índices de validade satisfatórios com IVC $(0,97)$, PABAK $(0,80)$, ICC $(0,92)$. A análise fatorial confirmatória indicou bom ajuste do modelo da EAFAA versão Espanhol, composta por 48 itens, divididos em quatro fatores. A análise da confiabilidade da escala estimada pelo Alfa de Cronbach apresentou índice satisfatório $(\alpha=0,80)$ resultado semelhante ao observado quando se testou a confiabilidade pelo teste de Mc Donald $(\Omega=0.90)$. Conclusões. A EAFAA adaptada e traduzida para o idioma Espanhol, apresentou validade de conteúdo e qualidades psicométricas robustas, o que permite afirmar que se trata de um instrumento válido e confiável, capaz de medir as atitudes frente ao álcool, ao alcoolismo e a pessoa com transtornos relacionados ao uso de álcool com acerácea no contexto cultural Colombiano.

Palavras-chave: Atitude do profissional de saúde, testes psicológicos, validade e confiabilidade, enfermagem 
Leon EG. Translation, cultural adaptation and validation of Attitude Scale of Alcohol, Alcoholism and alcoholics Spanish version. [Dissertation]. São Paulo: School of Nursing, University of São Paulo; 2015.

\begin{abstract}
The aim of this study was to translate, adapt and validate the instrument "attitudes scale towards alcohol, alcoholism and alcoholic" (EAFAA) to Spanish language. Methodology: this methodological study followed the international guidelines on translation and adaptation of measurement scales, to adapt the original scale to the Spanish language in the Colombian culture. The construct validity of translate and adapted version was performed by the classical theory of the test represented by confirmatory factor analysis. The reliability of the Spanish version of EAFAA was tested by Cronbach alpha coefficient and omega of McDonald. Result: The instrument has indicated satisfactory validity rates with a CVI (0.97), Kappa Index (0.80) and ICC (0.92). The confirmatory factor analysis indicated proper adjustment of the model EAFAA Spanish version, consisting of 48 items, divided into four factors. The scale reliability analysis estimated by alpha Cronbach presented satisfactory index $(\alpha=0.80)$ similar to the result observed when tested by the McDonald test $(\Omega=0.90)$. Conclusions: The EAFAA adapted and translated into Spanish language, presented content validity and robust psychometric properties, which allows affirm that this is a valid and reliable instrument, able to measure the attitudes towards alcohol, alcoholism and persons with related disorders to alcohol use with accuracy in the Colombian cultural context.
\end{abstract}

KEYWORDS: Psychological Tests, Attitude of Health Personnel, Validity, Reliability, nursing. 


\section{LISTA DE TABELAS}

Tabela 1. Interpretação do coeficiente de correlação intercalasses. (Mandeville 2005) ........... 34

Tabela 2. Interpretação dos índices de ajuste (Mangin ; Mallow 2006)................................... 38

Tabela 3. Interpretação do Coeficiente do Alpha de Cronbach (Gliem and Gliem 2003)....... 39

Tabela 4. Distribuição de frequências dos Enfermeiros segundo variáveis sociodemográficos

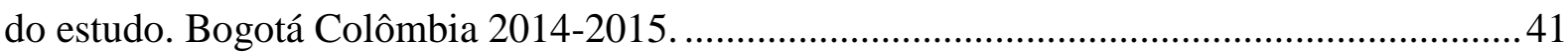

Tabela 5. Escores do índice de validade de Conteúdo da EAFAA …....................................... 48

Tabela 6. Coeficiente de correlação intraclasse para a EAFAA em sua totalidade...................49

Tabela 7. Coeficiente de correlação intraclasse para a EAFAA fator 1..................................49

Tabela 8. Coeficiente de correlação intraclasse para a EAFAA fator 2 ..................................50

Tabela 9. Coeficiente de correlação intraclasse para a EAFAA fator 3 ..................................50

Tabela 10. Coeficiente de correlação intraclasse escores para a EAFAA fator 4 ...................50

Tabela 11 Avaliação do ajuste do modelo de quatro fatores da EAFAA................................52

Tabela 12. Correlação entre os fatores da EAFAA. .............................................................52

Tabela 13. Alfa de Cronbach discriminado por fatores da EAFAA versão adaptada ao

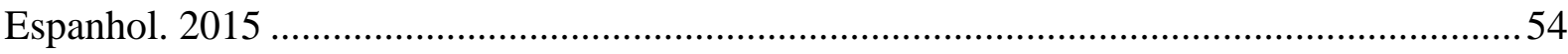

Tabela 14. Escores de Ômega de Mc Donald discriminados por fator. .....................................54

Tabela 15. Discriminação comparativa dos valores do Alfa de Cronbach e Ômega de Mc

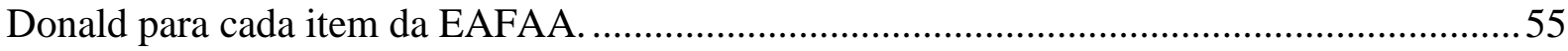

Tabela 16. Ponto de corte, sensibilidade e especificidade da EAFAA versão espanhol..........56 


\section{LISTA DE FIGURAS}

Figura 1. Trajetória metodológica processo de adaptação cultural Fase I (Beaton et al. 2000)

Figura 2. Diagrama de caminhos- Análise fatorial confirmatória modelo de quatro fatores...53

Figura 3. Curva ROC. "O alcoolista é grosso e mal educado"

\section{LISTA DE QUADROS}

Quadro 1. Caracterização dos juízes de acordo com o local de procedência e experiência.....32 Quadro 2. Versão Final da EAFAA discriminada por fatores após validação de construto.

Fator 1

Quadro 3. Versão Final da EAFAA discriminada por fatores após validação de construto.

Fator 2 58

Quadro 4. Versão Final da EAFAA discriminada por fatores após validação de construto.

Fator 3 58

Quadro 5. Versão Final da EAFAA discriminada por fatores após validação de construto. Fator 4. 


\section{LISTA DE ABREVIATURAS E SIGLAS}

AFC Análise fatorial confirmatória

AFE Análise fatorial exploratória

CICAD Comissão interamericana para o controle do abuso de drogas.

CID Código internacional de doenças

EAFAA Escala de atitudes frente ao álcool, ao alcoolismo e ao alcoolista.

ICC Coeficiente de correlação intercalasses

INPAD Instituto Nacional de Políticas Públicas do Álcool e Outras Drogas

IVC Índice de validade de conteúdo

OMS Organização Mundial de Saúde

OPS Organização Pan-Americana de Saúde

SDA Síndrome de dependência alcoólica

WHO World Health Organization

PABAK Prevalance and Bias Adjusted Kappa-Ordinal Scale 


\section{SUMÁRIO}

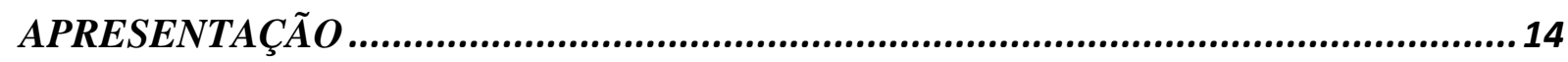

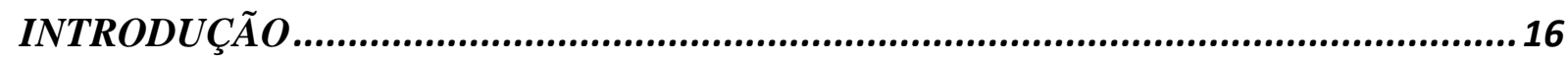

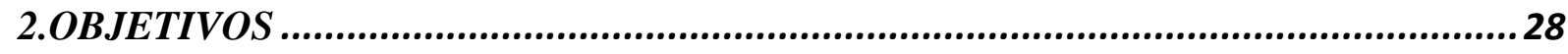

2.1 OBJETIVO GERAL ............................................................................................28

2.2 OBJETIVOS ESPECÍFICOS ..............................................................................28

ASPECTOS METODOLÓGICOS ......................................................................... 30

3.1 TIPO DE ESTUDO......................................................................................................30

3.2 PROCESSOS DE ADAPTAÇÃO CULTURAL E VALIDAÇÃO DE CONTEÚDO

DA EAFAA (FASE I) .............................................................................................................30

3.2.1 Tradução do instrumento original à língua da população alvo (espanhol)......................................30

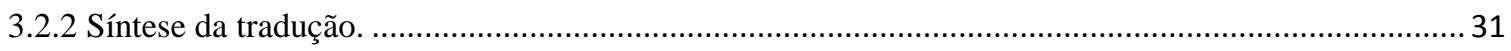

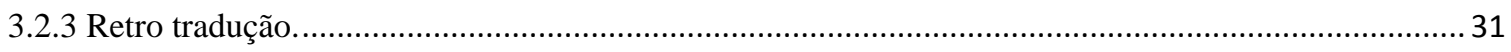

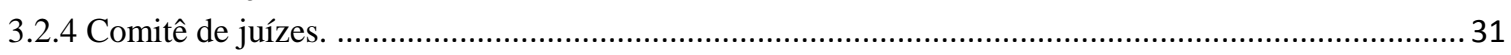

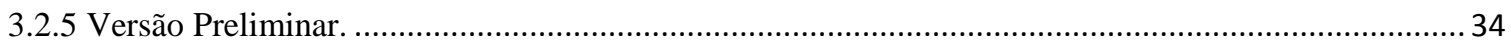

3.2.6 Submissão dos documentos produzidos em todas as etapas para avaliação. .................................... 36

3.3 VERIFICAÇÃO DAS PROPRIEDADES PSICOMÉTRICAS (FASE II) ...............36

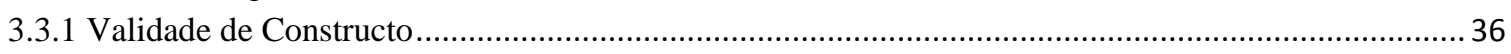

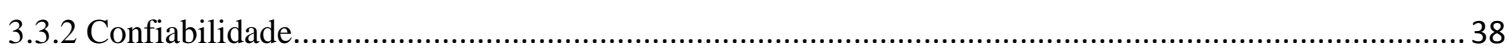

3.3.3 Sensibilidade e especificidade da EAFAA …............................................................................ 40

3.3.4 Sujeitos do estudo (validação de construto- versão adaptada da EAFAA) ...................................... 40

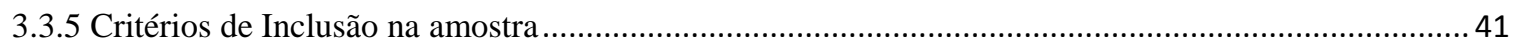

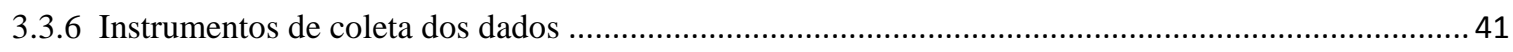

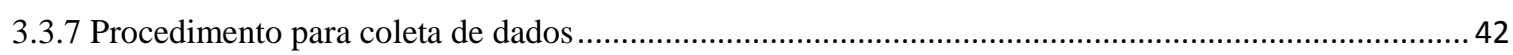

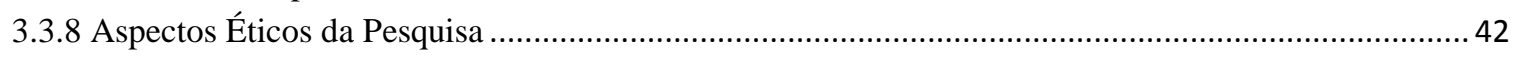

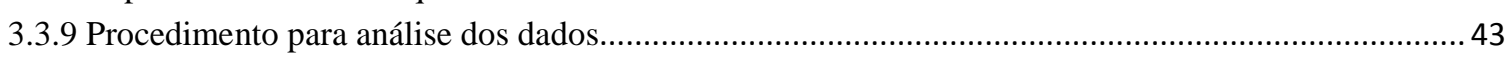

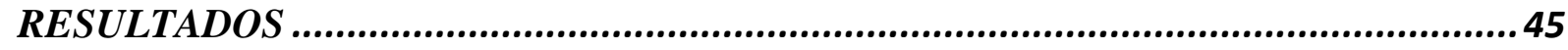

4.1 RESULTADOS DO PROCESSO DE ADAPTAÇÃO CULTURAL E VALIDAÇÃO DE CONTEÚDO DA EAFAA (FASE I) ..............................................45

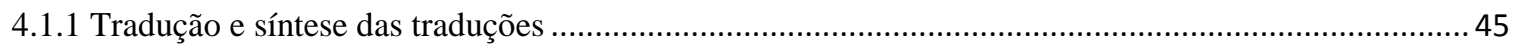

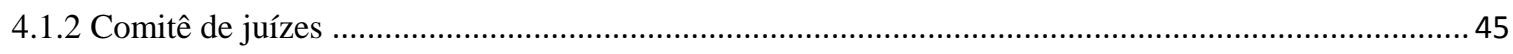

4.1.3 Aplicação da versão preliminar (pré-teste) ................................................................................ 51

\subsection{RESULTADOS DA VERIFICAÇÃO DAS PROPRIEDADES PSICOMETRICAS}

DA EAFAA (FASE II) ......................................................................................................51

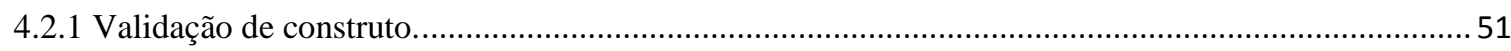

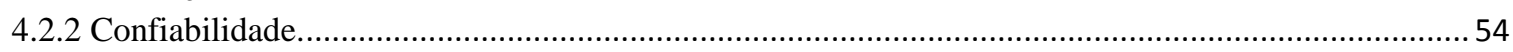

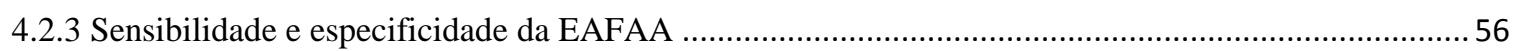

DISCUSSÃ O 


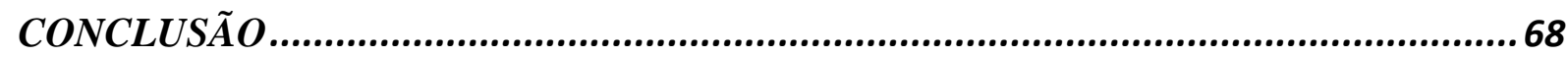

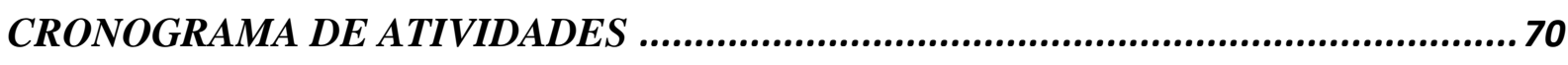

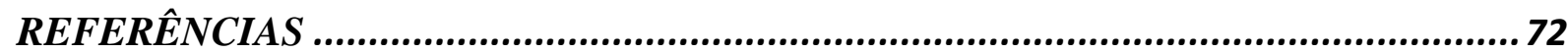

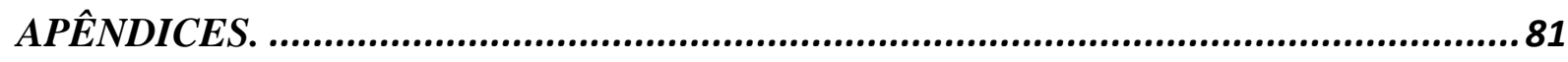

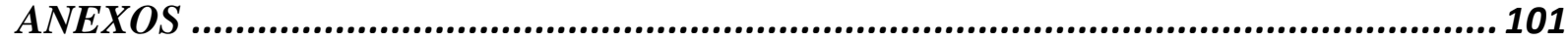




\section{APRESENTAÇÃ̃o}

O consumo de sustâncias psicoativas tem sido o tema de meu interesse há alguns anos desde a graduação. Estudei as estratégias de atendimento na Colômbia, e procurei diversos grupos de pesquisa dentro e fora do país. Fiz meu trabalho de conclusão de curso no Brasil na Escola de Enfermagem da Universidade de São Paulo, estabelecendo contato com o Professor Divane de Vargas, neste momento, diretor do Grupo de Estudos sobre Álcool e outras Drogas (GEAD). Solicitei sua orientação para o início da pesquisa "Acciones preventivas en salud para consumo de sustancias psicoactivas en adolescentes: en centros de atención especializados de São Paulo Brasil, 2011: Desafío de Salud Pública” no ano 2011. Sua finalização, foi apresentada como pôster no Seminário Internacional de Cuidado em enfermagem na cidade de Bogotá, Colômbia, e publicada como artigo na Revista Comuncuidado. Após este trabalho, surgiu minha inquietude por conhecer em profundidade o comportamento dos profissionais de enfermagem frente à temática do consumo de álcool, observando se as atitudes deles influenciam na qualidade do atendimento à população.

Uma vez revisada a Escala de Atitudes frente ao Álcool, ao Alcoolismo e ao Alcoolista (EAFAA), construída pelo Professor Doutor. Divane de Vargas, o interesse de pesquisar nesta área tornou-se mais intenso, o que originou esse estudo visando realizar a validação e adaptação cultural da EAFAA para seu uso nos países hispano falantes como instrumento que permita identificar as atitudes dos profissionais de enfermagem que prestam o atendimento a essa população. 
INTRODUÇÃO 


\section{INTRODUÇÃO}

Estudos realizados apontam para um incremento constante no que se diz respeito ao uso de drogas, em que observou-se que a droga legal com maior incidência é o álcool, e seu uso inicia-se cada vez mais precocemente. Quando se fala, especificamente, do consumo de álcool, $6.2 \%$ das mortes entre homens e $1.1 \%$ das mortes entre as mulheres, em todo o mundo, são decorrentes do consumo desta droga. Entre os jovens de 15 a 29 anos, esses índices chegam a 9\%. Globalmente $36 \%$ do álcool é consumido em cerveja, e esse consumo é muito maior na região das Américas, na qual a taxa per capita é 54,7\% (World Health Organization, 2011). Dados mais recentes indicam que 5,9\% das mortes da população mundial podem ser atribuídas ao consumo de álcool, com algumas diferenças importantes entre gênero em relação à proporção das mortes globais atribuídas ao álcool, 7,6\% homens e 4,0\% para mulheres (World Health Organization, 2014).

O consumo de álcool na América Latina é $40 \%$ maior que a média mundial, evidenciando-se que sua ingestão encontra-se em níveis prejudiciais. Por essa razão, a região ultrapassa a média global para diversos problemas decorrentes do uso abusivo de álcool transformando- o numa prioridade de saúde pública no hemisfério(Organização Panamericana da Saúde 2007; OPS 2009; Monteiro 2013). Num estudo comparativo entre seis países da América Latina, com população entre 15 e 64 anos de idade (CICAD, 2008), verificou-se variabilidade nos níveis de consumo entre as populações estudadas que superam em $50 \%$ na Argentina, Chile e Uruguai, $40 \%$ na Bolívia e 35\% no Equador e Peru. Além disso, o estudo encontrou dados importantes em relação ao consumo abusivo o qual atingiu 9\% no Uruguai, $13 \%$ na Argentina, $17 \%$ no Chile e Peru, ultrapassando $40 \%$ no Equador e Bolívia. Tais resultados justificam as afirmações da Organização Mundial da Saúde (World Health Organization, 2011) de que nos últimos cinco anos, houve um incremento significativo na produção e na venda de bebidas alcoólicas na América Latina, o que confere a este hemisfério $20 \%$ do consumo mundial dessa substância.

No que se refere à Colômbia em 2011, os estudos (Ministerio de justicia y derecho, Observatorio de Drogas de Colombia, 2011) apontaram que 40\% dos jovens colombianos, entre 11 e 18 anos, haviam consumido bebida alcoólica no último mês, com prevalências similares entre homens $(40,1 \%)$ e mulheres $(39,5 \%)$. Recentemente outro estudo realizado no mesmo país (Ministerio de Justicia y del Derecho - Observatorio de Drogas de Colombia, 2014) indicou que 2,5 milhões de pessoas fazem uso abusivo desta substância, dos quais 1,9 
milhões são homens e 0,6 milhões são mulheres. Estes dados representam $31 \%$ dos consumidores de álcool do último mês e 11,1\% da população do país entre 12 e 65 anos de idade.

Os índices de consumo de drogas psicoativas, principalmente o álcool que aparece como um fator contribuinte para mais de 60 condições listadas no CID (Código Internacional de Doenças). Ele está relacionado a mortes e internações por lesões intencionais e não intencionais decorrentes da violência doméstica, acidentes de trânsito, afogamentos, queimaduras, suicídios e homicídios (Meloni, 2004). Por esses motivos, os enfermeiros e os profissionais de saúde em geral estão cada dia mais sujeitos a ter contato com alcoolistas no seu cotidiano de trabalho. Essa constatação deve estimular o estudo das atitudes desses profissionais frente ao fenômeno já que existem evidências de que as atitudes são precursoras tanto da qualidade quanto da quantidade do cuidado prestado (Rassool, Villar, Carraro 2006; Rassool and Rawaf 2008; Vargas 2011).

Apesar da magnitude do uso de álcool na América Latina, e em especial, da Hispano América, são escassos estudos sobre as atitudes de profissionais de saúde de idioma Espanhol, o que pode se dever em parte pela carência de instrumentos disponíveis nessa língua para mensuração de atitudes. As ferramentas para esse fim são relevantes no contexto da enfermagem da América Latina, principalmente porque nesse continente, o idioma Espanhol é o idioma oficial em 21 países, representando 90\% da região. Assim, a disponibilização de um instrumento confiável para mensuração das atitudes desses trabalhadores frente ao álcool, ao alcoolismo e ao alcoolista no idioma espanhol, poderá beneficiar não só a prática dos enfermeiros hispano falantes, mas também na pesquisa em enfermagem na área de álcool e outras drogas, ainda incipiente na maioria dos países latino-americanos em especial aqueles de língua espanhola.

No entanto, apesar desse fenômeno já ser conhecido e documentado pela enfermagem brasileira (Pillon; Laranjeira 2005; Vargas; Labate 2006; Villar 2008; Vargas 2010, 2011) Norte Americana (Watson et al. 2007; Vadlamudi et al. 2008; Cund 2013), Europeia (Iqbal et al. 2015), Australiana (Happell et al. 2002; Crothers 2011) e Espanhola (Lopez, 2014) existe escassez de estudos latino-americanos desenvolvidos em países de idioma espanhol que objetivaram estudar esse fenômeno, tornando-o pouco conhecido nessa parte do continente. 


\section{Atitude}

Atitude, é um termo Francês que originou-se da expressão italiana attitudine, cuja raiz linguística provem do Latim aptitudo-aptitudin (Altmann, 2008). Conforme definição dos termos Mesh da National Center for Biotechnology Information (NCBI, 2014) as atitudes são consideradas como uma predisposição adquirida e duradoura a se comportar de uma maneira consistente em relação a uma determinada classe de objetos, ou como um estado mental persistente de prontidão para reagir a uma determinada classe de objetos. Numa revisão de literatura cujo intuito era analisar o conceito de atitude desde diversas concepções, apontou-se que entre todas as definições existiam três características comuns, dentre elas: 1. A concepção da atitude como um estado mental de consciência ou inconsciência; 2. Conceito que abrange valores, crenças e sentimentos;3. Como a predisposição para um comportamento ou ação (Altmann, 2008).

Historicamente as atitudes tem sido definidas por vários autores, dentre eles, Thurstone (Thurstone, 1946) a atitude é definida com o grau de afetividade positiva ou negativa diante de um objeto psicológico, este último termo, refere-se à representação mental de um símbolo, pessoa, slogan, frase, instituição, tópico frente ao qual a pessoa pode sentir um afeto positivo, é dizer ter uma atitude favorável ou negativo quando tem uma atitude desfavorável (Allen, 1957). Conforme outros autores (Allport, 1935) as atitudes podem ser consideradas como estados mentais de prontidão que influenciam as respostas comportamentais do indivíduo frente aos objetos com os que se relaciona.

Para Smith (1956), a atitude pode se determinar por meio da predisposição para perceber de diferentes situações com um afeto determinado o que permite agir com determinadas características diante de tais situações (Smith, 1956). Por outro lado Doob em 1947 apontou que as atitudes são respostas implícitas geradoras de impulsos considerados significativamente no contexto social (Torres, 2011).

As definições com abordagens multicomponentes dentre eles sentimento, pensamento e ação são muito comuns entre os autores, porém outras teorias argumentam que os sentimentos e as emoções podem influenciar crenças e atitudes sobre o objeto avaliando a atitude por meio de uma perspectiva uni componente.

O modelo tripartite proposto por Rosenberg (Rosenberg, 1960), deu a pauta para posteriores análises mais contemporâneas, trata-se de um modelo hierárquico que inclui o 
componente cognitivo, afetivo e comportamental, cada um definido independentemente com o intuito de compreender com um alto nível de abstração o construto atitude.(Ajzen 2005; Manuel 2006; Altmann 2008).

A atitude faz parte das relações do sujeito com seu contexto, físico, social, espiritual, etc., e todas essas relações são observáveis, se pensarmos numa medição direta de tais atitudes não seria possível, porém as relações que as compõem tornam-se o objetivo de medição (Cunha, 2007). Para tal efeito alguns estudiosos construíram escalas especificas para mensurar as atitudes, dentre eles:

A escala Guttman é composta por uma série de itens organizados em forma hierárquica com um grau de dificuldade, frente aos quais o sujeito deve manifestar sua concordância ou não, o fato de concordar com um item implica concordar com os precedentes. Geralmente tem poucos itens e é utilizada para medir atitudes concretas (Manuel 2006; Cunha 2007)

Um outro tipo de escala é a Thurstone que geralmente é constituída por um conjunto de itens em relação aos quais o sujeito avaliado deve manifestar o seu acordo ou desacordo. Mede-se a atitude do sujeito fazendo a média ponderada unicamente dos itens em que ele manifestou estar de acordo (Hogan 2006; Cunha 2007) .

Likert em 1932 propôs o método mais utilizado até hoje para a construção de uma escala de atitudes, nesse tipo de escala cada item fornece informações sobre atitude do indivíduo, e finalmente a soma de todas essas informações de todos os itens que compõem a escala permitiram obter uma visão holística em relação ao objeto alvo, para tal fim utiliza-se uma escala de cinco pontos cuja nomenclatura varia de Concordo totalmente a Discordo totalmente (Hogan, 2006). Em geral em relação ás outras escalas a escala tipo likert apresenta maior facilidade na sua elaboração, é mais precisa do que as outras devido ao número de possíveis respostas alternativas (Ospina, 2005).

\section{Atitudes do Enfermeiro frente ao álcool, ao alcoolismo e ao alcoolista}

$\mathrm{Na}$ Austrália, estudos realizados com enfermeiros em dois momentos, mostraram alguns resultados similares. O primeiro (Happell, 2002), realizado com 132 enfermeiros apontou que $64 \%$ apresentaram atitudes positivas. Já a pesquisa mais recente (Crothers , 2011), realizada numa amostra menor (70 participantes), na qual foram utilizadas três escalas especificas para mensuração de atitudes, dentre elas, (Marcus Alcoholism, Seaman Mannello 
Nurses' Attitudes toward Alcoholism, Alcohol and Alcohol Problems Perception Questionnaires) mostrou que as atitudes positivas prevaleciam sobre negativas e indicou que 1 em cada 7 (12\%) dos participantes relataram atitudes negativas. Os autores salientam que esse é ainda um resultado negativo, embora tinha sido melhor que nas décadas anteriores. Estudo multicêntrico realizado na Europa (Gilchrist et al. 2011), numa amostra de 866 profissionais de saúde, concluiu que as atitudes negativas da equipe de saúde devem ser considerados em relação às políticas de abuso de substâncias, já que podem constituir um obstáculo no acesso ao tratamento e têm um impacto negativo sobre seu resultado. Em contraste, outra pesquisa na Irlanda (Iqbal et al. 2015) que aplicou a escala Alcohol and Alcohol Problems Perception Questionnaire (SAAPPQ) em 204 profissionais de saúde, como enfermeiros, médicos e trabalhadores sociais em diversas áreas de atuação (emergência, psiquiatria, centro cirúrgico) demonstrou que existem diferenças significativas entre profissionais com formação e treinamento em adições, os quais tem atitudes mais positivas diante do usuário com transtornos decorrentes do uso de álcool em contraste com profissionais gerais que apresentaram atitudes negativas, concluindo assim que a capacitação da equipe de saúde tem uma influência positiva sobre as atitudes dos profissionais em relação ao cuidado dos usuários.

Quanto as atitudes dos profissionais de saúde, essas pesquisas destacaram a influência dos programas educacionais (Happell et al. 2002; Crothers 2011), da capacitação da equipe (Iqbal et al. 2015), além de fatores individuais, sociais e de relacionamento (Molina Mula et al. 2012). O estudo mais recente na Espanha (Lopez, 2014) destaca que o fator que influencia mais na atenção aos usuários, é o déficit de conhecimento, seguido das atitudes e percepções sociais (crenças e valores), além disso, acentua que os profissionais de Enfermagem apresentam um certo grau de resignação e insatisfação diante do trabalho com alcoolistas.

Essas atitudes puderam ser observadas também em estudo realizado na Bolívia (Navarrete, 2004) em que foi utilizada a escala Seaman Mannello Nurses' Attitudes toward Alcoholism, com 71 enfermeiras de hospitais públicos. Nela foi apontado que as atitudes desses profissionais poderiam ter sido influenciadas pela formação recebida e dos conhecimentos adquiridos por meio da experiência com a doença Esses fatos levaram os profissionais a considerar a pessoa com transtornos relacionados ao uso do álcool como “desagradável”, mas também como um indivíduo que precisa de ajuda e orientações. Nota-se, 
portanto, que não é o paciente da sua preferência, o que marca sem dúvida uma atitude com predominância negativa.

No entanto, outros autores(Villar, 2008) destacam que essa atitude negativa apresenta maior ênfase na falta de autocontrole como um comportamento errado e não aceitável entre os profissionais. Pesquisa realizada no Brasil, com a Escala de atitudes frente ao álcool, ao alcoolismo e ao alcoolista afirmou que embora uma parcela de profissionais conserva atitudes negativas, uma grande quantidade ainda considera que a bebida tem propriedades benéficas quando usada moderadamente, manifestando uma posição mais ambivalente.

Resquícios dessas constatações foram percebidos em estudo na Colômbia que avaliou as atitudes em uma amostra de 159 estudantes de enfermagem no último ano utilizando a escala NEADA. Os resultados evidenciaram que $2 \%$ dos participantes possuíam preparo teórico, apontando debilidades na abordagem do usuário. Embora os participantes tenham apresentado atitudes positivas frente ao atendimento de pessoas com transtornos relacionados ao uso de álcool, os autores consideram ser fundamental a formação dos profissionais de enfermagem para abordar a atenção à pessoa com transtornos decorrentes do uso de álcool e outras drogas.

Tais considerações correspondem com a revisão realizada por Molina na Espanha (Molina Mula et al. 2012), a qual apontou que existem vários tópicos em comum entre os estudos analisados, a saber: que fatores como as crenças individuais, idade, gênero, e religião, tem uma influência nas atitudes dos profissionais diante do usuário de álcool; algumas atitudes diferem com base na socialização e a natureza da interação com esse usuários, e finalmente, a denotação da escassa presença da temática de álcool e outras drogas na formação do recurso humano.

Esses estudos indicam que a produção científica nos últimos cinco anos, sobre a temática, atitudes dos enfermeiros no mundo, tem se concentrado na Austrália (Happell et al. 2002; Crothers 2011); Países nórdicos (Iqbal et al. 2015); Brasil,(Vargas 2010a; Vilela et al. 2010; Soares et al. 2011) e Estados Unidos(Watson et al. 2007). Observou-se, entretanto, uma escassez de produção na América Latina, em específico, estudos oriundos de países hispano falantes. 
Os resultados dos estudos publicados ao redor do mundo, sugerem algumas diferenças relevantes de acordo com a região onde são desenvolvidos. Dentre elas, os estudos Europeus (Gilchrist et al. 2011; Iqbal et al. 2015) semelhantemente aqueles realizados na Oceania (Happell et al. 2002; Crothers 2011), apontam que as atitudes dos profissionais de saúde estão fortemente relacionadas com o treinamento específico na área, sendo que as atitudes de profissionais treinados são mais positivas quando comparadas com aqueles que não passam por treinamentos para atuar na área, por isso salienta-se a importância da educação continuada.

Por outro lado, nas Américas, os estudos realizados nos Estados Unidos (Watson et al. 2007) e no Brasil, (Vargas 2006, 2010a; Vargas e Labate 2006; Vilela et al. 2010; Soares et al. 2011) especificamente, apresentam semelhanças significativas, principalmente no que se refere a ambivalência dos profissionais frente ao uso do álcool e a pessoa com transtornos decorrentes do seu uso. Neles notam-se atitudes positivas com relação ao uso do álcool, ao mesmo tempo em que predominam as atitudes negativas quando se trata de cuidar dessa população.

As pesquisas realizadas até agora têm utilizado instrumentos de mensuração e amostras diferentes, chegando a resultados próximos acerca das atitudes dos profissionais de saúde, entretanto, isso pode possibilitar vieses na interpretação de seus resultados, e influenciar a comparação do fenômeno nas diferentes culturas da América Latina. Por esse motivo, torna-se necessário investir em pesquisas realizadas com o mesmo instrumento em países de América Latina de idioma espanhol, uma vez que se pressupõe que as atitudes dos enfermeiros frente ao álcool, ao alcoolismo e a pessoa com transtornos relacionados ao uso de álcool caracterizam-se como um fenômeno comum através das culturas latino-americanas.

Essa prerrogativa, entretanto, parece prejudicada, pois quando analisadas as escalas disponíveis para mensuração das atitudes dos enfermeiros frente a pessoa com transtornos decorrentes do uso de álcool, evidencia-se que maioria delas se encontram disponíveis em língua inglesa e que, portanto, foram desenvolvidas naquele contexto social e cultural. Porém carecem de publicações que se ocupem em apresentar com rigor seus processos de construção e validação e mesmo de tradução para uso em outros idiomas que não aqueles de origem.

Dos instrumentos disponíveis para mensuração das atitudes dos enfermeiros, apenas dois foram traduzidos para língua espanhola (Navarrete; Villar 2004; Vásquez; Pillon 2005), a escala baseada no Nursing Education in Alcohol and Drug Education (NEADA) (Vásquez; 
Pillon 2005) e a Seaman Manello Nurses' Attitudes Towards Alcohol and Alcoholism Scale (Navarrete and Villar 2004).

A NEADA elaborada nos Estados Unidos na cidade de Conneticut no ano 1985, é uma escala do tipo likert (Anexo I), composta por trinta itens, distribuídos em cinco subescalas para avaliar atitudes e crenças do profissional de saúde como parte de um programa de treinamento de Enfermagem para estudantes, enfermeiros (as) e docentes para o trabalho com usuários com problemas decorrentes do uso de álcool. O instrumento foi traduzido inicialmente do inglês para o português por dois especialistas em álcool e outras drogas (Pillon 2006; Rassool et al. 2006); e posteriormente para o espanhol por um tradutor reconhecido oficialmente na Colômbia e submetido à comparação com o instrumento original pela pesquisadora responsável (Vásquez; Pillon 2005).

Apesar das características favoráveis do instrumento, apresentam-se algumas desvantagens, dentre elas a dificuldade de se acessá-lo na integra, pois foi necessário contatar a autora do estudo (Vásquez, 2005), para obter informação da mesma.

Outro estudo realizado entre enfermeiros hispano-falantes (Navarrete; Villar 2004) utilizou a escala Nurses Atittudes Toward Alcohol and Alcoholism de Seaman e Mannello, elaborada nos Estados Unidos na cidade de Búfalo, na década de 1970, e traduzida ao português em 1998 (Pillon, 1998), posteriormente traduzida ao espanhol e aplicada numa população hispano-falante especificamente na Bolívia (Navarrete ; Villar 2004). Trata-se de uma escala específica para medir as atitudes dos profissionais, relacionadas ao tratamento do alcoolismo e o uso de álcool. É do tipo likert, composta de 30 itens, distribuídos em cinco sub-escalas (Anexo II).

Avaliando o uso da escala Seaman e Mannello, alguns autores (Pillon et al. 1998; Vargas 2006; Alabarce et al. 2012) apontaram algumas limitações, como a ausência de estudos publicados sobre as qualidades psicométricas desse instrumento, mesmo em sua língua de origem. Além disso, o uso da escala no idioma espanhol possibilita questionamentos sobre o processo metodológico, já que não há clareza em relação aos procedimentos técnicos, os quais não atendem as recomendações internacionais sugeridas para os processos de adaptação o que compromete a validade e confiabilidade dos instrumentos nesse idioma.

Além dessas fragilidades metodológicas dos instrumentos apresentados, é preciso considerar que as escalas utilizadas foram elaboradas há mais de uma década, o que pode 
trazer dificuldades relacionadas às diferenças nas características populacionais observadas na época que foram construídas, em contraste com as características da população atual. Tais desvantagens apontam para a necessidade de disponibilizar-se um novo instrumento traduzido e validado para o uso entre esta população, que seja mais recente, e que possa mensurar várias dimensões atitudinais, quais sejam: comportamental, cognitiva e emocional (Vargas, 2005).

Nesse sentido, a Escala de Atitudes frente ao álcool ao alcoolismo, e a pessoa com transtornos relacionados ao uso do álcool (EAFAA) torna-se uma opção mais adequada quando comparada com as escalas até agora disponibilizadas. Isso se justifica, pois foi elaborada há poucos anos num país latino-americano, o que pressupõe que apesar das diferenças culturais se assemelha mais as características da população alvo desse estudo. Aliado a isso, a EAFAA possui uma trajetória metodológica rigorosa e disponibilizada em publicações acadêmicas, demonstrando bons índices de validade e confiabilidade, o que justifica sua validação com o intuito de oferecer subsídios para posteriores pesquisas que verifiquem as atitudes desses profissionais na América Latina.

\section{A Escala de Atitudes frente ao álcool, ao alcoolismo e a pessoa com transtornos relacionados ao uso de álcool. (EAFAA) (Anexo III).}

A EAFAA foi construída em 2008 no Brasil com o objetivo de abranger os principais grupos de atitudes (fator moral, fator doença, fator etiológico e fator humano) (Vargas, 2008). Previa elaboração do instrumento foi realizado um estudo exploratório de cunho qualitativo (Vargas et al. 2008) com vistas a conhecer as concepções e tendências atitudinais dos enfermeiros frente ao álcool e questões associadas a seu uso, além de subsidiar o processo de construção dos itens e a definição operacional da escala, o que resultou num instrumento composto por 225 itens distribuídos em cinco fatores. Entretanto, apesar de ter sido submetida a vários processos de refinamento posteriores e mostrar parâmetros psicométricos adequados, ( Alpha de Cronbach 0,90) (Vargas, 2008, 2011) o instrumento em sua versão ainda considerava-se extenso. Este problema, originou posteriores estudos e análises, resultando na redução dos itens e recomposição dos fatores da EAFAA de cinco da versão anterior (Vargas, 2011) para quatro na versão atual com 50 itens, a qual apresentou bons índices de confiabilidade e consistência interna (Alpha de Cronbach 0,89) (Vargas, 2014).

Atualmente pode se dizer que a EAFAA é uma escala do tipo likert de cinco pontos (1= Discordo totalmente, $2=$ Discordo, $3=$ indiferente, $4=$ Concordo, $5=$ Concordo totalmente), composta por 50 itens divididos em quatro fatores, assim definidos (Vargas, 2014): 
Fator 1: O trabalho e as relações interpessoais com o alcoolista, inclui itens relacionados à percepção, opiniões, sentimentos e atitudes frente ao cuidado prestado a pessoas com transtornos relacionados ao uso de álcool $(01,05,09,13,21,25,37,41,46,50)$ e ao relacionamento com os mesmos $(29,42,44)$, a habilidade ou preparo para trabalhar com essas pessoas (49), além da percepção sobre a própria legitimidade profissional para trabalhar nesta área $(17,48)$.

Fator 2: A pessoa com transtornos relacionados ao uso de álcool, encontra-se composta por itens referentes às concepções, percepções e atitudes do profissional frente à pessoa com transtornos relacionados ao uso de álcool, em que os itens expressam as concepções sobre as características pessoais do usuário $(02,06,10,14,18,22,30,45,47)$ e as expectativas que o profissional tem para trabalhar com o mesmo $(26,33,34,38)$.

Fator 3: Alcoolismo (Etiologia), esse fator agrupa itens referentes às percepções sobre as motivações/causas para o uso de álcool e para o alcoolismo. Baseou-se na explicação biopsicossocial para os transtornos relacionados ao uso de álcool e inclui itens relacionados aos fatores psíquicos $(07,11,27,31,35,43)$, sociais $(03,39,19)$, biológicos $(23)$ e morais $(15)$, os quais são atribuídos como causa do uso de álcool e os transtornos relacionados ao seu uso.

Fator 4: $O$ álcool e seu uso, reúne itens que se referem às opiniões e atitudes dos profissionais frente ao álcool $(08,12,16,32)$, seu uso $(20,24,28,36)$ e o direito que tem os indivíduos de fazer uso da bebida $(04,40)$.

Essa última versão da EAFAA encontra-se "constituída por itens predominantemente negativos, o que significa que, quanto maior o desacordo do sujeito em relação ao item, mais positiva sua atitude. Por isso, para interpretação dos dados coletados com essa escala, as respostas aos itens negativos devem ser calculadas com valores invertidos, devendo os escores ser assim computados: $(1=5),(2=4),(3=3),(4=2),(5=1)$. Consequentemente, escores altos indicam atitudes positivas enquanto que escores baixos tendem a indicar atitudes negativas" (Vargas, 2014).

Diferentemente das escalas citadas anteriormente (Navarrete, Villar 2004; Vásquez, Pillon 2005) a EAFAA apresenta estudos publicados sobre suas qualidades psicométricas no idioma de origem, indicando bons índices de validade e confiabilidade (Vargas 2005, 2008, 2011, 2014), e atualmente encontra-se em processo de tradução e validação para o inglês. Além disso a EAFAA avalia grupos de atitudes que não são contemplados em outros 
instrumentos e são considerados importantes no momento da atenção às pessoas com transtornos decorrentes do uso de álcool, dentre elas, as atitudes do enfermeiro frente ao trabalho e o relacionamento interpessoal com o usuário; as atitudes diante das motivações e causas do alcoolismo e o direito que os indivíduos têm de fazer uso da bebida. Assim, o instrumento torna-se uma ferramenta facilitadora na compreensão da relação enfermeirousuário no contexto do uso das bebidas alcoólicas. 
OBJETIVOS 


\section{OBJETIVOS}

\subsection{OBJETIVO GERAL}

Realizar a validação de construto da Escala de Atitudes frente ao álcool, ao alcoolismo e ao Alcoolista - EAFAA no idioma Espanhol.

\subsection{OBJETIVOS ESPECÍFICOS}

Realizar a tradução e adaptação cultural da Escala de Atitudes frente ao álcool, ao alcoolismo e à pessoa com transtornos relacionados ao uso de álcool versão espanhol.

$\checkmark$ Realizar a validade de conteúdo da escala de atitudes frente ao álcool, ao alcoolismo e a pessoa com transtornos relacionados ao uso de álcool versão espanhol.

$\checkmark$ Realizar análise das qualidades psicométricas da escala de atitudes frente ao álcool, ao alcoolismo e a pessoa com transtornos relacionados ao uso de álcool, segundo os parâmetros estatísticos. 
METODOLOGIA 


\section{ASPECTOS METODOLÓGICOS}

\subsection{TIPO DE ESTUDO}

Trata-se de um estudo metodológico, no qual a meta é alcançar um instrumento preciso e utilizável, e que possa ser empregado por outros pesquisadores, tratando da elaboração, validação e avaliação do instrumento na sua adaptação transcultural (Polit et al. 2006). A adaptação cultural da EAFAA foi realizada com a autorização prévia do autor da mesma, (Apêndice A). O instrumento foi adaptado para o idioma espanhol na cultura colombiana, conforme as seis etapas sugeridas pela literatura sobre as diretrizes de tradução e adaptação de instrumentos consideradas essenciais para obter um resultado de qualidade: tradução, síntese, retro tradução, avaliação da versão por um comitê de juízes, elaboração da versão preliminar ou pré-teste (Beaton et al. 2000). Em seguida, foram avaliadas as respectivas qualidades psicométricas na versão final do instrumento.

O processo metodológico desenvolveu-se em duas etapas: Fase I processo de adaptação cultural e Fase II avaliação das propriedades psicométricas.

\subsection{PROCESSOS DE ADAPTAÇÃO CULTURAL E VALIDAÇÃO DE CONTEÚDO DA EAFAA (FASE I)}

Quando procuramos instrumentos para mensurar atributos específicos como atitude, a maioria encontra-se desenvolvida em outras culturas ou línguas diferentes do Espanhol. Neste sentido, torna-se necessário realizar uma adaptação cultural do instrumento em questão que garanta o uso adequado da linguagem no que se refere à expressão e compreensão verbal da população, em que pretende-se aplicar o instrumento (Beaton et al. 1998, 2000; Maneesriwongul 2004; Comittee for translations and Protocols International RDC/TMD Consortium Network, 2013). No entanto, deve-se prestar atenção no processo de tradução , já que não basta apenas que ele esteja somente bem traduzido, é necessário realizar uma avaliação rigorosa da sua tradução e adaptação cultural (Lage et al. 2006). Conforme indicado anteriormente para a adaptação cultural da EAFAA utilizou-se a metodologia proposta por Beaton (2000) nas etapas que seguem na sequência:

\subsubsection{Tradução do instrumento original à língua da população alvo (espanhol).}

A primeira etapa foi realizada por dois tradutores bilíngues cada um deles nativo hispano-falante e conhecedor da língua e da cultura brasileira. Um deles devia conhecer os 
termos específicos relacionados à área de aplicação da escala, neste caso, contou-se com a participação de uma enfermeira colombiana. O segundo tradutor, um linguista sem conhecimento dos termos específicos já que é importante, nessa etapa segundo recomendação dos autores, que um dos tradutores fizesse uma tradução com significado técnico e o outro, uma tradução com o significado cultural, para garantir a identificação de terminologia ambígua. O resultado desse processo foram as duas versões traduzidas T1 e T2.

\subsubsection{Síntese da tradução.}

Após realizadas as traduções T1 e T2, os dois tradutores reuniram-se com um terceiro avaliador com o intuito de realizar a síntese das duas traduções, o que resultou num relatório elaborado pelo avaliador junto com uma nova versão do instrumento (S1).

\subsubsection{Retro tradução.}

A versão produzida na etapa anterior $(\mathrm{S} 1)$ foi traduzida novamente à linguagem original, ou seja, para o português. A tradução esteve a cargo de dois indivíduos que conheciam os termos de referência específicos e cuja língua nativa era o português. Como produto obtivemos BT1 e BT2. Posteriormente os retro tradutores reuniram-se com um terceiro avaliador, o que resultou na síntese dessa versão (S2), e garantiu que o objetivo da escala não fosse perdido na tradução.

\subsubsection{Comitê de juízes.}

Inicialmente foram enviados os convites via e-mail para 10 profissionais de diversas nacionalidades (México, Chile, Venezuela, Colômbia, Argentina, Uruguai, Costa Rica, Espanha) que atingiram os critérios de inclusão propostos: que tivessem como língua nativa o Espanhol e cuja expertise fosse a enfermagem em adições em álcool ou que tivessem experiência em adaptação e validação de instrumentos. Apenas seis responderam aceitando participar do comitê. A versão produzida na etapa anterior (S2) foi submetida a este comitê de seis juízes hispano-americanos. Como indicado anteriormente realizou-se inicialmente um convite via E-mail para cada um explicando o objetivo da pesquisa e os motivos pelos quais foram convidados a participar do comitê. Uma vez obtida a aceitação foram enviadas as instruções (Apêndice B) via e-mail individualmente para cada um dos juízes, junto com o instrumento original (Anexo III), a síntese da tradução (S1) (Apêndice G) e os formatos de avaliação (Apêndice C). O objetivo deste comitê foi assegurar a existência de equivalência semântica, idiomática, conceitual e experimental, e a validade de conteúdo, avaliando assim 
de forma qualitativa e quantitativa cada um dos itens do instrumento. Este comitê constituiuse dos seguintes profissionais:

- Dois enfermeiros com experiência em processos de adaptação e validação de instrumentos na área de saúde mental.

- Três enfermeiros com experiência em saúde mental especificamente na área de álcool e outras drogas.

- Um dos tradutores que participaram no processo da tradução inicial com formação linguística.

Conforme observa-se no quadro 1, foram escolhidos profissionais com diferentes nacionalidades latino-americanas, com vistas a tornar uma linguagem mais padronizada que facilitasse o uso do instrumento na América Latina.

Quadro 1. Caracterização dos juízes de acordo com o local de procedência e experiência.

\begin{tabular}{|c|c|c|}
\hline Titulo & Procedência & Experiência \\
\hline $\begin{array}{c}\text { Enfermeiro } \\
\text { Doutor }\end{array}$ & Colombiana & $\begin{array}{r}\text { Tem realizado estudos de adaptação cultural e validação de } \\
\text { instrumentos de avaliação em saúde mental. }\end{array}$ \\
\hline $\begin{array}{c}\text { Enfermeiro } \\
\text { Doutor }\end{array}$ & Chilena & $\begin{array}{r}\text { Professor titular e pesquisador na área de saúde mental, } \\
\text { especificamente na área de álcool e outras drogas. }\end{array}$ \\
\hline $\begin{array}{c}\text { Enfermeiro } \\
\text { Doutor }\end{array}$ & Espanhola & $\begin{array}{r}\text { Professor titular e pesquisador na área de saúde mental, } \\
\text { especificamente na área de álcool e outras drogas. }\end{array}$ \\
\hline $\begin{array}{c}\text { Enfermeiro } \\
\text { Doutor }\end{array}$ & Espanhola/Brasileira & $\begin{array}{r}\text { Realizou estudos de adaptação e validação de instrumentos } \\
\text { para mensurar grupos atitudinais, além de pesquisar na área de } \\
\text { saúde mental - álcool e outras drogas }\end{array}$ \\
\hline $\begin{array}{c}\text { Enfermeiro } \\
\text { Doutor }\end{array}$ & Argentina & Na área de saúde mental, especificamente na área de álcool e \\
\hline Linguista & outras drogas. \\
\hline Chileno & Especialista em processos de tradução e adaptação semântica \\
\hline
\end{tabular}

Fonte. Elaboração própria.

Os resultados das avaliações foram analisados pelos pesquisadores e agrupados em quadros-resumo para facilitar sua análise e a incorporação das sugestões, originando assim 
uma nova versão preliminar do instrumento. Foi avaliada a equivalência dos itens por meio da equivalência semântica, idiomática e conceitual. Além disso as avaliações dos juízes também foram submetidas a testes estatísticos para verificação da concordância. Dentre eles o Índice de Validade de Conteúdo (IVC), O Intraclass Correlation Coefficient (ICC) e o Prevalence Adjusted Bias Adjusted Kappa (PABAK).

\subsubsection{1 Índice de Validade de Conteúdo}

A avaliação de conteúdo é um processo de muita importância no desenvolvimento de instrumentos de medida, porque representa o início de mecanismos para associar conceitos abstratos com indicadores observáveis e mensuráveis de fenômenos específicos (Wynd et al. 2003). Consiste em julgar em que proporção os itens selecionados para medir uma construção teórica representam bem todas as facetas importantes do conceito a ser medido (Costa 2011). O índice de validade de conteúdo foi criado com o intuito de mesurar a porcentagem de juízes que estão em concordância no que se refere à representatividade, clareza, correspondência dos fatores para cada um dos itens do instrumento e compreensão da medida como um todo. Consiste numa escala tipo likert com pontuação de um a quatro, por este método, os itens e o instrumento como um todo, são considerados válidos, se obtiverem um IVC de 0,80. (Rubio et al. 2003; Costa 2011).

A fórmula usada para o cálculo do IVC, foi a seguinte:

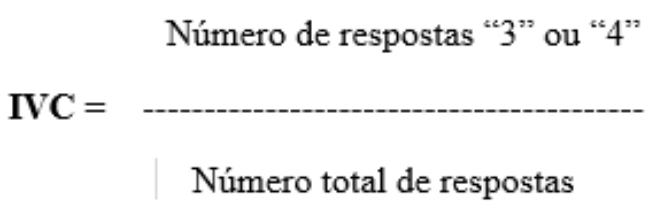

Por meio do IVC pretendeu-se calcular se a proporção dos itens selecionados para medir a atitude representavam bem todas as facetas importantes do conceito: representatividade de cada item, clareza, e dimensão teórica do fator (Pasquali 2010; Alexandre and Coluci 2011):

- Representatividade do item: refere-se à capacidade do item para representar e descrever a definição teórica, neste caso as atitudes do enfermeiro.

- Clareza da linguagem: a redação das frases é de fácil compreensão. 
- Dimensão teórica do Fator: Indica se o item realmente corresponde à categoria ou fator onde se encontra localizado.

\subsubsection{Coeficiente de correlação intraclasse}

Este método permite avaliar o acordo global entre dois ou mais métodos de medição ou observação com base em um modelo de análise de variância (ANOVA). É realizado por meio de medidas repetidas que permitem determinar o grau de concordância das observações realizadas por diferentes observadores de um mesmo instrumento (Bland and Altman 1990; Bartko 1996; Mandeville 2005). O escore da escala será interpretado segundo o grau de concordância como indica a tabela 1 .

Tabela 1. Interpretação do coeficiente de correlação intercalasses. (Mandeville 2005)

\begin{tabular}{|l|c|}
\hline Grau de Concordância & Valor \\
\hline Pobre & 0 \\
\hline Leve & $0,01-0,20$ \\
\hline Regular & $0,21-0,40$ \\
\hline Moderado & $0,41-0,60$ \\
\hline Substancial & $0,61-0,80$ \\
\hline Quase prefeito & $0,81-1,00$ \\
\hline
\end{tabular}

Fonte. El Coeficiente de Correlación Intraclasse (Mandeville 2005)

\subsubsection{Prevalence Adjusted Bias Adjusted Kappa}

Este teste permite achar a média de todos os cruzamentos dos observadores dois a dois, como a confiabilidade geral, calculando proporção máxima de concordância devido ao acaso (Byrt et al. 1993; Chen et al. 2009; Costa and Orpinelli 2011). A fórmula para o cálculo é a seguinte (Byrt et al. 1993): $\quad$ PABAK $=\frac{(2 n / N)-0.5}{1-0.5}=2 p_{\circ}-1$.

O escore pode apresentar valores desde -1 até +1 , no qual zero significa um nível de concordância de 50\%; os valores menores que zero indicam uma concordância mínima ou inadequada e os valores superiores a zero indicam um grau de concordância forte quando mais aproximados de 1 .

\subsubsection{Versão Preliminar.}

A versão obtida na etapa anterior após ajustes realizados, foi aplicada numa amostra de 30 enfermeiros conforme indicação dos autores(Beaton et al. 2000; Pasquali 2010) com o inutito de realizar a análise semântica dos itens, ou seja, verificar se todos os itens eram compreensiveis para a população alvo. Esses sujeitos foram contatados pelo pesquisador 
principal nos locais de trabalho (hospitais de médio e grande porte) na cidade de Bogotá (Colômbia). Num primeiro momento explicou-se os objetivos do estudo solicitando que os mesmos avaliassem a EAFAA em relação à compreensão dos itens e a dificuldade no preenchimento. Para isso, responderam, um questionário de validação com duas perguntas dicotômicas, uma que avaliava a compreensão de cada item da escala e a segunda que avaliava a dificuldade no preenchimento da escala (Anexo V), seguindo-se um espaço para sugestões e críticas caso apresentassem alguma dificuldade na compreensão dos itens da escala ou em seu preenchimento. Para aplicação desta versão do instrumento utilizaram-se os seguintes passos.

\subsubsection{Sujeitos do estudo (Avaliação semântica - versão preliminar)}

Foram selecionados por conveniência 30 indivíduos que cumpriram com os critérios de inclusão: ser enfermeiro; ter experiência clínica; que sua linguagem nativa fosse espanhole e estivessem inseridos nas instituições participantes (hospitais de médio e grande porte) na capital Colombiana, Bogotá, DC.

Os participantes do teste piloto que objetivou verificar a validade semântica e compreensão no preenchimento da Escala de Atitudes frente ao álcool, ao alcoolismo e ao alcoolista, caracterizavam-se por ser enfermeiros alocados em serviços de saúde colombianos predominantemente do sexo feminino (80\%), com idade média de 30 anos, solteiros $(63,3 \%)$, e sem formação em nível de pós-graduação $(46,7 \%)$.

\subsubsection{Instrumentos de Coleta}

Utilizaram-se a versão adaptada da Escala de Atitudes frente ao alcoolismo, ao álcool e pessoas com transtornos relacionados a seu uso. Responderam adicionalmente a um questionário de dados sócio-demográficos e, finalmente, um formato com perguntas relacionadas à compreensão e clareza de cada um dos itens.

\subsubsection{Procedimento para coleta dos dados}

Os enfermeiros foram contatados pessoalmente no local de trabalho pela pesquisadora. Após a explicação do objetivo da pesquisa, foi realizado o convite verbal junto com a entrega e leitura conjunta do Termo de Consentimento Livre e Esclarecido (TCLE) (Apêndice F). Assim, uma vez aceita a participação e assinado o TCLE foi entregue para cada, um envelope com as instruções para o preenchimento da versão adaptada do 
instrumento, o questionário sócio demográfico e o formato de perguntas em relação a compreensão dos itens.

\subsubsection{Submissão dos documentos produzidos em todas as etapas para avaliação.}

$\mathrm{Na}$ fase final da adaptação cultural foram revisados detalhadamente pelos pesquisadores (Orientador - autora) os documentos produzidos em cada uma das etapas descritas anteriormente, com o objetivo de verificar se todos os passos indicados pelos autores (Beaton et al. 2000) foram realizados satisfatoriamente, o que torna-se um indicador de uma adaptação razoável.

Figura 1. Trajetória metodológica processo de adaptação cultural Fase I (Beaton et al. 2000)

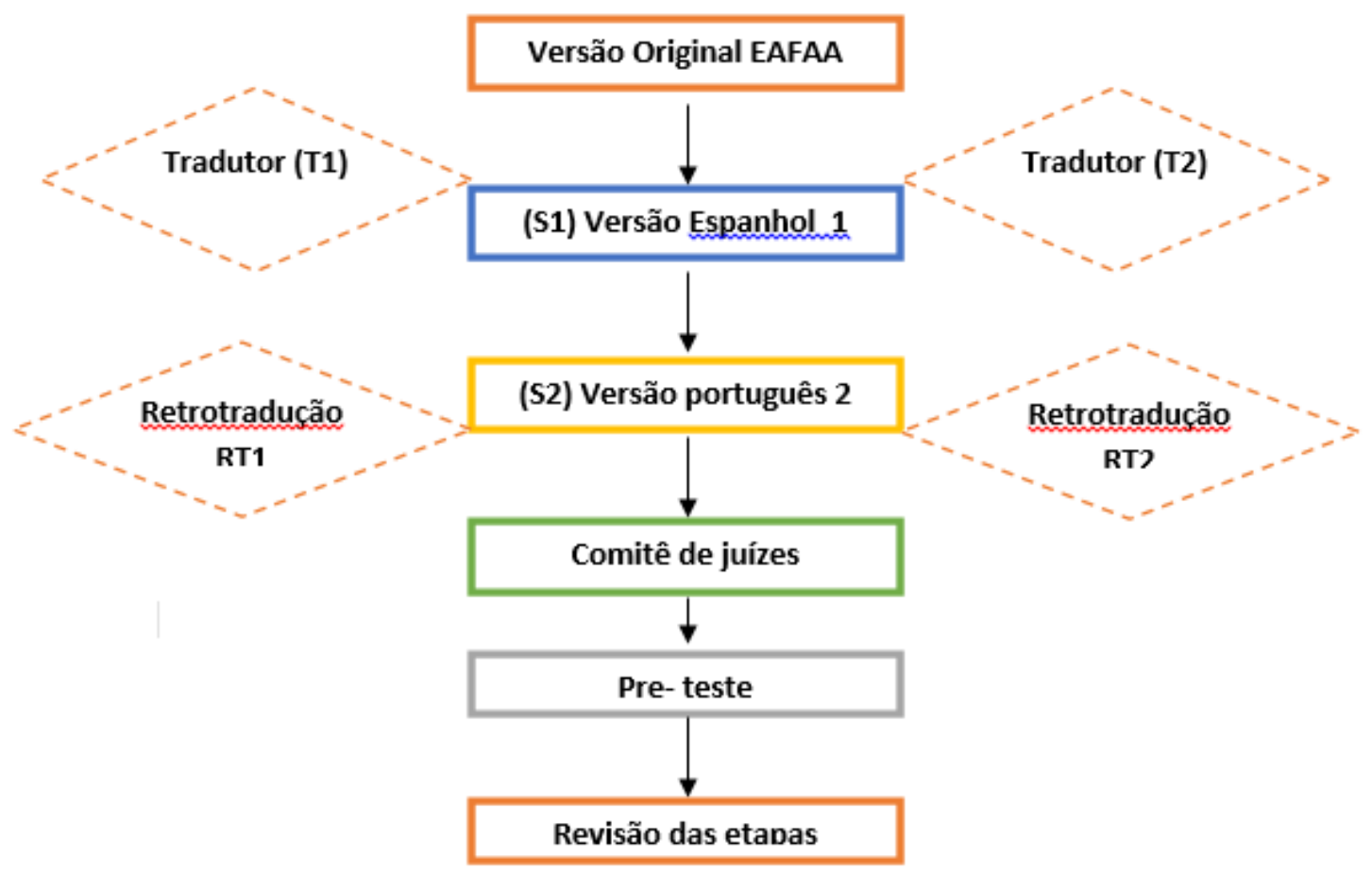

\subsection{VERIFICAÇÃO DAS PROPRIEDADES PSICOMÉTRICAS (FASE II)}

Com vistas a verificar se as características do instrumento original haviam sido mantidas e encontrar evidências de que a escala na versão espanhol avaliava com segurança o construto, foram realizados testes estatísticos para avaliar as qualidades psicométricas da versão adaptada.

\subsubsection{Validade de Constructo}

A validade de construto trata-se de um processo estatístico, cujo resultado verifica a correlação entre as variáveis que são mesuradas no instrumento. Dentre as teorias que embasam os procedimentos ou técnicas estatísticas utilizadas para realizar a validade de 
constructo encontra-se a teoria clássica dos testes (TCT), a qual pretende explicar a manifestação de uma característica de personalidade ou traço latente através de instrumentos de medida. Uma das técnicas mais utilizadas por esta teoria e que merece destaque é a analise fatorial (Artes 1998; Perez et al. 2000; Pasquali 2003, 2010).

\subsubsection{Análise Fatorial,}

A análise fatorial é particularmente aplicada a escalas que consistem de uma grande quantidade de itens para mensurar um atributo. A validade de constructo é reforçada se a estrutura fatorial da escala é consistente com os construtos que o instrumento propõe medir (Pasquali, 2012). Existem dois tipos de análise fatorial: a exploratória e a confirmatória. No que se refere ao tamanho da amostra, segundo diversos autores (Gorsuch 1983; Hair et al. 2009; Pasquali 2010) deve conter pelo menos cinco participantes por variável e uma amostra total de pelo menos duzentos sujeitos.

\subsubsection{Análise Fatorial Confirmatória}

A análise fatorial confirmatória é um teste usado com muita frequência em processo de elaboração ou validação de escalas que permite examinar a estrutura latente verificando a relação entre variáveis e fatores nos instrumentos de medida. Além disso, possibilita a avaliação da estabilidade de um modelo fatorial previamente estabelecido com base na teoria ou evidencia no que diz respeito ao número de fatores usado para agrupar as variáveis (Browm, 2006). Finalmente a AFC é determinada pela magnitude das cargas fatoriais e a intercorrelação dos fatores.

Para realização da análise fatorial confirmatória devem-se garantir as etapas que seguem (Mangin; Mallow 2006):

Especificação do modelo: pode se determinar por meio de uma análise exploratória prévia ou de estudos que evidenciem uma configuração adequada para o modelo.

Identificação: com vistas a garantir que a matriz é adequada para realização da AFC, deve-se avaliar por meio do teste Kaiser-Meyer-Olkin.

D Estimação de parâmetros: é realizado com o intuito de gerar uma matriz de covariâncias muito similar à matriz amostral, o método mais comum é a estimação por mínimos quadrados ponderados. 
$>$ Avaliação do ajuste: determina o grau em que a estrutura definida na matriz modelo pode reproduzir as covariâncias observadas ou amostrais (Hair et al. 2009). Dentre os testes mais usados para avaliar os índices de ajuste temos a raiz quadrática média do erro de aproximação (RMSEA), e o SMRR. Há também os testes que comparam o ajuste global do modelo proposto com um modelo de referência, geralmente, um modelo que não apresenta relações entre as variáveis, como o Índice de Tucker-Lewis (TLI) e o Índice comparativo de ajuste (CFI).

Interpretação dos índices de ajuste: As interpretações dos valores para cada teste de índice de ajuste podem se observar na tabela 2.

Tabela 2. Interpretação dos índices de ajuste (Mangin ; Mallow 2006)

\begin{tabular}{|c|c|}
\hline Índice de ajuste & \multicolumn{1}{|c|}{ Interpretação } \\
\hline $\boldsymbol{R M S E A}$ & Valores inferiores a 0,05 indicam bom ajuste \\
\hline $\boldsymbol{S R M R}$ & Valores inferiores a 0,8 ajuste ideal do modelo. \\
\hline $\boldsymbol{T L I}$ & Valores superiores a 0,9 indicam bom ajuste \\
\hline $\boldsymbol{C F I}$ & Valores superiores a 0,9 indicam bom ajuste \\
\hline
\end{tabular}

Fonte. Modelización con estructuras de covarianzas en Ciencias Sociales: temas esenciales, avanzados y aportaciones especiales (Mangin; Mallow 2006)

Interpretação do modelo fatorial - Gráfico de caminhos: Uma vez calculados os índices de ajuste, deve-se verificar a adequação do modelo em relação ao número de fatores predefinidos e a dimensionalidade do instrumento, ou seja, avalia-se a correlação entre os fatores que compõem a escala adaptada, além de identificar as cargas fatoriais de cada item. Essas últimas fornecem informações quanto a relação do item com o respetivo fator. Utiliza-se o gráfico de caminhos para facilitar a interpretação dos dados por meio de diagramas que indicam as cargas fatoriais e as relações estabelecidas no modelo de fatores.

\subsubsection{Confiabilidade}

É a capacidade de um instrumento para reproduzir um resultado consistentemente, em indivíduos ou unidades de tempo diferentes (Costa ; Orpinelli 2011). Alguns testes têm sido desenvolvidos para verificar a confiabilidade de escalas de mensuração, dentre eles o 
Alpha de Cronbach (Gliem, 2003) o teste que tem sido mais utilizado no estudos de validação e Ômega de Mc Donald (Silva Junior et al. 2011; Dunn et al. 2014).

\subsubsection{Alfa de Cronbach}

Por meio do teste são calculadas as correlações entre o escore de cada item e o escore total dos demais itens. Assim o valor do alfa é a medida de todos os coeficientes de correlação (Martins, 2006). De acordo com a literatura (Artes 1998; Pasquali 2003) trata-se de um processo estatístico cujo resultado verifica a correlação entre as variáveis que são mensuradas no instrumento. A fórmula para realizar o cálculo da confiabilidade pelo Alfa de Cronbach está apresentada na sequência:

$$
\alpha=\frac{N \bar{\rho}}{[1+\bar{\rho}(N-1)]}
$$

Onde $\mathrm{N}$ é o número de itens, e $p$ a média dos coeficientes de correlação linear (Pearson) entre os itens. O resultado pode ser interpretado como indicam os dados da tabela:

Tabela 3. Interpretação do Coeficiente do Alpha de Cronbach (Gliem, 2003).

\begin{tabular}{|c|c|}
\hline Valor & Interpretação da confiabilidade \\
\hline Valores superiores $\boldsymbol{a} 0.9$ & Excelente \\
\hline Valores superiores $\boldsymbol{a} 0.8$ & Boa \\
\hline Valores superiores $\boldsymbol{a} 0.7$ & Aceitável \\
\hline Valores superiores $\boldsymbol{a} 0.6$ & Questionável \\
\hline Valores superiores $\boldsymbol{a} 0.5$ & Pobre \\
\hline Valores inferiores $\boldsymbol{a} 0.5$ & Inaceitável \\
\hline
\end{tabular}

Fonte. Calculating, Interpreting, and Reporting Cronbach's Alpha Reliability Coefficient for LikertType Scales (Gliem, 2003).

\subsubsection{2 Ômega de Mc Donald}

É um teste proposto por Mc Donald em 1999 como alternativa a outras técnicas para avaliar a confiabilidade de instrumentos de medida. O ômega fornece uma estimativa mais próxima da confiabilidade quando comparado com outras técnicas, uma vez que é baseado num cálculo hierárquico de fatores por meio do quadrado da correlação entre a pontuação da escala e a variável latente (fator) comum a todos os indicadores que constituem as sub-escalas (Palacios et al. 2013). O ômega é calculado a partir do modelo de fatores comuns utilizandose a expressão,

$$
\omega_{t}=1-\frac{\sum\left(1-h_{j}^{2}\right)}{\operatorname{Var}(X)}=1-\frac{\sum u^{2}}{\operatorname{Var}(X)}
$$


Nota-se que valores acima de 0,5 podem ser considerados como adequados (Dunn et al. 2014).

\subsubsection{Sensibilidade e especificidade da EAFAA}

A sensibilidade de uma escala permite identificar se o teste realmente identifica os verdadeiros positivos, ou seja que os participantes foram corretamente diagnosticados pelo indicador, no caso do presente estudo, a atitude positiva, já a especificidade permite identificar se o instrumento distingue os positivos dos negativos, ou seja, os participantes que não apresentaram o desfecho (Cerdas 2012; Vargas 2014) . A sensibilidade e especificidade da EAFAA foi calculada utilizando a técnica de curva ROC, a qual é uma representação direta da habilidade da variável em classificar sujeitos em grupos, oferecendo um conjunto de regras de classificação, segundo os pontos de corte que compõem a curva. Tal representação deve ser verificada através da comparação do instrumento com um padrão ouro, ou seja, um critério padrão que possa ser utilizado para estabelecer inequivocamente a presença ou não do trazo latente. O objetivo é estabelecer se o instrumento testado é capaz de mensurar e classificar acertadamente aquilo que se propõe. Sendo que quanto menor seja o ponto de corte, com relação a pontuação total da escala, considera-se que a sensibilidade é adequada.

Levando em consideração que não existem em língua portuguesa, instrumentos que objetivem a avaliar os mesmos grupos atitudinais que compõem a EAFAA, ou seja instrumentos que possam ser considerados como padrão ouro, a curva ROC foi realizada utilizando uma pergunta dicotômica que visava classificar a atitude frente ao álcool, ao alcoolismo e ao alcoolista como positiva ou negativa: 1. ¿La persona con trastornos relacionados al uso de bebidas alcohólicas es grosera, agresiva y mal educada? Para a interpretação da curva ROC foram levados em consideração os maiores valores obtidos de sensibilidade, especificidade, e exatidão nos pontos de corte indicados pelo padrão ouro.

\subsubsection{Sujeitos do estudo (validação de construto- versão adaptada da EAFAA)}

Para realizar os testes estatísticos referentes a análise psicométrica da EAFAA versão em espanhol, o instrumento validado na etapa anterior (validade de conteúdo) foi aplicado a uma amostra de 303 enfermeiros oriundos de três hospitais $(60 \%)$ e dois (40\%) unidades básicas de atenção. A tabela 4 , ilustra as características dos participantes na fase de validação de construto. 
Tabela 4. Distribuição de frequências dos Enfermeiros segundo variáveis sociodemográficos do estudo. Bogotá Colômbia 2014-2015.

\begin{tabular}{|c|c|c|}
\hline \multicolumn{3}{|l|}{ Estado civil } \\
\hline & Frequência & $\%$ \\
\hline Casado & 75 & 24,75 \\
\hline Separado & 21 & 6,93 \\
\hline Solteiro & 150 & 49,5 \\
\hline Amasiado & 47 & 15,51 \\
\hline Viúvo & 10 & 3,3 \\
\hline \multicolumn{3}{|c|}{ Experiência profissional } \\
\hline Não & 170 & 56,11 \\
\hline Sim & 133 & 43,89 \\
\hline \multicolumn{3}{|c|}{ Frequência de atendimento a usuários de álcool } \\
\hline Diariamente & 37 & 12,85 \\
\hline Mensalmente & 55 & 19,1 \\
\hline Nunca & 152 & 52,78 \\
\hline Semanalmente & 44 & 15,28 \\
\hline \multicolumn{3}{|l|}{ Pós-graduação } \\
\hline Doutorado & 1 & 0,33 \\
\hline Especialização & 102 & 33,77 \\
\hline Mestrado & 13 & 4,3 \\
\hline Não tem & 186 & 61,58 \\
\hline \multicolumn{3}{|c|}{ Preparo em álcool e outras drogas } \\
\hline Não & 128 & 42,38 \\
\hline Sim & 174 & 57,62 \\
\hline
\end{tabular}

Fonte. Coleta de dados realizada pela autora. Bogotá Colômbia

\subsubsection{Critérios de Inclusão na amostra}

Constituíram critérios de inclusão: ser enfermeiro, possuir como língua nativa o espanhol, estar vinculado a instituições de saúde, estar exercendo sua profissão no momento de aplicação da EAFAA.

\subsubsection{Instrumentos de coleta dos dados}

Foram utilizados os seguintes instrumentos:

Questionário de dados sócio-demográficos (Anexo VII), baseou-se no instrumento elaborado por Vargas durante a validação da EAFAA em profissionais 
de saúde (Vargas, 2011), e contêm dados sócio demográficos (idade, estado civil, sexo) e questões relacionadas à formação do Enfermeiro, e à experiência com pessoas com transtornos decorrentes do uso de substâncias.

\section{$>\quad$ Versão adaptada da Escala de Atitudes frente ao alcoolismo, ao álcool e pessoas com transtornos relacionados a seu uso (Apêndice E): Instrumento composto por quarenta e nove afirmações agrupadas em quatro fatores, os quais podiam ser respondidos por meio de uma escala do tipo likert, com quatro opções de resposta que variam entre (1) discordo totalmente a (5) concordo totalmente.}

\subsubsection{Procedimento para coleta de dados}

Após o contato com os diretores do hospital, e previa aprovação do projeto pelos comitês de ética de cada instituição participante (Anexo VI), entrou-se em contato com os enfermeiros durante seu horário e no local de trabalho em cada um dos plantões manhã, tarde e noite. Foram apresentados os objetivos e a justificativa da pesquisa, além da orientação sobre a liberdade de recusar-se a participar em qualquer momento, em seguida foi entregue um envelope de forma pessoal com o termo de consentimento livre e esclarecido, o questionário sócio-demográfico e a versão adaptada da EAFAA com as instruções para o seu correto preenchimento. O processo de recolecção foi realizado pela pesquisadora e um colaborador devidamente treinado na aplicação do instrumento.

\subsubsection{Aspectos Éticos da Pesquisa}

Os aspectos éticos desse estudo em todas as suas etapas foram garantidos pela aprovação do projeto pelo comitê de ética em pesquisa da Escola de Enfermagem da Universidade de São Paulo número 843.95520 de outubro de 2014 (Anexo IV) em conformidade com a Resolução 466 de 2012 pela que se sustenta a pesquisa em seres humanos segundo determinação do Conselho Nacional de Saúde e o Ministério de Saúde do Brasil. Na Colômbia, respeitando a legislação local, representada pela Resolução 8430 de 1993 do Ministério de Salud de la República de Colômbia para realização de pesquisa com seres humanos, obteve-se a autorização de todas as instituições que aceitaram participar da pesquisa e todos os participantes assinaram o Termo de Consentimento Livre e esclarecido (TCLE) (Apêndice F). 


\subsubsection{Procedimento para análise dos dados}

Os dados coletados foram armazenados numa base de dados no programa Microsoft Excel e analisados por meio do Software R (R Project for Statistical Computing) versão 3. No que se refere à verificação das propriedades psicométricas, os dados foram submetidos à validação de construto por meio de análise fatorial confirmatória, com o intuito de avaliar se os dados obedeciam à estrutura esperada. Posteriormente realizou-se análise da confiabilidade da escala versão espanhol, utilizando o teste Alfa de Cronbach, e Ômega de Mc Donald. Avaliou-se a sensibilidade e especificidade da EAFAA utilizando a técnica da curva ROC. Todos os testes estatísticos foram realizados adotando-se um nível de confiança de $5 \%$. 
RESULTADOS 


\section{RESULTADOS}

\subsection{RESULTADOS DO PROCESSO DE ADAPTAÇÃO CULTURAL E VALIDAÇÃO DE CONTEÚDO DA EAFAA (FASE I)}

\subsubsection{Tradução e síntese das traduções}

Inicialmente a versão original da EAFAA em português foi traduzida para o espanhol por dois tradutores, os quais se reuniram com um terceiro avaliador com o objetivo de realizar a síntese das traduções e gerar uma nova versão do instrumento. Para isso foi realizado um relatório descrevendo todas as mudanças realizadas e suas respectivas explicações. O mesmo procedimento realizou-se com a retro tradução, em que os dados do quadro mostram todos os conflitos e a solução empregada para resolvê-los nessa etapa, conforme se encontra disponível no Apêndice G.

\subsubsection{Comitê de juízes}

Após os processos de tradução e retro tradução, resultou uma nova versão do instrumento que foi encaminhada ao comitê de especialistas para a avaliação junto às sínteses das traduções; instruções precisas para avaliar sua equivalência semântica, conceitual e idiomática, além de um formato para a validade de conteúdo avaliando a representatividade, a clareza e a correspondência do item com o fator. Durante este processo, os juízes realizaram algumas sugestões as quais encontram-se descritas no Apêndice H, o qual contém para cada item as seguintes categorias: item inicial, que se refere a versão produzida na síntese realizada pelo grupo de tradutores; a avaliação de cada juiz em relação aos aspectos mencionados, as modificações realizadas conforme consenso entre os pesquisadores e, por último, a versão final de cada item. Quanto às avaliações de cada item por categoria surgiram as modificações que serão descritas a seguir.

\subsubsection{Equivalências dos itens:}

Equivalência semântica: $O$ conceito indicado para revisão foi a palavra “álcool”, já que segundo a cultura da população alvo, a palavra "alcohol” não faz referência exclusiva para bebida alcoólica e, sim, para outros compostos utilizados para diversos fins. Por esta razão decidiu-se mudar para expressão "uso de bebida alcohólica" em todos os itens com a expressão "consumo de álcool”. 
$>$ Equivalência Conceitual: para todos os itens do instrumento foi revisado o conceito de usuário, paciente, persona e indivíduo e tentou-se padronizar para todos os itens do instrumento o uso da palavra "persona" como o sujeito que participa da relação de cuidado com o profissional de saúde. Foi recomendado ter precaução com o uso da palavra cuidado, sendo que o significado pode ser interpretado em dois contextos: no cuidado propriamente dito como uma ação de atenção em saúde brindada pelo enfermeiro ou como alerta de precaução. Por este motivo mudou-se expressão "Es preciso tener cuidado" (Item 46, "Es preciso tener cuidado para no ser agredido al trabajar com personas que tienen transtornos relacionados al uso de bebidas alcoholicas”) pela expressão “debo tener precaución”.

$>$ Equivalência idiomática: Neste caso houve poucas sugestões em relação as expressões coloquiais utilizadas devido a que foram mínimas as expressões desse tipo utilizadas no instrumento. Houve dificuldade em chegar se num consenso com a expressão "Bom senso" (item 02"Las personas com transtornos relacionados al uso de bebidas alcohólicas no tienen critica de la realidad "), já que as expressões da cultura alvo indicadas pelo grupo de tradutores (sentido comun, razonar bien) não explicavam completamente a essência da expressão. Após discussão com alguns dos juízes via e-mail, e analisadas as opções pelos pesquisadores (Orientador-autora) definiu-se a expressão "tener critica de la realidad" como a mais indicada. Em geral $100 \%$ dos juízes avaliaram o instrumento como adequado no que se refere à equivalência idiomática. Além da avaliação qualitativa da adaptação que buscava tornar o conteúdo do instrumento de fácil e adequada compreensão para a população alvo, foram aplicados testes estatísticos com vistas a estabelecer uma medida quantificável e confiável em relação ao conteúdo do instrumento:

\subsubsection{2 Índice de Validade de Conteúdo (IVC)}

O IVC total foi de 0,97 o que indica que o instrumento possui validade de conteúdo, porém quando calculados os índices de cada item separadamente, e em cada uma das categorias avaliadas (Representatividade do item, Clareza e Dimensão teórica do Fator), alguns índices mostraram-se abaixo do considerado valido $(0,80)$. Dentre eles o item número 29 "Las personas con transtornos relacionados al uso de bebidas alcohólicas nunca aceptan lo que los profesionales de salud dicen sobre sus problemas con la bebida" $(0,67)$, e o item número 42 "El paciente con transtornos relacionados al uso de bebidas alcohólicas es una 
persona que le cuesta relacionarse con los otros" $(0,33)$ no que se refere a correspondência do item com o fator. O item 15 "Lo que falta en una persona con transtornos relacionados al uso de bebidas alcohólicas es fuerza de voluntad" e o item 38 "De todas las personas, las que tienen trastornos relacionados al uso de bebidas alcohólicas, son las más difíciles de cuidar. (Tabela 5). 
Tabela 5. Escores do índice de validade de Conteúdo da EAFAA.

\begin{tabular}{|c|c|c|c|}
\hline No. Ítem & Representatividade & Clareza & $\begin{array}{c}\text { Dimensão teorica do } \\
\text { fator }\end{array}$ \\
\hline 1 & 1,00 & 1,00 & 1,00 \\
\hline 5 & 1,00 & 0,83 & 0,83 \\
\hline 9 & 1,00 & 1,00 & 1,00 \\
\hline 13 & 0,83 & 0,83 & 0,83 \\
\hline 17 & 1,00 & 1,00 & 1,00 \\
\hline 21 & 0,83 & 0,83 & 0,83 \\
\hline 25 & 1,00 & 1,00 & 1,00 \\
\hline 29 & 0,67 & $\mathbf{0 , 6 7}$ & 0,67 \\
\hline 37 & 1,00 & 1,00 & 1,00 \\
\hline 41 & 1,00 & 1,00 & 1,00 \\
\hline 42 & 0,67 & 0,67 & 0,33 \\
\hline 44 & 1,00 & 1,00 & 1,00 \\
\hline 46 & 1,00 & 1,00 & 1,00 \\
\hline 48 & 1,00 & 1,00 & 0,83 \\
\hline 49 & 1,00 & 1,00 & 1,00 \\
\hline 50 & 1,00 & 1,00 & 8,3 \\
\hline 2 & 1,00 & 1,00 & 1,00 \\
\hline 6 & 1,00 & 1,00 & 1,00 \\
\hline 10 & 1,00 & 1,00 & 1,00 \\
\hline 14 & 1,00 & 1,00 & 8,3 \\
\hline 18 & 1,00 & 1,00 & 0,83 \\
\hline 22 & 1,00 & 1,00 & 0,83 \\
\hline 26 & 1,00 & 1,00 & 1,00 \\
\hline 30 & 1,00 & 1,00 & 1,00 \\
\hline 33 & 1,00 & 1,00 & 1,00 \\
\hline 34 & 1,00 & 1,00 & 0,83 \\
\hline 38 & 1,00 & 1,00 & 0,50 \\
\hline 45 & 1,00 & 1,00 & 1,00 \\
\hline 47 & 1,00 & 1,00 & 1,00 \\
\hline 3 & 1,00 & 1,00 & 0,83 \\
\hline 7 & 1,00 & 1,00 & 1,00 \\
\hline 11 & 1,00 & 1,00 & 0,83 \\
\hline 15 & 1,00 & 1,00 & 0,67 \\
\hline 19 & 1,00 & 1,00 & 1,00 \\
\hline 23 & 1,00 & 1,00 & 1,00 \\
\hline 27 & 1,00 & 1,00 & 1,00 \\
\hline 31 & 1,00 & 1,00 & 1,00 \\
\hline 35 & 1,00 & 1,00 & 1,00 \\
\hline 39 & 1,00 & 1,00 & 1,00 \\
\hline 43 & 1,00 & 1,00 & 1,00 \\
\hline 4 & 1,00 & 1,00 & 1,00 \\
\hline 8 & 1,00 & 1,00 & 1,00 \\
\hline 12 & 1,00 & 1,00 & 1,00 \\
\hline 16 & 1,00 & 1,00 & 1,00 \\
\hline 20 & 1,00 & 1,00 & 1,00 \\
\hline 24 & 1,00 & 1,00 & 1,00 \\
\hline 28 & 0,83 & 0,83 & 1,00 \\
\hline 32 & 0,83 & 0,83 & 1,00 \\
\hline 36 & 1,00 & 1,00 & 1,00 \\
\hline 40 & 0,83 & 0,83 & 1,00 \\
\hline
\end{tabular}

Fonte. Dados obtidos da avaliação da EAFAA realizada pelo comitê de especialistas. 


\subsubsection{Coeficiente de correlação intraclasse}

Conforme os dados apresentados na Tabela 6, indica-se o grau de correlação entre as avaliações dos juízes para o instrumento em sua totalidade. Os índices dos fatores analisados individualmente são apresentados nas tabelas 7,8,9,10.

Tabela 6. Coeficiente de correlação intraclasse para a EAFAA em sua totalidade.

\begin{tabular}{|c|c|c|}
\hline Tipo & $\begin{array}{c}\text { Correlação } \\
\text { Intraclasse }\end{array}$ & Sig \\
\hline Representatividade & $.800^{\mathrm{c}}$ &, 000 \\
\hline Clareza & $.926^{\mathrm{c}}$ &, 000 \\
\hline $\begin{array}{c}\text { Dimensão teórica do } \\
\text { Fator }\end{array}$ & $.074^{\mathrm{b}}$ &, 000 \\
\hline
\end{tabular}

Fonte. Dados obtidos da avaliação da EAFAA realizada pelo comitê de especialistas.

Tabela 7. Coeficiente de correlação intraclasse para a EAFAA fator 1.

\begin{tabular}{|c|c|c|}
\hline Tipo & $\begin{array}{c}\text { Correlação } \\
\text { Intraclasse }\end{array}$ & Sig \\
\hline Representatividade & $.793 \mathrm{c}$ &, 000 \\
\hline Clareza & $.795 \mathrm{c}$ &, 000 \\
\hline $\begin{array}{c}\text { Dimensão teórica do } \\
\text { Fator }\end{array}$ & $.698 \mathrm{c}$ &, 003 \\
\hline
\end{tabular}

Fonte. Dados obtidos da avaliação da EAFAA realizada pelo comitê de especialistas. 
Tabela 8. Coeficiente de correlação intraclasse para a EAFAA fator 2.

\begin{tabular}{|c|c|c|}
\hline Tipo & Correlação Intraclasse & Sig \\
\hline Representatividade & $.861^{\mathrm{c}}$ &, 000 \\
\hline Clareza & $.885^{\mathrm{c}}$ &, 000 \\
\hline $\begin{array}{c}\text { Dimensão teórica do } \\
\text { Fator }\end{array}$ & $.457^{\mathrm{c}}$ &, 097 \\
\hline
\end{tabular}

Fonte. Dados obtidos da avaliação da EAFAA realizada pelo comitê de especialistas.

Tabela 9. Coeficiente de correlação intraclasse para a EAFAA fator 3.

\begin{tabular}{|c|c|c|}
\hline Tipo & Correlação Intraclasse & Sig \\
\hline Representatividade & $.550^{\mathrm{c}}$ &, 067 \\
\hline Clareza & $.444^{\mathrm{c}}$ &, 140 \\
\hline $\begin{array}{c}\text { Dimensão teórica do } \\
\text { Fator }\end{array}$ & $.627^{\mathrm{c}}$ &, 024 \\
\hline
\end{tabular}

Fonte. Dados obtidos da avaliação da EAFAA realizada pelo comitê de especialistas.

Tabela 10. Coeficiente de correlação intraclasse escores para a EAFAA fator 4.

\begin{tabular}{|c|c|c|}
\hline Tipo & Correlação Intraclasse & Sig \\
\hline Representatividade & $.874^{\mathrm{c}}$ &, 000 \\
\hline Clareza & $.812^{\mathrm{c}}$ &, 000 \\
\hline $\begin{array}{c}\text { Dimensão teórica do } \\
\text { Fator }\end{array}$ & $.727^{\mathrm{c}}$ &, 000 \\
\hline
\end{tabular}

Fonte. Dados obtidos da avaliação da EAFAA realizada pelo comitê de especialistas. 


\subsubsection{Kappa adaptado à prevalência do viés ajustada}

Os resultados obtidos com o PABAK foram os seguintes para cada categoria avaliada: Representatividade do item: 0,891. Clareza: 0,877. Dimensão teórica do fator: 0,765.

\subsubsection{Aplicação da versão preliminar (pré-teste)}

Os dados obtidos no processo de análise semântica que avaliavam a EAFAA em relação à compreensão dos itens e a dificuldade em seu preenchimento (Anexo V) foram organizados e analisados no programa Microsoft Excel 2013, por meio do cálculo das frequências de resposta de todos os participantes. 95\% dos respondentes compreenderam semanticamente cada um dos itens que compõem a EAFAA e 100\% manifestaram não ter nenhuma dificuldade no preenchimento da mesma.

\subsection{RESULTADOS DA VERIFICAÇÃO DAS PROPRIEDADES PSICOMETRICAS DA EAFAA (FASE II)}

\subsubsection{Validação de construto.}

\subsubsection{Análise Fatorial Confirmatória.}

Para realizar a análise fatorial confirmatória da EAFAA foi necessário verificar se a matriz de dados era adequada para tal fim, por meio do teste Kaiser-Meyer-Olkin (KMO), o qual apontou um resultado de 0,86 .

Conforme as etapas sugeridas na literatura para realização de análise fatorial confirmatória, calcularam-se os índices de ajuste do modelo fatorial sob o método de estimação de mínimos quadrados ponderados. Para realizar esse cálculo foram inclusos no modelo os 49 itens remanescentes da validação de conteúdo, da EAFAA, com imposição previa de quatro fatores, com o intuito de manter a análise o mais consistente possível quanto ao instrumento original. Os valores obtidos ilustram-se na tabela 11. 
Tabela 11 Avaliação do ajuste do modelo de quatro fatores da EAFAA.

\begin{tabular}{|c|c|}
\hline Índice de ajuste & Resultado \\
\hline RMSEA & 0,05 \\
\hline SRMR & 0,007 \\
\hline Tucker - Lewis Index (TLI) & 0,91 \\
\hline CFI & 0,92 \\
\hline
\end{tabular}

Fonte: Dados obtidos da coleta de dados realizada na Colômbia, utilizando a EAFAA versão adaptada ao Espanhol.

Uma vez verificados os índices de ajuste, foi verificada a adaptação ao modelo de quatro fatores por meio do gráfico de caminhos (figura 3). À esquerda da figura, apresentamse as correlações obtidas entre os fatores e à direita as cargas fatoriais de cada item.

Apresentam-se, para os fatores as seguintes correlações (Tabela 12):

Tabela 12. Correlação entre os fatores da EAFAA.

\begin{tabular}{|l|c|c|c|}
\hline & Fator 2 & Fator 3 & Fator 4 \\
\hline Fator 1 & 0,67 & 0,31 & 0,57 \\
\hline Fator 2 & & 0,59 & 0,57 \\
\hline Fator 3 & & & 0,50 \\
\hline
\end{tabular}

Fonte: Dados obtidos da coleta de dados realizada na Colômbia, utilizando a EAFAA versão adaptada ao Espanhol.

Todas as correlações obtidas entre os fatores oscilam entre moderadas e fortes, com exceção da relação entre o fator 1 e o fator 3 que se mostrou fraca, sendo que os valores considerados adequados devem ser superiores a 0,5 (Hair et al. 2009). Nessa análise percebese que o item com menor carga fatorial é I45: "Las personas con trastornos relacionados al uso de bebidas alcohólicas cooperan en su tratamiento. " (Figura 2) 
Figura 2. Diagrama de caminhos- Análise fatorial confirmatória modelo de quatro fatores.

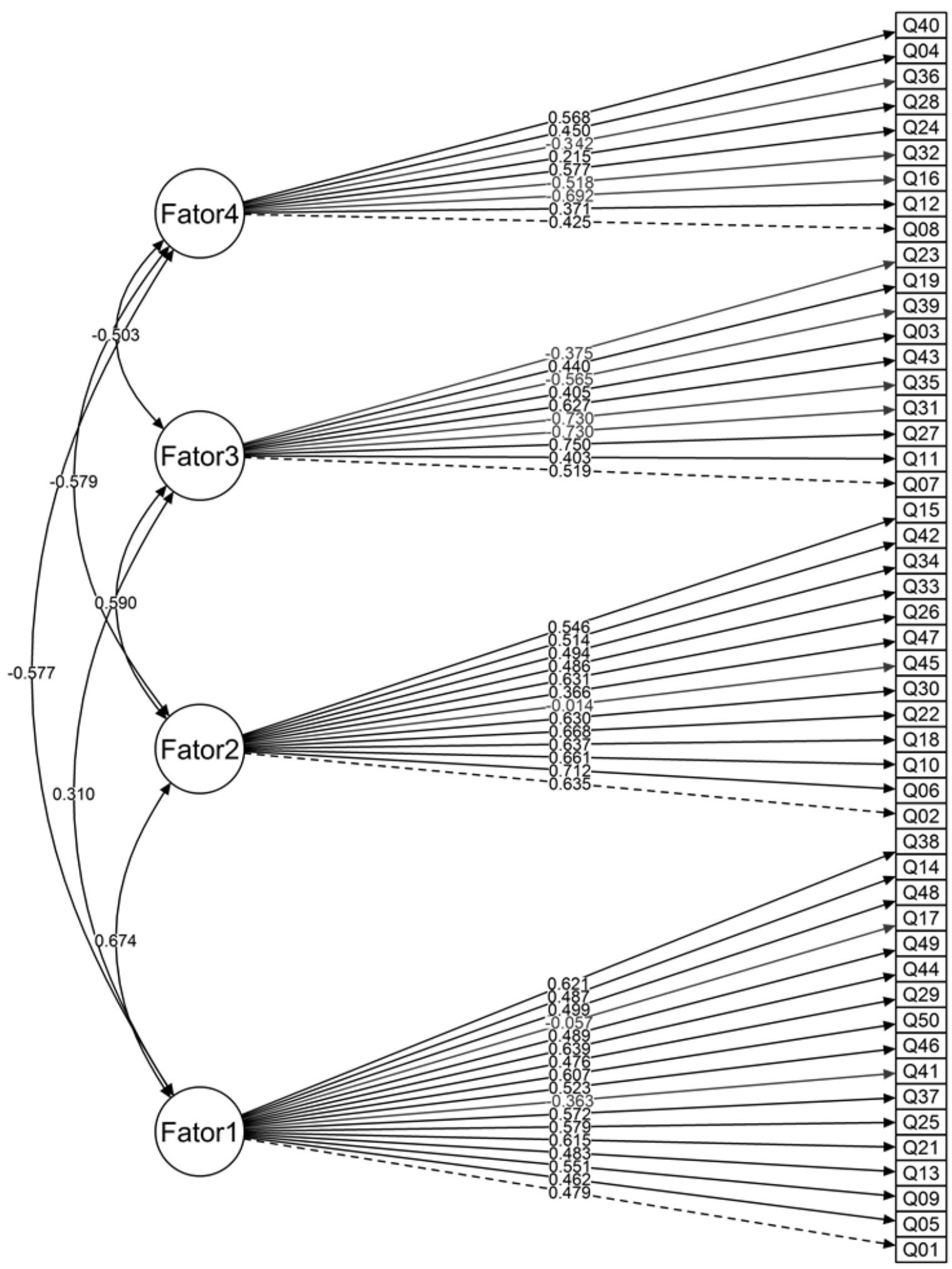




\subsubsection{Confiabilidade.}

Verificou-se a confiabilidade, por meio do Alfa de Cronbach, o índice total da escala na íntegra, composta por 49 itens e sem divisão por fatores foi de $0,78 \mathrm{com}$ um intervalo de confiança de 0,742-0,818, sendo que os valores de cada item se mantiveram acima de 0,75 (tabela 13). Quando calculado num segundo momento, após exclusão do item 45, o índice total aumentou para 0,80 . Aliás foram calculados os valores de confiabilidade para cada fator conforme ilustra a tabela 14 .

Apesar da técnica de Alpha de Cronbach ser a mais utilizada em estudos dessa natureza, alguns autores (Dunn et al. 2014) apontam que esse índice de confiabilidade não está isento de limitações e questionamentos e, por tal motivo, foi utilizada outra técnica que tem o mesmo objetivo, qual seja verificar a confiabilidade ou consistência interna da EAFAA. Trata-se do teste Ômega de Mc Donald, que mostrou um índice de confiabilidade de 0,97 da EAFAA versão espanhol na íntegra e valores superiores a 0,8 quando calculada para os itens individualmente, conforme ilustram as tabelas 15 e 16.

Tabela 13. Alfa de Cronbach discriminado por fatores da EAFAA versão adaptada ao Espanhol. 2015

\section{Fator}

Alfa de

Cronbach

Fator 1: "El trabajo y las relaciones interpersonales con personas con trastornos 0,88 relacionados al uso de alcohol"

Fator 2: "La persona con trastornos relacionados al uso de bebidas alcohólicas" 0,85

Fator 3: "El alcoholismo (Etiología)" 0,79

Fator 4: "Las bebidas alcohólicas y su uso" 0,65

Fonte. Dados obtidos da coleta de dados realizada na Colômbia, utilizando a EAFAA versão adaptada ao Espanhol.

Tabela 14. Escores de Ômega de Mc Donald discriminados por fator.

\begin{tabular}{|l|c|c|c|c|c|}
\hline Ômega de Mc Donald & $\boldsymbol{g}$ & $\boldsymbol{F 1}$ & $\boldsymbol{F} \mathbf{2}^{*}$ & $\boldsymbol{F 3}^{*}$ & $\boldsymbol{F 4}^{*}$ \\
\hline Corelação de escores entre fatores & 0.81 & 0.89 & 0.59 & 0.88 & 0.85 \\
\hline Ômega total para as subescalas & 0.92 & 0.87 & 0.831 & 0.72 & 0.52 \\
\hline Omega na íntegra & & \multicolumn{2}{|c|}{0,92} \\
\hline
\end{tabular}


Tabela 15. Discriminação comparativa dos valores do Alfa de Cronbach e Ômega de Mc Donald para cada item da EAFAA.

\begin{tabular}{|c|c|c|c|}
\hline No & Itens & Alfa & Omega \\
\hline 01 & Tengo miedo de abordar el problema del alcohol con los pacientes. & 0,802 & 0,738 \\
\hline 05 & Me siento inseguro (a) ante la agresividad de una persona con trastornos relacionados al uso de bebidas alcohólicas. & 0,801 & 0,717 \\
\hline 09 & Me siento frustrado (a) cuando trabajo con personas con trastornos relacionados al uso de bebidas alcohólicas. & 0,799 & 0,595 \\
\hline 13 & $\begin{array}{l}\text { De todas las personas, las que tienen trastornos relacionados al uso de bebidas alcohólicas, son las que dan mas } \\
\text { trabajo. }\end{array}$ & 0,801 & 0,785 \\
\hline 17 & $\begin{array}{l}\text { Debo ofrecer ayuda y orientaciones a la persona con trastornos relacionados al uso de bebidas alcohólicas, aunque } \\
\text { no crea que necesita cuidar de su salud. }\end{array}$ & 0,811 & 0,971 \\
\hline 14 & $\begin{array}{l}\text { Personas con trastornos relacionados al uso de bebidas alcohólicas tienen mayores probabilidades de reaccionar en } \\
\text { forma violenta contra mi. }\end{array}$ & 0,801 & 0,742 \\
\hline 21 & $\begin{array}{l}\text { Incluso, cuando la persona con trastornos relacionados al uso de bebidas alcohólicas.no está intoxicada, es } \\
\text { irrespetuosa con los miembros del equipo de salud. }\end{array}$ & 0,798 & 0,66 \\
\hline 25 & Siento rabia al trabajar con personas que tienen trastornos relacionados al uso de bebidas alcohólicas. & 0,799 & 0,508 \\
\hline 29 & $\begin{array}{l}\text { Las personas con trastornos relaciona dos al uso de bebidas alcohólicas nunca aceptan lo que lo que los } \\
\text { profesionales de salud dicen sobre sus probelmas con la bebida. }\end{array}$ & 0,8 & 0,756 \\
\hline 37 & $\begin{array}{l}\text { Abordar el problema del alcohol con personas con trastornos relacionados a su uso, implica dedicar menos tiempo a } \\
\text { otros pacientes. }\end{array}$ & 0,8 & 0,7 \\
\hline 38 & $\begin{array}{l}\text { De todas las personas, las que tienen trastornos relacionados al uso de bebidas alcohólicas, son las mas dificiles de } \\
\text { cuidar. }\end{array}$ & 0,799 & 0,605 \\
\hline 41 & $\begin{array}{l}\text { Prefiero trabajar con pacientes con trastornos relacionados al uso de bebidas alcohólicas que trabajar con otros } \\
\text { pacientes. }\end{array}$ & 0,819 & 0,743 \\
\hline 44 & $\begin{array}{l}\text { Es difícil para mi, estabelcer uma relación terapeútica con personas que tienen trastornos relacionados al uso de } \\
\text { bebidas alcohólicas. }\end{array}$ & 0,798 & 0,552 \\
\hline 46 & $\begin{array}{l}\text { Debo tener precaución para no ser agredido (a) al trabajar con personas que tienen trastornos relacionados al uso } \\
\text { de bebidas alcohólicas. }\end{array}$ & 0,801 & 0,744 \\
\hline 48 & $\begin{array}{l}\text { Cuando la persona con trastornos relaciona dos al uso de bebidas alcohólicas, no acepta que tiene problemas } \\
\text { relacionados al consumo, la mejor decisión es desistir de ayudar. }\end{array}$ & 0,801 & 0,641 \\
\hline 49 & $\begin{array}{l}\text { Cuando trabajo con personas con trastornos relacionados al uso de bebidas alcohólicas, no sé cómo manejar la } \\
\text { situación. }\end{array}$ & 0,801 & 0,666 \\
\hline 50 & Cuidar pacientes con trastornos relacionados al uso de bebidas alcohólicas no es gratificante para mí. & 0,799 & 0,552 \\
\hline 02 & Las personas con trastornos relaciona dos al uso de bebidas alcohólicas no tienen crítica de la realidad. & 0,798 & 0,643 \\
\hline 06 & Las personas con trastornos relaciona dos al uso de bebidas alcohólicas son mal educadas. & 0,796 & 0,548 \\
\hline 10 & Las personas con trastornos relacionados al uso de bebidas alcohólicas son irresponsables. & 0,798 & 0,531 \\
\hline 15 & Lo que falta en una persona con trastornos relacionados al uso de bebidas alcohólicas es fuerza de voluntad. & 0,8 & 0,602 \\
\hline 18 & Las personas com problemas de alcoholismo son débiles de carácter. & 0,797 & 0,449 \\
\hline 22 & Las personas con trastornos relacionados al uso de bebidas alcohólicas no se quieren cuidar. & 0,797 & 0,411 \\
\hline 26 & Los relatos de las personas con trastornos relaciona dos al uso de bebidas alcohólicas no son confiables. & 0,797 & 0,569 \\
\hline 30 & La persona con trastornos relacionados al uso de bebidas alcohólicas es culpable de sus problemas de salud. & 0,799 & 0,524 \\
\hline 33 & La persona con trastornos relacionados al uso de bebidas alcohólicas es un caso perdido. & 0,8 & 0,527 \\
\hline 34 & $\begin{array}{l}\text { La persona con trastornos relaciona dos al uso de bebidas alcohólicas acaba siempre volviendo al servicio de salud } \\
\text { por el mismo problema. }\end{array}$ & 0,801 & 0,767 \\
\hline 42 & $\begin{array}{l}\text { El paciente con trastornos relacionados al uso de bebidas alcohólicas es una persona que le cuesta relacionarse con } \\
\text { los otros. }\end{array}$ & 0,801 & 0,76 \\
\hline 45 & Las personas con trastornos relaciona dos al uso de bebidas alcohólicas cooperan en su tratamiento. & 0,812 & 0,865 \\
\hline 47 & Las personas con trastornos relaciona dos al uso de bebidas alcohólicas no toman en serio su tratamiento. & 0,804 & 0,834 \\
\hline 03 & La disfunción familiar puede llevar al alcoholismo & 0,808 & 0,716 \\
\hline 07 & Las personas tímidas o inhibidas tienen mayor tendencia a desarrollar alcoholismo. & 0,803 & 0,785 \\
\hline 11 & La depresión puede provocar alcoholismo. & 0,809 & 0,638 \\
\hline 19 & Las problemáticas sociales llevan a uma persona a beber. & 0,809 & 0,587 \\
\hline 23 & Factores hereditários conducen al alcoholismo. & 0,817 & 0,831 \\
\hline 27 & Las personas insatisfechas abusan de las bebidas alcohólicas. & 0,804 & 0,484 \\
\hline 31 & Las personas que desarrollan alcoholismo tienen baja autoestima. & 0,817 & 0,89 \\
\hline 35 & Las personas con trastornos relacionados al uso de alcohol son psicológicamente inestables. & 0,822 & 0,606 \\
\hline 39 & Las personas beben para sentirse más sociables. & 0,818 & 0,609 \\
\hline 43 & La persona con trastornos relacionados al uso de alcohol bebe porque no es capaz de enfrentar su propia realidad. & 0,805 & 0,644 \\
\hline 04 & Las personas tienen derecho a bebersi asílo desean. & 0,814 & 0,793 \\
\hline 08 & La bebida alcohólica es agradable y proporciona bienestar a quien la usa. & 0,817 & 0,618 \\
\hline 12 & El uso de bebida alcohólica es algo normal. & 0,816 & 0,597 \\
\hline 16 & Beber alcohol en cualquier cantidad causará siempre dependencia. & 0,801 & 0,725 \\
\hline 24 & El uso de bebida alcohólica es perjudicial en cualquier circunstancia. & 0,822 & 0,786 \\
\hline 28 & Estoy a favor de beber com moderación *(Hombres menos de 5 dosis, y mujeres menos de 4 dosis por ocasión). & 0,813 & 0,865 \\
\hline 32 & Dosis pequeñas de alcohol pueden causar dependencia. & 0,804 & 0,761 \\
\hline 36 & Las bebidas alcohólicas en cantidades reducidas son benéficas. & 0,815 & 0,694 \\
\hline 40 & Las personas pueden beber con tal que mantengan el control sobre su uso. & 0,813 & 0,835 \\
\hline
\end{tabular}




\subsubsection{Sensibilidade e especificidade da EAFAA}

A sensibilidade e especificidade da EAFAA, foi calculada por meio da curva ROC (Figura 3), conforme ilustram os resultados na tabela 16.

Figura 3. Curva ROC. "O alcoolista é grosso e mal educado"

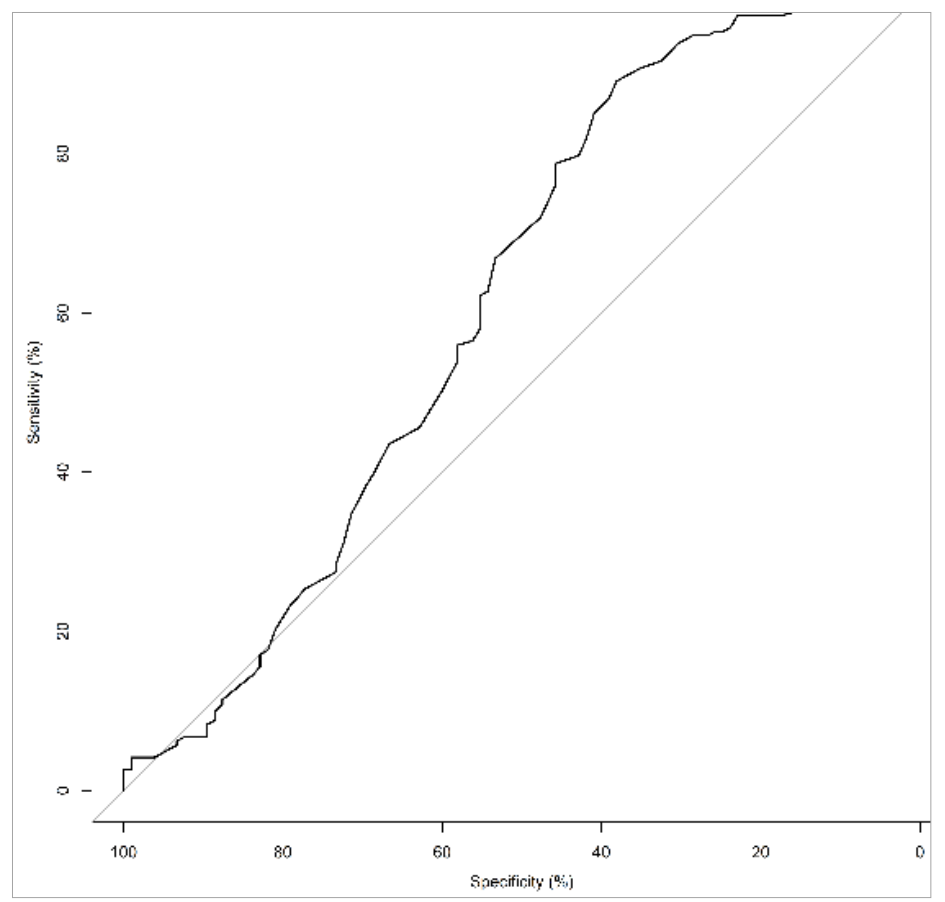

Tabela 16. Ponto de corte, sensibilidade e especificidade da EAFAA versão espanhol.

\begin{tabular}{|c|c|c|c|c|c|c|}
\hline Pergunta 2 & $\begin{array}{c}\text { Ponto } \\
\text { de Corte }\end{array}$ & Especificidade & Sensibilidade & $\begin{array}{c}\text { Preditividade } \\
\text { positiva }\end{array}$ & $\begin{array}{c}\text { Preditividade } \\
\text { negativa }\end{array}$ & Acurácia \\
\hline $\begin{array}{c}\text { iEl } \\
\text { alcohólico } \text { es } \\
\text { grosero, }\end{array}$ & 3,2 & $56,6 \%$ & $66,7 \%$ & $72,6 \%$ & $46,3 \%$ & $62 \%$ \\
$\begin{array}{c}\text { agresivo y } \\
\text { mal } \\
\text { educado? }\end{array}$ & & & & & & \\
\hline
\end{tabular}

Fonte. Dados obtidos da aplicação da EAFAA versão adaptada ao Espanhol.

Finalmente, como resultado de todas as etapas anteriormente descritas obteve-se como produto final a versão adaptada da EAFAA versão espanhol, composta por 48 itens, distribuídos em quatro fatores conforme ilustram os quadros 1,2,3 e, 4. 
Quadro 2. Versão Final da EAFAA discriminada por fatores após validação de construto. Fator 1

\begin{tabular}{|c|c|c|}
\hline Id & Ítem & Fator \\
\hline 01 & Tengo miedo de abordar el problema del alcohol con los pacientes. & \multirow{17}{*}{$\begin{array}{c}\text { Factor 1: El } \\
\text { trabajo y las } \\
\text { relaciones } \\
\text { interpersonales } \\
\text { con personas cor } \\
\text { trastornos } \\
\text { relacionados al } \\
\text { uso de alcohol. }\end{array}$} \\
\hline 05 & $\begin{array}{l}\text { Me siento inseguro (a) ante la agresividad de una persona con trastornos relacionados al uso de } \\
\text { bebidas alcohólicas. }\end{array}$ & \\
\hline 09 & $\begin{array}{l}\text { Me siento frustrado (a) cuando trabajo con personas con trastornos relacionados al uso de } \\
\text { bebidas alcohólicas. }\end{array}$ & \\
\hline 13 & $\begin{array}{l}\text { De todas las personas, las que tienen trastornos relacionados al uso de bebidas alcohólicas, son } \\
\text { las que dan más trabajo. }\end{array}$ & \\
\hline 17 & $\begin{array}{l}\text { Debo ofrecer ayuda y orientaciones a la persona con trastornos relacionados al uso de bebidas } \\
\text { alcohólicas, aunque no crea que necesita cuidar de su salud. }\end{array}$ & \\
\hline 14 & $\begin{array}{l}\text { Personas con trastornos relacionados al uso de bebidas alcohólicas tienen mayores } \\
\text { probabilidades de reaccionar en forma violenta contra mí. }\end{array}$ & \\
\hline 21 & $\begin{array}{l}\text { Incluso, cuando la persona con trastornos relacionados al uso de bebidas alcohólicas. No está } \\
\text { intoxicada, es irrespetuosa con los miembros del equipo de salud. }\end{array}$ & \\
\hline 25 & $\begin{array}{l}\text { Siento rabia al trabajar con personas que tienen trastornos relacionados al uso de bebidas } \\
\text { alcohólicas. }\end{array}$ & \\
\hline 29 & $\begin{array}{l}\text { Las personas con trastornos relacionados al uso de bebidas alcohólicas nunca aceptan lo que lo } \\
\text { que los profesionales de salud dicen sobre sus problemas con la bebida. }\end{array}$ & \\
\hline 37 & $\begin{array}{l}\text { Abordar el problema del alcohol con personas con trastornos relacionados a su uso, implica } \\
\text { dedicar menos tiempo a otros pacientes. }\end{array}$ & \\
\hline 38 & $\begin{array}{l}\text { De todas las personas, las que tienen trastornos relacionados al uso de bebidas alcohólicas, son } \\
\text { las más difíciles de cuidar. }\end{array}$ & \\
\hline 41 & $\begin{array}{l}\text { Prefiero trabajar con pacientes con trastornos relacionados al uso de bebidas alcohólicas que } \\
\text { trabajar con otros pacientes. }\end{array}$ & \\
\hline 44 & $\begin{array}{l}\text { Es difícil para mí, establecer una relación terapéutica con personas que tienen trastornos } \\
\text { relacionados al uso de bebidas alcohólicas. }\end{array}$ & \\
\hline 46 & $\begin{array}{l}\text { Debo tener precaución para no ser agredido (a) al trabajar con personas que tienen trastornos } \\
\text { relacionados al uso de bebidas alcohólicas. }\end{array}$ & \\
\hline 48 & $\begin{array}{l}\text { Cuando la persona con trastornos relacionados al uso de bebidas alcohólicas, no acepta que } \\
\text { tiene problemas relacionados al consumo, la mejor decisión es desistir de ayudar. }\end{array}$ & \\
\hline 49 & $\begin{array}{l}\text { Cuando trabajo con personas con trastornos relacionados al uso de bebidas alcohólicas, no sé } \\
\text { cómo manejar la situación. }\end{array}$ & \\
\hline 50 & $\begin{array}{l}\text { Cuidar pacientes con trastornos relacionados al uso de bebidas alcohólicas no es gratificante } \\
\text { para mí. }\end{array}$ & \\
\hline
\end{tabular}


Quadro 3. Versão Final da EAFAA discriminada por fatores após validação de construto. Fator 2.

\begin{tabular}{|c|c|c|}
\hline Id & Ítem & Fator \\
\hline 02 & $\begin{array}{l}\text { Las personas con trastornos relacionados al uso de bebidas alcohólicas no tienen crítica de la } \\
\text { realidad. }\end{array}$ & \multirow{13}{*}{$\begin{array}{c}\text { Factor 2: La } \\
\text { persona con } \\
\text { trastornos } \\
\text { relacionados } \\
\text { al uso de } \\
\text { bebidas } \\
\text { alcohólicas. }\end{array}$} \\
\hline 06 & Las personas con trastornos relacionados al uso de bebidas alcohólicas son mal educadas. & \\
\hline 10 & Las personas con trastornos relacionados al uso de bebidas alcohólicas son irresponsables. & \\
\hline 15 & $\begin{array}{l}\text { Lo que falta en una persona con trastornos relacionados al uso de bebidas alcohólicas es fuerza de } \\
\text { voluntad. }\end{array}$ & \\
\hline 18 & Las personas con problemas de alcoholismo son débiles de carácter. & \\
\hline 22 & Las personas con trastornos relacionados al uso de bebidas alcohólicas no se quieren cuidar. & \\
\hline 26 & $\begin{array}{l}\text { Los relatos de las personas con trastornos relacionados al uso de bebidas alcohólicas no son } \\
\text { confiables. }\end{array}$ & \\
\hline 30 & $\begin{array}{l}\text { La persona con trastornos relacionados al uso de bebidas alcohólicas es culpable de sus problemas } \\
\text { de salud. }\end{array}$ & \\
\hline 33 & La persona con trastornos relacionados al uso de bebidas alcohólicas es un caso perdido. & \\
\hline 34 & $\begin{array}{l}\text { La persona con trastornos relacionados al uso de bebidas alcohólicas acaba siempre volviendo al } \\
\text { servicio de salud por el mismo problema. }\end{array}$ & \\
\hline 42 & $\begin{array}{l}\text { El paciente con trastornos relacionados al uso de bebidas alcohólicas es una persona que le cuesta } \\
\text { relacionarse con los otros. }\end{array}$ & \\
\hline 45 & $\begin{array}{l}\text { Las personas con trastornos relacionados al uso de bebidas alcohólicas cooperan en su } \\
\text { tratamiento. }\end{array}$ & \\
\hline 47 & $\begin{array}{l}\text { Las personas con trastornos relacionados al uso de bebidas alcohólicas no toman en serio su } \\
\text { tratamiento. }\end{array}$ & \\
\hline
\end{tabular}

Quadro 4. Versão Final da EAFAA discriminada por fatores após validação de construto. Fator 3.

\begin{tabular}{|l|l|c|}
\hline Id & \multicolumn{1}{|c|}{ Ítem } & Fator \\
\hline 03 & La disfunción familiar puede llevar al alcoholismo & \\
\hline 07 & Las personas tímidas o inhibidas tienen mayor tendencia a desarrollar alcoholismo. & Factor 3: El \\
\hline 11 & La depresión puede provocar alcoholismo. & alcoholismo \\
\hline 19 & Las problemáticas sociales llevan a una persona a beber. & (Etiología) \\
\hline 23 & Factores hereditarios conducen al alcoholismo. & \\
\hline 27 & Las personas insatisfechas abusan de las bebidas alcohólicas. & \\
\hline 31 & Las personas que desarrollan alcoholismo tienen baja autoestima. & \\
\hline 35 & Las personas con trastornos relacionados al uso de alcohol son psicológicamente inestables. & \\
\hline 43 & Las personas beben para sentirse más sociables. & La persona con trastornos relacionados al uso de alcohol bebe porque no es capaz de enfrentar su \\
\hline
\end{tabular}


Quadro 5. Versão Final da EAFAA discriminada por fatores após validação de construto. Fator 4.

\begin{tabular}{|c|c|c|}
\hline Id & Ítem & Fator \\
\hline 04 & Las personas tienen derecho a beber si así lo desean. & \multirow{10}{*}{$\begin{array}{c}\text { Factor 4: Las } \\
\text { bebidas } \\
\text { alcohólicas y } \\
\text { su uso. }\end{array}$} \\
\hline 08 & La bebida alcohólica es agradable y proporciona bienestar a quien la usa. & \\
\hline 12 & El uso de bebida alcohólica es algo normal. & \\
\hline 16 & Beber alcohol en cualquier cantidad causará siempre dependencia. & \\
\hline 24 & El uso de bebida alcohólica es perjudicial en cualquier circunstancia. & \\
\hline 28 & $\begin{array}{l}\text { Estoy a favor de beber con moderación *(Hombres menos de } 5 \text { dosis, y mujeres menos de } 4 \\
\text { dosis por ocasión). }\end{array}$ & \\
\hline 32 & Dosis pequeñas de alcohol pueden causar dependencia. & \\
\hline 36 & Las bebidas alcohólicas en cantidades reducidas son benéficas. & \\
\hline 40 & Las personas pueden beber con tal que mantengan el control sobre su uso. & \\
\hline & $\begin{array}{l}* \text { Una dosis equivale: } 1 \text { lata de cerveza }=350 \mathrm{ml}, 1 \text { copa de vino }=140 \mathrm{ml}, 1 \text { trago sencillo de } \\
\qquad \text { destilado }=40 \mathrm{ml}, 1 \text { trago de aperitivo }=40 \mathrm{ml}\end{array}$ & \\
\hline
\end{tabular}




\section{DISCUSSÃO}

Esse estudo se propôs a realizar a validação de construto da EAFAA. Durante esse processo, a escala foi traduzida e adaptada culturalmente para a população alvo e, posteriormente avaliou-se sua validade de conteúdo, além disso, foi realizado um teste piloto com a versão adaptada da escala para garantir sua validade semântica e, assim, verificar a validade de construto, a confiabilidade, a sensibilidade e especificidade da escala na sua versão em espanhol.

$\mathrm{Na}$ adaptação transcultural e validação de conteúdo do instrumento, $32 \%$ dos itens precisaram de alterações linguísticas e estruturais, classificadas pelos membros do comitê de especialistas segundo as equivalências entre o instrumento original e a versão adaptada, conforme ilustra-se na matriz conceitual (Apêndice H). Tais alterações foram analisadas em conjunto com os testes estatísticos (ICC, PABAK, IVC) que também forneceram critérios de ajuste e exclusão para cada item da EAFAA.

No processo de tradução e retro tradução da EAFAA encontraram-se expressões sem tradução literal, dentre elas, a expressão "bom senso" no item 02: "Pessoas com transtornos relacionados ao uso do álcool não têm bom senso" incluso no fator 2 , cuja tradução inicial foi "sentido comum" o que gerou discordância entre os dois tradutores. Por esse motivo considerou-se importante a inclusão de um terceiro avaliador com vistas a subsidiar maiores auxílios na síntese dos processos de tradução e, finalmente, a expressão foi substituída por “crítica de la realidad" já que não era suficiente, apenas uma tradução simples da expressão, conforme os estudos indicam (Rubio et al. 2003; Alexandre, 2011), é necessário verificar que cada termo seja adequado e compreensível para a população alvo. A presença de um terceiro avaliador para resolver as discrepâncias entre dois tradutores, é pouco explicitada nos estudos publicados sobre adaptação de instrumentos. No entanto, a adoção do terceiro avaliador constitui-se num cuidado adicional para diminuição de possível viés que pode causar a perda da essência do instrumento original quando traduzido incorretamente para população alvo. (Beaton et al. 1998, 2000; Pasquali 2010).

Atendendo as sugestões realizadas pelo comitê de juízes, substituiu-se o termo paciente por "persona," em todos os itens da EAFAA, já que eles argumentam que a palavra paciente faz referência ao indivíduo como um ser passivo na relação de cuidado, eliminando sua autonomia e dificultando o desenvolvimento da autoeficácia (Saito et al. 2013). 
Quando calculado o índice validade de conteúdo (IVC) da EAFAA, foram considerados para exclusão ou deslocação os itens que apresentavam valores inferiores a 0,7, conforme dados apresentados na Tabela 13. Esse entendimento resultou, na exclusão do item 20 "Beber con moderação no es prejudicial" incluso no fator 4 e, posteriormente, na modificação estrutural do item 28, no mesmo fator: "Estoy a favor de beber con moderación" Essas alterações foram realizadas utilizando as definições indicadas pelo comitê de juízes , as quais estavam baseadas nas diretrizes da Organização Mundial de Saúde (World Health Organization, 2014), resultando no seguinte item: "Estoy a favor de beber com moderación" (Hombres menos de 5 dosis en una ocasión. Mujeres menos de 4 dosis en una ocasión) esclarecendo que as definições de dose padrão seguem a seguinte forma: Dosis = 1 lata de cerveza $350 \mathrm{ml}, 1$ copa de vino $140 \mathrm{ml}, 1$ trago de destilado 40ml, 1 trago de aperitivo 40ml.

Conforme sugestões dos juízes e indicadores do IVC dois itens situados no fator 1 foram deslocados para o fator 2 , dentre eles o item 42: "La persona con trastornos relacionados al uso de alcohol es una persona que le cuesta relacionarse con los otros" e o Item 15: "Lo que falta en una persona con trastornos relacionados al uso de alcohol es fuerza de voluntad", uma vez que constatou-se que o conteúdo dos itens referia-se as características pessoais do usuário, indicando uma forte relação com a definição operacional do fator 2.

Apesar de o item 14 "Pacientes con trastornos relacionados al uso de alcohol tienen mayores probabilidades de reaccionar en forma violenta contra mí" e do item 38 "De todos mis pacientes, el que posee trastornos relacionados al uso de alcohol es el más difícil de cuidar" situados no fator 2, apresentarem valores considerados adequados para o índice de validade de conteúdo , os juízes sugeriram que era necessário desloca-los para o fator 1: ” El trabajo y las relaciones interpersonales con personas con trastornos relacionados al uso de alcohol.” Tal sugestão foi acatada, uma vez que, quando se analisou a matriz conceitual dos itens resultante da avaliação dos juízes, identificou-se que seu conteúdo estava adequado à definição operacional do fator de destino, pois os itens referem-se à relação interpessoal enfermeiro - usuário.

Em contraste com outros itens que apresentaram valores inferiores no IVC, o item 29, "Las personas con trastornos relacionados al uso de bebidas alcohólicas nunca aceptan lo que lo que los profesionales de salud dicen sobre sus problemas con la bebida" incluso no fator 1 com um índice de 0,33 na categoria que se refere a clareza do item, manteve-se sem alterações. Isso ocorreu pelo fato de ter sido sugerido pelos juízes uma revisão mais 
aprofundada da sua redação para posteriores pesquisas. Eles argumentaram que sua compreensão poderia estar influenciada pela percepção social do uso de álcool, sendo que é uma droga licita e socialmente aceita, e seu uso poucas vezes é concebido como um problema, inclusive por profissionais da saúde.

Embora o índice de validade de conteúdo seja uma medida robusta e usada frequentemente em estudos de validação de instrumentos é importante verificar se o acordo dos juízes com os parâmetros avaliados nos itens não se deu ao acaso. Autores (Beckstead 2009; Claro 2012) apontam que não deve considerar-se o IVC como único teste para determinar a validez de conteúdo, questionando o fato de ele estar baseado em índices de correlação entre os juízes e representar a tendência de fazer os mesmos julgamentos sobre algum item.

Diante desse postulado, foram aplicados outros testes estatísticos, para verificar o grau de concordância entre os juízes que compuseram o comitê de especialistas dentre eles o ICC e o PABAK. Os dados obtidos indicaram que o grau de concordância é substancial, ou seja, que a proporção de acordo entre juízes é maior do que poderia ser esperado se tivessem concordado em suas repostas ao acaso.

Para finalizar a etapa de adaptação cultural e validação de conteúdo, a versão adaptada da EAFAA foi submetida ao estudo piloto, cujos resultados indicaram que houve 95\% de compreensão dos itens, garantindo sua compreensão entre a população alvo. Portanto esse índice é consistente com aquele recomendado por autores especializados na temática (Beaton et al. 1998, 2000; Sousa ; Rojjanasrirat 2011).

Uma vez finalizado teste piloto, a EAFAA foi aplicada numa amostra de enfermeiros para a verificação das suas propriedades psicométricas. Para esse fim optou-se por realizar a validação de constructo por meio de uma análise fatorial confirmatória, uma vez que tratavase de um instrumento cujo modelo já havia sido validado seguindo teorias de mensuração consistentes, definida por meio de Análise Fatorial Exploratória, durante o processo de elaboração e refinamento da versão original (Vargas et al. 2008; Vargas 2011, 2014). Assim foi possível realizar diretamente a análise fatorial confirmatória, já que a estrutura da EAFAA versão espanhol foi estabelecida sobre bases empíricas e teóricas bem sustentadas, conforme indica a literatura (Browm, 2006). 
Para verificar a adequação da amostra para análise fatorial, realizou-se o teste KMO, o qual indicou a viabilidade dos dados para esse fim $(0,86)$. Em seguida, foram avaliados os índices de ajuste do modelo, os quais se mostraram adequados para uma distribuição de quatro fatores. Isso significa que a versão adaptada da EAFAA conservou a estrutura da escala original no que se refere à quantidade de dimensões teóricas de agrupação dos itens.

Quando avaliadas as correlações entre os quatro fatores e as cargas fatoriais para os 49 itens remanescentes da validade de conteúdo, por meio do gráfico de caminhos (figura 3), constatou-se a unidimensionalidade da escala, sendo que todos os fatores apresentaram valores de correlação adequados, indicando que eles representam satisfatoriamente o construto mensurado.

Por outro lado, o item 45: "Las personas con transtornos relacionados al uso de bebidas alcohólicas cooperan en su tratamiento" apresentou carga fatorial inferior $(0,014)$. Esta constatação foi realizada por uma verificação integrada da matriz conceitual, composição operacional da escala e valores obtidos na análise fatorial com vistas a considerar a eliminação do item e manter a estabilidade dos parâmetros de validade da EAFAA. O resultado foi, sua eliminação sem alteração da estrutura do instrumento.

A EAFAA mostrou-se confiável, uma vez que os índices do Alfa de Cronbach indicaram a existência de uma correlação forte entre os 48 itens que a compõem, sendo que todos eles revelaram valores acima do requerido para garantir a consistência interna dos dados (Gliem, 2003; Pasquali 2010). Esses resultados foram consistentes com os apresentados na versão original (Vargas, 2014), no entanto com vistas a buscar maiores subsídios para confirmar a confiabilidade da EAFAA versão em espanhol, realizou-se o teste Ômega de Mc Donald, o qual constatou que a EAFAA também por esse teste, possui uma excelente consistência interna.

O fato de ter aplicado um teste diferente dos usados até agora para verificar a confiabilidade da EAFAA na sua língua de origem (Vargas 2008, 2014; Pires 2013) sugere que trata-se de uma escala com uma estrutura robusta e, portanto, caracteriza-se como um instrumento confiável para ser utilizado com elevados índices de confiabilidade independentemente dos contextos e populações.

A análise da sensibilidade e especificidade da EAFAA na sua versão adaptada ao espanhol, demonstrou que o ponto de corte que apontou maior sensibilidade $(66,7 \%)$, 
especificidade $(56,6 \%)$ e acurácia $(62 \%)$ foi 3,2. Tais resultados são semelhantes em estudos realizados no Brasil, que visaram validar a escala entre profissionais de saúde e estudantes de enfermagem, em que se observou pontos de corte de 3,15 e 3,2 respectivamente. Essas semelhanças indicam que a escala é capaz de identificar com acurácia as atitudes positivas e negativas quando aplicada em profissionais de enfermagem hispano-falantes, confirmando até agora que todas as características verificadas no presente estudo sugerem à EAFAA como um instrumento adequado para mensuração de atitudes.

Embora os resultados do presente estudo indiquem que a EAFAA é uma escala válida e confiável para ser utilizada na língua espanhola, existem algumas limitações a serem consideradas. $\mathrm{O}$ estudo foi realizado em uma região especifica da América Latina, limitandose às características especificas de algumas cidades da Colômbia, que de fato podem ter semelhanças culturais com outras regiões do país e do continente, porém sugerem-se também repetições do estudo em diferentes populações e em outras regiões da América Latina, para considerar com maior segurança o uso da escala na sua versão em espanhol.

Por outro lado, a amostra foi composta unicamente por enfermeiros e, embora essa fosse a população alvo do estudo, recomenda-se a aplicação da escala em outras categorias de profissionais, pois a atenção à pessoa com problemas decorrentes do uso de álcool, envolve o trabalho de uma equipe multidisciplinar.

Apesar dessas limitações, a validação da EAFAA para a língua espanhola, com comprovada validade e confiabilidade representa um avanço no conhecimento ao disponibilizar uma escala confiável para o uso nesse idioma. Em última análise, esse estudo pode subsidiar pesquisas posteriores que possam avaliar as atitudes dos profissionais de saúde em populações hispano-falantes, possibilitando ainda reconhecer diferenças e semelhanças entre as atitudes através das culturas latino-americanas. A utilização de um único instrumento, certamente oferecerá maior confiabilidade aos resultados obtidos com um mesmo instrumento independentemente da cultura, auxiliando também na construção de um corpo de conhecimento ao redor das atitudes desses profissionais, ainda incipiente na América Latina,

Para prática o fato de conhecer as atitudes desses profissionais frente ao fenômeno, pode contribuir na construção de estruturas curriculares mais sólidas no que diz respeito a formação dos profissionais de saúde na área. Além disso, programas de treinamento específicos e programas de educação continuada que garantem a quebra do paradigma assistencial, o qual reverterá na melhora da qualidade da atenção à pessoa com transtornos 
decorrentes do uso de álcool e outras drogas. Aliado a isso, a EAFAA mostrou capacidades preditivas, o que a torna um instrumento útil na identificação de perfis profissionais baseados nas atitudes dos mesmos, na gestão de recursos humanos. 
CONCLUSÕES 


\section{CONCLUSÃO}

A EAFAA versão em espanhol mostrou-se como um instrumento válido e confiável, capaz de medir as atitudes em enfermeiros na cultura Colombiana frente ao álcool, ao alcoolismo, e a pessoa com transtornos decorrentes do uso de álcool. Sugere-se a utilização em outras culturas hispano-falantes, a fim de buscar a padronização e a uniformização de seu uso entre essas culturas. 
CRONOGRAMA 
CRONOGRAMA DE ATIVIDADES

\begin{tabular}{|l|c|c|c|c|c|c|c|c|}
\hline \multicolumn{1}{|c|}{$\begin{array}{c}\text { Unidade de tempo } \\
\text { Etapas }\end{array}$} & 1 trim & 2 trim & 3 trim & 4 trim & 5 trim & 6 trim & 7 trim & 8 trim \\
\hline Levantamento bibliográfico & $\mathrm{x}$ & $\mathrm{x}$ & $\mathrm{x}$ & $\mathrm{x}$ & $\mathrm{x}$ & $\mathrm{x}$ & $\mathrm{x}$ & $\mathrm{x}$ \\
\hline Fichamento dos textos & $\mathrm{x}$ & $\mathrm{x}$ & $\mathrm{x}$ & $\mathrm{x}$ & $\mathrm{x}$ & $\mathrm{x}$ & $\mathrm{x}$ & $\mathrm{x}$ \\
\hline Planejamento do estudo & $\mathrm{x}$ & $\mathrm{x}$ & & & & & & \\
\hline Plano de coleta de dados & & $\mathrm{x}$ & & & & & & \\
\hline Coleta de dados & & & $\mathrm{x}$ & & & & & \\
\hline Transcrição de entrevistas & & & $\mathrm{x}$ & $\mathrm{x}$ & & & & \\
\hline Análise dos dados & & & & & $\mathrm{x}$ & $\mathrm{x}$ & $\mathrm{x}$ & \\
\hline Interpretação dos dados & & & & & $\mathrm{x}$ & $\mathrm{x}$ & $\mathrm{x}$ & \\
\hline Qualificação & & & & & $\mathrm{x}$ & & & \\
\hline Primera redação & & & & & $\mathrm{x}$ & $\mathrm{x}$ & & \\
\hline Correção & & & & & & $\mathrm{x}$ & $\mathrm{x}$ & \\
\hline $\begin{array}{l}\text { Defesa e apresentação da } \\
\text { versão final da dissertação à } \\
\text { FAPESP }\end{array}$ & & & & & & & & \\
\hline
\end{tabular}




\section{REFERENNCIAS}




\section{REFERÊNCIAS}

Ajzen I. Attitudes, Personality, and Behavior [Internet]. McGraw-Hill Education (UK); 2005 p. 192

Alabarce J, Romero MM, Fernández I, Viñals EC, Trujillo AG, Isabel A, et al. ¿Existen instrumentos válidos para medir actitudes profesionales frente al drogodependiente? Evidentia. 2012; 9 (39).

Alexandre NMC, Coluci MZO. Validade de conteúdo nos processos de construção e adaptação de instrumentos de medidas. Cien Saude Colet 2011 ;16 (7):3061-3068. Disponível: $\quad$ http://www.scielo.br/scielo.php?script=sci_arttext\&pid=S1413$1232011000800006 \& \operatorname{lng}=$ en $\& n r m=$ iso $\&$ tlng $=$ pt.

Allen E. Techniques of Attitude Scale Construction [Internet]. 1st ed. Appletton Century Crofts, editor. New York; 1957

Allport G. A Handbook of Social Psychology. Clark Univ. Worcester; 1935.

Altmann TK. Attitude: a concept analysis. Nurs Forum [Internet]. 2008 Jan [cited 2015 Mar 28];43(3):144-50. Disponível: http://www.ncbi.nlm.nih.gov/pubmed/18715347

Artes R. Aspectos estatisticos da análise fatorial de escalas de avaliação. Rev. Psiquiatr. Clín. 1998;25(5):223-228. Disponível: http://www.hcnet.usp.br/ipq/revista/vol25/n5/conc255d.htm

Bartko J. The intraclass correlation coefficient as a measure of reliability. Psychol Rep 1996 ;19. Disponível: http://www.amsciepub.com/doi/pdf/10.2466/pr0.1966.19.1.3

Beaton D, Bombardier C, Guillemin F, Ferraz M. Guidelines for the Process of Cross-Cultural Adaptation of Self-Report Measures. Spine 2000; 25 (24): 3186-3191. Disponível: http://ovidsp.tx.ovid.com/sp-3.15.0a/ovidweb.cgi?

Beaton D, Bombardier C, Guillemin F, Ferraz MB. Recommendations for the Cross-Cultural Adaptation of Health Status Measures. American Academy of Orthopaedic Surgeons Institute for Work and Health 1998.

Beckstead JW. Content validity is naught. Int J Nurs Stud 2009; 46 (9): 1274-1283. Disponível: http://www.sciencedirect.com/science/article/pii/S0020748909001576 
Bland J, Altman G. A note on the use of the intraclass correlation coefficient in the evaluation of agreement between two methods of measurement. Compur Rio/ Med. 1990; 30 (5). Disponível: http://ac.els-cdn.com/001048259090013F/1-s2.0001048259090013Fmain.pdf?_tid=82187fb6-ce48-11e4-afa500000aacb35e\&acdnat=1426777334_59393dce99815fe3dd89aa1736489b51

Browm T. Conformatory factor analysis for applied research. Londres. Guilford press, editor; 2006.

Byrt T, Bishop J, Carlin JB. Bias, prevalence and kappa. J Clin Epidemiol. 1993; 46 (5): 423429. Disponível: http://www.sciencedirect.com/science/article/pii/089543569390018V

Cerda J, Cifuentes L. Using ROC curves in clinical investigation: theoretical and practical issues. Rev. Chilena Infectol; 2012; 29 (2): 138-141. Disponível: http://www.scielo.cl/scielo.php?script=sci_arttext\&pid=S0716-

$10182012000200003 \& \operatorname{lng}=\mathrm{es} \& n r m=$ iso \&thng=es

Chen G, Faris P, Hemmelgarn B, Walker RL, Quan H. Measuring agreement of administrative data with chart data using prevalence unadjusted and adjusted kappa. BMC Med Res Methodol. 2009; 9 (1): 5. Disponível: http://www.biomedcentral.com/1471-2288/9/5 Comisión interamericana para el control del abuso de drogas (CICAD). Elementos orientadores para las políticas públicas sobre drogas en la subregión. 2008.

Claro H, Oliveira MAF, Paglione HB, Pinho PH, Pereira MO, Vargas D. Tradução e adaptação cultural do global appraisal of individual needs - initial. Rev. esc. Enferm. USP 2012; $46 \quad$ (5). Disponível:http://www.scielo.br/scielo.php? Pid=S008062342012000500016\&script=sci_arttext

Comittee for translations and Protocols International RDC/TMD Consortium Network. Guidelines for Establishing Cultural Equivalency of Instruments. Buffalo; 2013.

Costa N, Orpinelli M. Validade de conteúdo nos processos de construção e adaptação de instrumentos de medidas. Cien Saude Colet. 2011;16(7):3061-3068.

Crothers E. Determinants of Nurses' Attitudes toward the Care of Patients with Alcohol Problems. $\quad$ ISRN Nurs. 2011;2011 (11). Disponível: 
Cund A. Alcohol education revisited: exploring how much time we devote to alcohol education in the nursing curriculum. Nurse Educ Pract; 2013; 13 (1): 35-39. Disponível: http://www.ncbi.nlm.nih.gov/pubmed/22858311

Cunha LM. Modelos Rasch e Escalas de Likert e Thurstone na medição de atitudes. [Dissertação] Universidad de Lisboa. 2007.

Dunn TJ, Baguley T, Brunsden V. From alpha to omega: A practical solution to the pervasive problem of internal consistency estimation. Br J Psychol. 2014; 105:399-412.

Gilchrist G, Moskalewicz J, Slezakova S, Okruhlica L, Torrens M, Baldacchino. Staff regard towards working with substance users: a European multi-centre studya. Addiction. 2011.

Gliem J a Gliem RR. Calculating, Interpreting, and Reporting Cronbach's Alpha Reliability Coefficient for Likert-Type Scales. Midwest Res to Pract Conf Adult, Contin Community Educ. 2003;(1992):82-88.

Gorsuch, R. L. Factor analysis, 2nd NJ: LEA. Hillsdale editor 1983.

Hair J, Black WC, Babin BJ, Anderson RE. Análise Fatorial. Análise multivariada de dados. 6 th Ed. Bookman editor, 2009.

Happell B, Carta B, Pinikahana J. Nurses' knowledge, attitudes and beliefs regarding substance use: A questionnaire survey. Nurs Heal Sci. 2002; 4 (4): 193-200. Disponível: http://doi.wiley.com/10.1046/j.1442-2018.2002.00126.x

Hogan T. Introdução à prática de Testes Psicológicos. Ed LAF Pontes. Rio de Janeiro. 2006. Iqbal N, McCambridge O, Edgar L, Young C, Shorter GW. Health-care professionals' attitudes across different hospital departments regarding alcohol-related presentations. Drug Alcohol Rev.2015; Disponível: http://www.ncbi.nlm.nih.gov/pubmed/25693922

Lage L V., Levy RA, Ciconelli RM. Instrumentos de avaliação em reumatologia: importância de sua tradução e validação para nosso idioma. Rev. Bras Reumatol; 2006;46(4):237. Disponível: $\quad$ http://www.scielo.br/scielo.php?script=sci_arttext\&pid=S0482$50042006000400001 \& \operatorname{lng}=\mathrm{en} \& \mathrm{nrm}=\mathrm{iso} \& \operatorname{lng}=\mathrm{pt}$

Lopez J. Percepción, conocimientos y actitudes de las enfermeras de urgencias y salud mental frente al alcoholismo y otras drogodependencias. Metas Enferm. 2014;17(2):22-31. 
Mandeville P. El Coeficiente de Correlación Intra clase. Cienc UANL. 2005;8(3):414-6. Disponível: http://www.redalyc.org/pdf/402/40280322.pdf

Maneesriwongul W, Dixon JK. Instrument translation process: a methods review. J Adv Nurs 2004; 48 (2): 175-186. Disponível: http://doi.wiley.com/10.1111/j.1365-2648.2004.03185.x

Mallon, J. V., Piiieiro, J. A., \& Tobio, T. B. Análisis Factorial Confirmatorio. Modelización con estructuras de covarianzas en Ciencias Sociales: temas esenciales, avanzados y aportaciones especiales, 239. España; Netbiblo editor; 2006. p. 131-140.

Manuel G. Escala Mixta Likert - Thurstone. Rev. andaluza ciencias Soc [Internet]. 2006 ;5.

Martins G a. Sobre confiabilidade e validade. Rev. Bras Gest Negocios. 2006; 8: 1-12.

Meloni JN Laranjeira R. Custo social e de saúde do consumo de álcool. Rev. Bras Psiquiatr. 2004;1(26):7-10.

Ministerio de justicia y derecho - Observatorio de Drogas de Colombia. Estudio Nacional de Consumo de Sustancias Psicoactivas en Colombia.2014, Disponível: http://www.unodc.org/documents/colombia/2014/Julio/Estudio_de_Consumo_UNODC.pdf

Ministerio de justicia y derecho, Observatorio de Drogas de Colombia. Estudio nacional de consumo de sustancias psicoactivas en población escolar Colombia - 2011 1. 2011.

Molina Mula J, Hernández Sánchez D, Sanz Álvarez E, Clar Aragón F. Impacto de las actitudes de las enfermeras en la calidad de los cuidados en drogodependientes. Index de Enfermería; 2012; $21 \quad$ (4): 214-218. Disponível: http://scielo.isciii.es/scielo.php?script=sci_arttext\&pid=S1132$12962012000300008 \& \operatorname{lng}=\mathrm{es} \& n r m=i s o \& \operatorname{lng}=\mathrm{es}$

Monteiro M. Alcohol and Public Health in Latin America: ¿how to prevent a health disaster? Revista Adicciones 2013; 25 (2): 99-105.

Navarrete PR, Villar M. Actitud de la enfermera de un complejo hospitalario en relación al paciente alcohólico. Rev. Lat. Am Enfermagem. 2004; 12:420-6.

NCBI. Attitude - MeSH - NCBI [Internet]. 2014 [cited 2015 Mar 28]. Disponível: http://www.ncbi.nlm.nih.gov/mesh/68001290 
Organización Panamericana de Salud. Epidemiología del uso de drogas en América Latina y el Caribe: Un enfoque de salud pública 2009.

Organización Panamericana de Salud. Alcohol y Salud Pública en las Américas. 2007 Disponível:

http://www.who.int/substance_abuse/publications/alcohol_public_health_americas_spanish.p df

Ospina B. la escala likert en la valoración de los conocimientos y las actitudes de los profesionales de enfermería en el cuidado de la salud. Rev Investig y Educ en Enfermería. $2005 ; 23(1)$.

Palacios A, Arias V, Arias B. Attitudes Towards Mathematics: Construction and Validation of a Measurement Instrument. Rev. Psicodidact. 2013;19(1):67-91. Disponível: http://www.ehu.es/ojs/index.php/psicodidactica/article/view/8961

Pasquali L. Psicometria, teoria dos testes na psicología e na educação. Brasil; Vo Editora 2003.

Pasquali L. Instrumentação Psicológica: Fundamentos e práticas. São Paulo, 3 th ed. Artmed, editor.2010.

Pasquali L. O Uso da Análise Fatorial: Algumas Diretrizes para Pesquisadores. Brasilia: LabPam editor; 2012.

Perez J, Chacon M, Moreno R. Validez de constructo: el uso de análisis factorial exploratório confirmatorio para obtener evidencias de validez. Psicothema. 2000;12(2).

Pillon S, Laranjeira R, Dunn J. Nurses' attitudes towards alcoholism: factor analysis of three commonly used scales. Sao Paulo Med J; 1998;116(2):1661-1666. Disponível: http://www.scielo.br/scielo.php?script=sci_arttext\&pid=S1516-

$31801998000200004 \& \operatorname{lng}=$ en\&nrm=iso\&tlng=en

Pillon SC. Atitudes dos enfermeiros com relação ao alcoolismo: uma avaliação de conhecimentos. Rev. eletrônica Enferm. 2006;7(3).

Pillon SC, Laranjeira RR. Formal education and nurses' attitudes towards alcohol and alcoholism in a Brazilian sample. Sao Paulo Med J Rev. Paul Med. 2005;123(4):175-80. Disponível: http://www.ncbi.nlm.nih.gov/pubmed/16389415 
Pires N. Atitudes de estudantes de psicologia acerca do álcool, do alcoolismo e do alcoolista. (Dissertação). São Paulo, Universidade de São Paulo; 2013.

Polit DF, Beck CT, Hungler BP. Fundamentos de pesquisa em enfermagem: métodos, avaliação e utilização. São Paulo. Artmed; 2006

Rassool, M. Villar, T. Carraro GL. Undergraduate nursing students' perceptions of substance use and misuse: a Brazilian position. J Psychiatr Ment Heal Nurs. 2006;13.

Rassool GH, Rawaf S. Educational intervention of undergraduate nursing students' confidence skills with alcohol and drug misusers. Nurse Educ Today. 2008;28(3):284-92. Disponível: http://www.ncbi.nlm.nih.gov/pubmed/17643558

Rassool GH, Villar-Luis M, Carraro TE, Lopes G. Undergraduate nursing students' perceptions of substance use and misuse: a Brazilian position. J Psychiatr Ment Health Nurs. 2006;13(1):85-9. Disponível: http://www.ncbi.nlm.nih.gov/pubmed/16441398

Rosenberg MJ. Cognitive, affective, and behavioral components of attitudes. Attitude organization and change: An analysis of consistency among attitude components, 1960; 3:114.

Rubio DM, Berg-Weger M, Tebb SS, Lee ES, Rauch S. Objectifying content validity: Conducting a content validity study in social work research. Soc Work Res. 2003;27(2):94104. Disponível: http://swr.oxfordjournals.org/content/27/2/94.short

Saito DY, Zoboli EL, Schveitzer MC, Maeda ST. Usuário, cliente ou paciente? qual o termo mais utilizado pelos estudantes de enfermagem? Texto Context - Enferm. Revista Texto \& Contexto-Enfermagem; 2013; $22 \quad$ (1): 175-83. Disponível: http://www.scielo.br/scielo.php?script=sci_arttext\&pid=S010407072013000100021\&lng=en\&nrm=iso\&tlng=pt

Silva Junior SH, Vasconcelos AG, Griep RH, Rotenberg L. Validade e confiabilidade do índice de capacidade para o trabalho (ICT) em trabalhadores de enfermagem. Cad Saude Publica. 2011;27(6):1077-87.

Smith, M. B., Bruner, J. S., \& White RW. Opinions and personality. New York: John Wiley. Jhon Wiley and Sons, editor. New York; 1956.

Soares J, Vargas D de, Oliveira MAF de. Atitudes e conhecimentos de profissionais de saúde diante do álcool, alcoolismo e do alcoolista: levantamento da produção científica nos últimos 
50 anos. SMAD Rev. eletrônica saúde Ment álcool e Drog; 2011;7(1):45-52. Disponível: http://pepsic.bvsalud.org/scielo.php?script=sci_arttext\&pid=S1806$69762011000100008 \& \operatorname{lng}=$ pt\&nrm=iso\&tlng=pt

Sousa V, Rojjanasrirat W. Translation, adaptation and validation of instruments or scales for use in cross-cultural health care research: a clear and user-friendly guideline. J Eval Clin Pract. 2011;17(2):268-74. Disponível: http://www.ncbi.nlm.nih.gov/pubmed/20874835

Thurstone LL. Theories of intelligence. Sci Mon. 1946; 62:101-12.

Torres C, Neiva ER. Psicologia Social [Internet]. Artmed; 2011. p. 352.

Vadlamudi RS, Adams S, Hogan B, Wu T, Wahid Z. Nurses' attitudes, beliefs and confidence levels regarding care for those who abuse alcohol: impact of educational intervention. Nurse $\begin{array}{lllll}\text { Educ } & \text { Pract. } & \text { 2008; } & 8 & \text { (4): 290-298. Disponível: }\end{array}$ http://www.ncbi.nlm.nih.gov/pubmed/18042433

Vargas D. Atitudes de enfermeiros de hospital geral frente ao uso do álcool e alcoolismo. Rev. Bras Enferm. 2006;59(1):47-51.

Vargas D. Atitudes de enfermeiros frente as habilidades de identificação para ajudar o paciente aloolista. Rev. Bras Enferm. 2010a;3(63):190-5.

Vargas D. A construção de uma escala de atitudes frente ao álcool, ao alcoolismo e ao alcoolista: um estudo psicométrico. (Tese) São Paulo. Universidade de São Paulo Escola de Enfermagem de Ribeirão Preto; 2005.

Vargas D. Development and validation of a scale of attitudes towards alcohol, alcoholism and alcoholics. Ver Latinoam Enferm. 2008;16(5):895-902. Disponível: http://www.ncbi.nlm.nih.gov/pubmed/19061028

Vargas D. Versão reduzida da escala de atitudes frente ao álcool, alcoolismo e ao alcoolista: resultados preliminares. Rev. da Esc. Enferm. USP. 2011. Disponível: http://www.scielo.br/pdf/reeusp/v45n4/v45n4a18.pdf

Vargas D. Validação de construto da Escala de Atitudes Frente ao Álcool, ao Alcoolismo e a Pessoas com Transtornos Relacionados ao Uso do Álcool. Rev. Psiquiatr. Clin. 2014;55(11).

Vargas D, Antonia M, Luis V. Development and validation of a scale of attitudes towards alcohol, Rev. Lat Am Enfermagem. 2008;16(5). 
Vargas D, Labate RC. Atitudes de enfermeiros de hospital geral frente ao uso do álcool e alcoolismo. Rev. Bras Enferm. Associação Brasileira de Enfermagem; 2006;59(1):47-51. Disponível: $\quad$ http://www.scielo.br/scielo.php?script=sci_arttext\&pid=S0034$71672006000100009 \& \operatorname{lng}=\mathrm{pt} \& n r m=\mathrm{iso} \& \operatorname{lng}=\mathrm{pt}$

Vargas D, Oliveira MAF. Psychosocial care Center for Alcohol and Drugs (CAPS ad): nursing insertion and practices in Sao Paulo City, Brazil. Rev. Lat. Am Enfermagem. 2010;19(1):115-22. Disponível: http://www.sinab.unal.edu.co:3103/sp-3.8.1a/ovidweb.cgi

Vásquez E, Pillon SC. La formación de enfermeras y el fenómeno de las drogas en Colombia: conocimientos, actitudes y creencias. Rev. Lat. Am Enfermagem.; 2005;13(spe):845-853. Disponível: $\quad$ http://www.scielo.br/scielo.php?script=sci_arttext\&pid=S0104$11692005000700012 \& \operatorname{lng}=\mathrm{en} \& \mathrm{nrm}=\mathrm{iso} \& \operatorname{lng}=\mathrm{es}$

Vilela MV, Aparecida C, Ventura A, Cristina E. Conocimientos de estudiantes de enfermería sobre alcohol y drogas. Rev. Latino-Am Enferm, 2010;18: 529-534.

Villar M, Vargas D. Alcohol, alcoholismo y alcohólico: concepciones y actitudes de alcohol. Revista Latino-americana de Enfermagem, 2008;16(spe), 543-550

Watson H, Maclaren W, Kerr S. Staff attitudes towards working with drug users: development of the Drug Problems Perceptions Questionnaire. Addiction. 2007;102(2):20615. Disponível: http://www.ncbi.nlm.nih.gov/pubmed/17222274

World Health Organization. Global status report on alcohol and health. United States 2011; World Health Organization. Global Status Report on alcohol and health. 2014. Disponível: http://apps.who.int/iris/bitstream/10665/112736/1/9789240692763_eng.pdf

Wynd C, Schmidt B, Atkins M. Two Quantitative Approaches for Estimating Content Validity. West J Nurs Res. 2003; 25 (5). Disponível: http://www.uk.sagepub.com/salkind2study/articles/06Article04.pdf 
APÊNDICES 


\section{APÊNDICES.}

\section{Apêndice A.}

\section{AUTORIZAÇÃO DO AUTOR DO INSTRUMENTO PARA REALIZAR A ADAPTAÇÃO CULTURAL E VALIDAÇÃO DA EAFAA}

São Paulo, 06 de fevereiro 2014

Escola de Enfermagem da Universidade de São Paulo

Av. Dr Enéas de Carvalho Aguiar, 419

05403-000 - São Paulo - SP.

Autorizo a ERIKA GISSETH LEON RAMIREZ, mestranda do programa de pósgraduação em enfermagem para a utilização da Escala de Atitudes frente ao álcool, ao alcoolismo, e ao alcoolista EAFAA no seu projeto de pesquisa que pretende adaptar e validar tal instrumento ao espanhol para seu uso na América Latina sob minha supervisão. Me declaro ciente dos métodos que serão utilizados em sua pesquisa e concordo com eles.

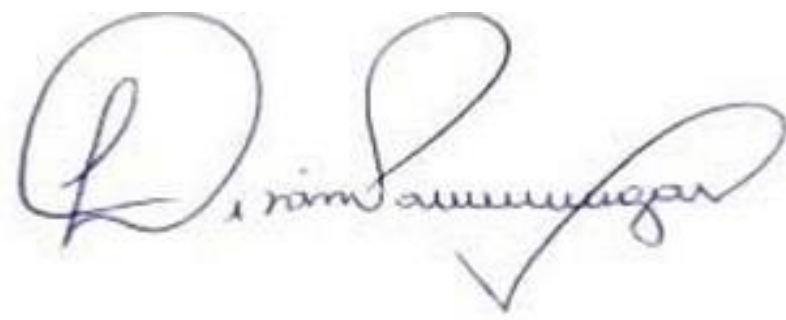

DIVANE DE VARGAS

Professor Doutor. Livre Docente

Escola de Enfermagem Universidade de São Paulo

Líder do Núcleo de pesquisa de Enfermagem em adições, álcool e outras drogas NEPEAA 


\section{Apêndice B.}

\section{INSTRUCCIONES PARA JUECES}

\section{VALIDEZ DE CONTENIDO DE LA ESCALA DE ACTITUDES FRENTE A LAS BEBIDAS ALCOHÓLICAS, AL ALCOHOLISMO Y LA PERSONA CON TRASTORNOS POR USO DE ALCOHOL. EAFAA}

El cuestionario adjunto solicita evaluar que tan representativos son los ítems del instrumento con el dominio de contenido de actitudes hacia las bebidas alcohólicas, el alcoholismo y personas con trastornos relacionados al uso de alcohol. ¿Es decir, en qué medida cree usted que cada pregunta en el cuestionario mide las actitudes hacia las bebidas alcohólicas, el alcoholismo y personas con trastornos relacionados al uso de alcohol? Debido a que las actitudes frente a estas cuestiones son compuestas de múltiples factores, se solicita también que indique si está de acuerdo con la ubicación del ítem en cada factor. La claridad de cada ítem es otro aspecto importante que deberá ser evaluado. Adicionalmente solicitamos evaluar la equivalencia semántica, idiomática y conceptual de instrumento

\section{INSTRUCCIONES:}

Este instrumento está diseñado para evaluar la validez de contenido de la medida (EAFAA).Por favor evalúe cada ítem de la siguiente manera considerando los siguientes conceptos (Rubio et al. 2003; Costa 2011):

a. Representatividad (R): Capacidad de un ítem para representar y describir la definición teórica.

b. Claridad (C): Frase o ítem con lenguaje y redacción fácil de comprender

c. Factor (F): Indica si el ítem realmente corresponde a determinado factor o dominio.

d. Visión general del instrumento: Evalúa la necesidad de eliminar o adicionar ítems a cada factor. 
- Equivalencia semántica: Correspondencia gramatical de los términos utilizados.

- Equivalencia idiomática: Dificultad en la traducción de expresiones coloquiales.

- Equivalencia conceptual: Los conceptos utilizados son adecuados al contexto cultural.

Por favor coloque las sugerencias relacionada a los aspectos anteriores en la casilla de observaciones.

Califique colocando el número correspondiente en cada casilla en frente de cada ítem.

\section{a. Representatividad (R)}

$1=$ El ítem no es representativo

2 = El ítem requiere revisiones importantes para ser representativo.

3 = El ítem necesita revisiones menores para ser representativo

$4=$ El ítem es representativo

(Si su respuesta es 1, 2, o 3, por favor, especifiquen el tipo de revisión que requiere en la casilla observaciones)

\section{b. Claridad (C)}

$1=$ El ítem no es claro

2 = El ítem requiere revisiones importantes para ser claro

3 = El ítem necesita revisiones menores para ser claro

4 = El ítem es claro

(Si su respuesta es 1, 2, o 3, por favor, especifiquen el tipo de revisión que requiere en la casilla observaciones)

\section{c. Factor (F)}

Ver en anexo la definición operacional de cada factor y califique en la casilla correspondiente:

$1=$ Si considera que el ítem realmente no pertenece a este factor.

$2=$ Si considera que el ítem realmente corresponde a este factor.

(Si su respuesta es 1 por favor, justifique en la casilla observaciones) 


\section{Apêndice C. FORMATO DE EVALUACIÓN DE CONTENIDO DE LA EAFAA}

\begin{tabular}{|c|c|c|c|c|c|}
\hline \multirow{2}{*}{$\begin{array}{l}\mathrm{F} \\
\mathrm{N}\end{array}$} & \multicolumn{5}{|c|}{$\begin{array}{c}\text { Factor 1: El trabajo y las relaciones interpersonales con pacientes con } \\
\text { trastornos relacionados al uso de bebidas alcohólicas. }\end{array}$} \\
\hline & Ítem & $\mathbf{R}$ & C & $\mathbf{F}$ & Observaciones \\
\hline 01 & Tengo miedo de abordar el problema del alcohol con mis pacientes. & & & & \\
\hline 05 & $\begin{array}{l}\text { Tengo miedo de la agresividad del paciente con trastornos relacionados al } \\
\text { consumo de alcohol. }\end{array}$ & & & & \\
\hline 09 & $\begin{array}{l}\text { Me siento frustrado cuando trabajo con pacientes con trastornos relacionados } \\
\text { al uso de alcohol. }\end{array}$ & & & & \\
\hline 13 & $\begin{array}{l}\text { De todos mis pacientes, el que tiene trastornos relacionados al uso de } \\
\text { alcohol, es el que da más trabajo. }\end{array}$ & & & & \\
\hline 17 & $\begin{array}{l}\text { Debo cuidar al paciente con trastornos relacionados al uso de alcohol, así el } \\
\text { crea no necesitar cuidar de su salud. }\end{array}$ & & & & \\
\hline 21 & $\begin{array}{l}\text { Incluso, cuando el paciente con trastornos relacionados con el uso de alcohol } \\
\text { no está intoxicado, es irrespetuoso con los miembros del equipo. }\end{array}$ & & & & \\
\hline 25 & $\begin{array}{l}\text { Siento rabia al trabajar con pacientes con trastornos relacionados al uso de } \\
\text { alcohol. }\end{array}$ & & & & \\
\hline 29 & $\begin{array}{l}\text { Los pacientes con trastornos relacionados al uso de alcohol nunca aceptan lo } \\
\text { que los profesionales de la salud dicen sobre sus problemas con la bebida. }\end{array}$ & & & & \\
\hline 37 & $\begin{array}{l}\text { Abordar el problema del alcohol con pacientes con trastornos relacionados a } \\
\text { su uso, implica dedicar menos tiempo para otros pacientes. }\end{array}$ & & & & \\
\hline 41 & $\begin{array}{l}\text { Prefiero trabajar con pacientes con trastornos relacionados al uso de alcohol a } \\
\text { trabajar con otro tipo de pacientes }\end{array}$ & & & & \\
\hline 42 & $\begin{array}{l}\text { La persona con trastornos relacionados al uso de alcohol es una persona que } \\
\text { le cuesta relacionarse con los otros. }\end{array}$ & & & & \\
\hline 44 & $\begin{array}{l}\text { Considero que es difícil establecer una relación terapéutica con pacientes con } \\
\text { trastornos relacionados al uso de alcohol. }\end{array}$ & & & & \\
\hline 46 & $\begin{array}{l}\text { Es preciso tener cuidado para no ser agredido al trabajar con pacientes con } \\
\text { trastornos relacionados al consumo de alcohol. }\end{array}$ & & & & \\
\hline 48 & $\begin{array}{l}\text { Cuando el paciente con trastornos relacionados al uso de alcohol no acepta } \\
\text { que tiene problemas relacionados al consumo, la mejor decisión es desistir de } \\
\text { ayudar. }\end{array}$ & & & & \\
\hline 49 & $\begin{array}{l}\text { Cuando trabajo con pacientes con trastornos relacionados al uso de alcohol, } \\
\text { no sé cómo manejar la situación. }\end{array}$ & & & & \\
\hline 50 & $\begin{array}{l}\text { Cuidar pacientes con trastornos relacionados al uso de alcohol no es } \\
\text { gratificante para mí. }\end{array}$ & & & & \\
\hline $\mathrm{F}$ & $\begin{array}{l}\text { Factor 2: La persona con trastornos relacionados al u } \\
\text { alcohólicas }\end{array}$ & & & & \\
\hline $\mathrm{N}$ & Ítem & $\mathbf{R}$ & $\mathrm{C}$ & $\mathbf{F}$ & Observaciones \\
\hline 02 & $\begin{array}{l}\text { Las personas con trastornos relacionados al uso de alcohol no tienen sentido } \\
\text { común. }\end{array}$ & & & & \\
\hline 06 & $\begin{array}{l}\text { Las personas con trastornos relacionados al uso de alcohol son mal } \\
\text { educadas. }\end{array}$ & & & & \\
\hline 10 & $\begin{array}{l}\begin{array}{l}\text { Las personas con trastornos relacionados al uso de alcohol son } \\
\text { irresponsables. }\end{array} \\
\end{array}$ & & & & \\
\hline 14 & $\begin{array}{l}\text { Pacientes con trastornos relacionados al uso de alcohol tienen mayores } \\
\text { probabilidades de reaccionar en forma violenta contra mí. }\end{array}$ & & & & \\
\hline 18 & $\begin{array}{l}\text { Creo que las personas con problemas de alcoholismo son débiles de } \\
\text { carácter. }\end{array}$ & & & & \\
\hline 22 & $\begin{array}{l}\text { Percibo que los pacientes con trastornos relacionados al uso de alcohol no se } \\
\text { quieren cuidar. }\end{array}$ & & & & \\
\hline 26 & $\begin{array}{l}\text { No confío en las informaciones que cuentan los pacientes con trastornos } \\
\text { relacionados al consumo de alcohol. }\end{array}$ & & & & \\
\hline 30 & $\begin{array}{l}\text { Creo que la persona con trastornos relacionados al uso de alcohol es } \\
\text { culpable de sus problemas de salud. }\end{array}$ & & & & \\
\hline
\end{tabular}




\begin{tabular}{|c|c|c|c|c|c|}
\hline 33 & $\begin{array}{l}\text { Considero al paciente con trastornos relacionados al uso de alcohol como un } \\
\text { caso perdido. }\end{array}$ & & & & \\
\hline 34 & $\begin{array}{l}\text { La persona con trastornos relacionados al uso de alcohol acaba siempre } \\
\text { volviendo al servicio de salud por el mismo problema. }\end{array}$ & & & & \\
\hline 38 & $\begin{array}{l}\text { De todos mis pacientes, el que posee trastornos relacionados al uso de } \\
\text { alcohol es el más difícil de cuidar. }\end{array}$ & & & & \\
\hline 45 & $\begin{array}{l}\text { Los pacientes con trastornos relacionados al uso de alcohol son personas } \\
\text { que cooperan en su tratamiento. }\end{array}$ & & & & \\
\hline 47 & $\begin{array}{l}\text { Las personas con trastornos relacionados al consumo de alcohol no toman en } \\
\text { serio su tratamiento. }\end{array}$ & & & & \\
\hline $\mathbf{F}$ & Factor 3: Alcoholism (Etiologia) & & & & \\
\hline 03 & Creo que la disfunción familiar puede llevar al alcoholismo. & & & & \\
\hline 07 & $\begin{array}{l}\text { Las personas tímidas } 0 \text { inhibidas tienen mayor tendencia a desarrollar } \\
\text { alcoholismo. }\end{array}$ & & & & \\
\hline 11 & Creo que la depresión puede provocar alcoholismo. & & & & \\
\hline 15 & $\begin{array}{l}\text { Lo que falta en una persona con trastornos relacionados al uso de alcohol es } \\
\text { fuerza de voluntad. }\end{array}$ & & & & \\
\hline 19 & Las problemáticas sociales llevan a un individuo a beber. & & & & \\
\hline $\mathbf{N}$ & ítem & $\mathbf{R}$ & C & $\mathbf{F}$ & Observaciones \\
\hline 23 & Factores hereditarios conducen al alcoholismo. & & & & \\
\hline 27 & Las personas insatisfechas abusan del alcohol. & & & & \\
\hline 31 & Las personas que desarrollan alcoholismo tienen baja autoestima. & & & & \\
\hline 35 & $\begin{array}{l}\text { Las personas con trastornos relacionados al uso de alcohol son } \\
\text { psicológicamente inestables }\end{array}$ & & & & \\
\hline 39 & Las personas beben para sentirse más sociables. & & & & \\
\hline 43 & $\begin{array}{l}\text { La persona con trastornos relacionados al uso de alcohol bebe porque no es } \\
\text { capaz de enfrentar su propia realidad. }\end{array}$ & & & & \\
\hline $\mathbf{F}$ & Factor 4: Las bebidas alcohólicas y su uso & & & & \\
\hline 04 & Creo que las personas tienen derecho a beber si así lo desean. & & & & \\
\hline 08 & $\begin{array}{l}\text { La bebida alcohólica es agradable y proporciona bienestar a quien la } \\
\text { consume. }\end{array}$ & & & & \\
\hline 12 & El uso de bebida alcohólica es algo normal & & & & \\
\hline 16 & Beber alcohol en cualquier cantidad causará siempre dependencia. & & & & \\
\hline 20 & Beber con moderación no es perjudicial. & & & & \\
\hline 24 & Estoy en contra del uso del alcohol en cualquier circunstancia & & & & \\
\hline 28 & Estoy a favor de beber con moderación. & & & & \\
\hline 32 & Dosis pequeñas de alcohol pueden causar dependencia. & & & & \\
\hline 36 & El alcohol en cantidades reducidas es benéfico & & & & \\
\hline$\overline{40}$ & Las personas pueden beber desde que sepan controlarse. & & & & \\
\hline
\end{tabular}

d. Visión General del Instrumento: Evalúe la necesidad de eliminar o adicionar ítems a cada factor, indicándolos a continuación.

Muchas Gracias por su colaboración, le solicitamos cordialmente que el material sea devuelto dentro de un plazo de 20 días, en caso de duda por favor comunicarse con los responsables del presente estudio.

\section{Divane de Vargas - vargas@usp.br}




\section{Apêndice D. CUESTIONARIO DE DATOS SOCIODEMOGRÁFICOS EAFAA} (VARGAS 2005)

Datos personales:

Sexo: M F

1. Edad:

2. Estado civil:

Casado Soltero Viudo Separado Unión libre

3. Profesión:

4. ¿Usted tiene experiencia profesional con personas con trastornos relacionados al uso de bebidas alcohólicas? SI NO

5. ¿Si la respuesta anterior fue SI, con qué frecuencia usted se ha enfrentado a personas con trastornos relacionados al uso de bebidas alcohólicas y otras drogas en su trabajo?

Diariamente Semanalmente Mensualmente Nunca

6. Año de graduación como Enfermero(a):

7. ¿Realizo algún curso de pos graduación? SI NO

Especialización Maestría Doctorado

En qué área:

8. Usted estudió en: Universidad Privada Universidad Pública

9. ¿Durante su pregrado usted recibió preparación para trabajar con personas con trastornos relacionados al uso de alcohol y otras drogas?

SI NO

10. Si su respuesta fue SI, ¿cuál fue la carga horaria dedicada a esta preparación?: 5 horas 10 horas 15 horas 20 horas 30 horas Otras

11. ¿Usted ha tenido experiencia práctica con personas con trastornos relacionados al uso de alcohol y otras drogas?:

Antes del pregrado Durante el pregrado Después del pregrado

12. Cuándo y cómo fue esta experiencia práctica

13. Responda afirmativa o negativamente a las siguientes preguntas:

a. ¿El alcoholismo es una Enfermedad? SI NO

b. ¿La persona con trastornos relacionados al uso de bebidas alcohólicas es grosera, agresiva y mal educada? SI NO 


\section{Apêndice E. EAFAA VERSÃO ADAPTADA EM ESPANHOL}

En el siguiente instrumento Indique en qué medida se encuentra de acuerdo o en desacuerdo con cada una de las afirmaciones marcando un número en la línea derecha de cada afirmación.

1-Totalmente de desacuerdo

2- Parcialmente en desacuerdo

3- Tengo duda 4- Parcialmente de acuerdo

5- Totalmente de acuerdo

\begin{tabular}{|c|c|c|c|c|c|c|}
\hline $\mathrm{N}$ & tem & & & & & \\
\hline 01 & Tengo miedo de abord ar los proble mas relacionad os al uso abusino de bebidas alcohólicas con los pacientes. & 1 & 2 & 3 & 4 & 5 \\
\hline 05 & Me sento inseguro ante la agresividad de una persona con trastomos relacionados al uso de bebidas alcohólicas. & 1 & 2 & 3 & 4 & 5 \\
\hline 09 & Me sento frustrado (a) cuando trabajo con personas con trastomos relacion ados al uso de bebidas alcohólicas. & 1 & 2 & 3 & 4 & 5 \\
\hline 13 & De todas las personas, las que tienen trastomos relacionados al uso de bebidas alcohólicas, son las que dan más trabajo. & 1 & 2 & 3 & 4 & 5 \\
\hline 17 & $\begin{array}{l}\text { Debo ofrecer ayuda yorientaciones a la persona con trasto mos relacionados al uso de bebid as alcohólicas, aun que qea que no necesita cuidar } \\
\text { de su salud. }\end{array}$ & 1 & 2 & 3 & 4 & 5 \\
\hline 14 & Personas con trastomos rel acionados al uso de alcohol fenen mayores prob abiidades de reaccionar en forma violenta contra mi. & 1 & 2 & 3 & 4 & 5 \\
\hline 21 & $\begin{array}{l}\text { Induso, cuando la per son a com transto mos relacionados al uso de be bidas alcohólicas no está intoxicada, es irrespetuosa con los miembros del } \\
\text { equipo de salud. }\end{array}$ & 1 & 2 & 3 & 4 & 5 \\
\hline 25 & Siento rabia al trabajar con personas que fenen trastomos relacion ados al uso de bebidas alcohólicas & 1 & 2 & 3 & 4 & 5 \\
\hline 29 & $\begin{array}{l}\text { Las personas com tran stomos relacionados al uso de bebidas alcohólicas nunca aceptan lo que los profesionales de salud dicen sobre sus } \\
\text { problemas con la bebida. }\end{array}$ & 1 & 2 & 3 & 4 & 5 \\
\hline 37 & Abordar el problema del alcohol con personas con trastomos relacionad os a su uso, implica dedicar menos tiempo para otros pacientes. & 1 & 2 & 3 & 4 & 5 \\
\hline 38 & De todos las personas, las que tienen trastomos relacionados al uso de bebid as alcohólicas son las más dificles de cuidar. & 1 & 2 & 3 & 4 & 5 \\
\hline 41 & Prefero trabajar con pacientes con trastomos relacionados al uso de bebidas alcohólicas que trabajar con otros pacientes. & 1 & 2 & 3 & 4 & 5 \\
\hline 44 & Es difici para mi establecer una relación terapéufca con person as que fenen trastomos relacionados al uso de bebidas alcohólicas. & 1 & 2 & 3 & 4 & 5 \\
\hline 46 & Debo tener precaución para no ser agredido (a) al trabajar con personas que tienen trastom os relacion ados al uso de bebidas alcohólicas. & 1 & 2 & 3 & 4 & 5 \\
\hline 48 & $\begin{array}{l}\text { Cuando el paciente con trastom os relacionados al uso de bebidas al condicas no acepta que tiene problemas relacionados al consu mo, la mejor } \\
\text { decisión es desistr de ayudar. }\end{array}$ & 1 & 2 & 3 & 4 & 5 \\
\hline 49 & Cuando trabajo con pacientes con trastomos relacionados al uso de bebidas alcohólicas, no sé ćmo manejar la sìuación. & 1 & 2 & 3 & 4 & 5 \\
\hline 50 & Cuidar pacientes con trastomos relacionados al uso de be bidas al coh d́licas no es gr afficante para mi. & 1 & 2 & 3 & 4 & 5 \\
\hline 02 & Las personas con trastomos relacionados al uso de bebidas alcohólicas no tienen crtica de la realidad. & 1 & 2 & 3 & 4 & 5 \\
\hline 06 & Las personas con trastomos relacionad os al uso de bebidas alcohólicas son mal educadas. & 1 & 2 & 3 & 4 & 5 \\
\hline 10 & Las personas con trastomos relacionados al uso de alcohol son irresponsables. & 1 & 2 & 3 & 4 & 5 \\
\hline 15 & Lo que fatta en una person a con trastomos relacionados al uso de bebidas alcohólicas es fuerza de voluntad & 1 & 2 & 3 & 4 & 5 \\
\hline 18 & Las personas con problemas de alcoholismo son débiles de carácter. & 1 & 2 & 3 & 4 & 5 \\
\hline 22 & Las personas con trastomos relacionados al uso de alochol no se quieren cuidar. & 1 & 2 & 3 & 4 & 5 \\
\hline
\end{tabular}


LOS relatos de las personas con trastomos relacionados al uso de be bidas al condilicas no son confiables

La persona con trastomos relacionados al uso de bebidas al cohólicas es culpable de sus problemas de salud.

La persona con trastomos relacionados al uso de bebidas alcohólicas es un caso perdido.

La persona con trastomos relacionados al uso de bebidas al coh dicas acaba sempre volvendo al servicio de salud por el mismo problema.

El paciente con trastom os relacion ados al uso de bebidas alcohólicas es una persona que le cuesta rel acionarse con los otros.

Las personas con trastomos relacionados al uso de bebidas alcohólicas cooperan en su tratamiento

Las personas con trastomos relacionados al uso de bebidas alcohólicas no toman en serio su tratamiento.

La distuncoin familiar puede llever al alcoholismo.

Las personas timid as o inhibid as fenen mayor tendencia a desarrol ar alcoholismo.

La depresión puede provocar alcoholismo.

Las problemáticas sociales leven a una persona a beber

Factores hereditarios conducen al alcoho ismo

Las personas in satisfechas abusan de las bebidas alcohólicas.

Las personas que desarrolan alcoholismo tenen baja autoestma.

Las personas con trastomos relacionados al uso de alcohol son psicologicamente inestables

Las personas beben para sentirse más sociables.

La persona con trastomos relacionados al uso de alcohol bebe porque no es capaz de enfrentar su propia realidad

$\begin{array}{lllll}1 & 2 & 3 & 4 & 5\end{array}$

\begin{tabular}{l|l|l|l|l|}
1 & 2 & 3 & 4 & 5
\end{tabular}

$\begin{array}{llllll}1 & 2 & 3 & 4 & 5\end{array}$

$\begin{array}{llllll}1 & 2 & 3 & 4 & 5\end{array}$

$\begin{array}{lllll}1 & 2 & 3 & 4 & 5\end{array}$

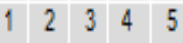

$\begin{array}{lllll}1 & 2 & 3 & 4 & 5\end{array}$

$\begin{array}{llllll}1 & 2 & 3 & 4 & 5\end{array}$

$\begin{array}{lllll}1 & 2 & 3 & 4 & 5\end{array}$

$\begin{array}{llllll}1 & 2 & 3 & 4 & 5\end{array}$

$\begin{array}{llllll}1 & 2 & 3 & 4 & 5\end{array}$

$1 \quad 2 \quad 3 \quad 4 \quad 5$

$\begin{array}{llllll}1 & 2 & 3 & 4 & 5\end{array}$

$\begin{array}{llllll}1 & 2 & 3 & 4 & 5\end{array}$

$\begin{array}{llllll}1 & 2 & 3 & 4 & 5\end{array}$

$\begin{array}{llllll}1 & 2 & 3 & 4 & 5\end{array}$

$\begin{array}{llllll}1 & 2 & 3 & 4 & 5\end{array}$

Las personas tienen derecho a beber sasi lo desean.

La bebida alcohólica es agradable y proporciona bienestar a quien la usa.

$\begin{array}{llllll}1 & 2 & 3 & 4 & 5\end{array}$

El uso de bebida alcohólica es algo normal

Beber al cohol en cualquier cantidad causará siempre dependencia.

$\begin{array}{llllll}1 & 2 & 3 & 4 & 5\end{array}$

\begin{tabular}{l|l|l|l|l|}
1 & 2 & 3 & 4 & 5
\end{tabular}

El uso de bebidas alcohólicas es perjudicial en cualquier circunstanca

$\begin{array}{llllll}1 & 2 & 3 & 4 & 5\end{array}$

Estoy a favor de beber con moderación. (Hombres menos de 5 dosis en una ocasión. Mujeres menos de 4 dosis en una ocasión).

Dosis $=1$ Lata de cerveza $350 \mathrm{ml} \quad 1$ copa de vno $140 \mathrm{ml} 1$ trago sencillo de destilado $40 \mathrm{ml} \quad 1$ trago de aperitvo $40 \mathrm{ml}$

Dosis pequeñas de alcohol pueden causar dependencia.

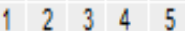

Las bebidas alcohólicas en canidades reduadas son benéficas.

Las personas pueden beber con tal que mantengan el control sobre su uso. 


\section{Apêndice F. TERMO DE CONSENTIMENTO LIVRE E ESCALRECIDO PARA OS PARTICIPANTES DA PESQUISA}

I- Datos de identificación:

Nombre del entrevistado:

II - Datos sobre la investigación:

Título: “TRADUCCIÓN, ADAPTACIÓN CULTURAL Y VALIDACIÓN DE LA ESCALA DE ACTITUDES FRENTE AL ALCOHOLISMO, A LAS BEBIDAS ALCOHÓLICAS Y A LA PERSONA CON TRASTORNOS RELACIONADOS A SU USO- EAFAA VERSIÓN ESPANHOL.".

Investigadores: Erika Gisseth León Ramírez - Egresada Facultad de Enfermería Universidad Nacional de Colombia en el programa de Pos-Graduación de la Escola de Enfermagem de la Universidad de São Paulo - SP Teléfono: +55 (11) 8080-4722 / 3123831716 email: egleonr@usp.br

Coordinador del Proyecto - Profesor. Doctor. Divane de Vargas - Profesor Asociado del Departamento de Enfermagem Materno-Infantil e Psiquiátrica de la Escola de Enfermagem de la Universidad de São Paulo vargas@usp.br

III - Registro de la explicación a los participantes acerca de la Investigación:

La presente investigación tiene como objetivo validar la Escala de Actitudes frente al alcoholismo, a las bebidas alcohólicas y las personas con trastornos relacionados a su uso, y a su vez tornarla asequible para su uso entre enfermeros(as) hispano hablantes con el fin de identificar las actitudes del enfermero(a) delante de algunas afirmaciones asociadas al alcohol definidas en 50 ítems agrupados en cuatro factores: El trabajo y las relaciones interpersonales con personas con trastornos relacionados al uso de bebidas alcohólicas, Etiología del alcoholismo, Las bebidas alcohólicas y su uso, La persona con trastornos relacionados al uso de bebidas alcohólicas. El instrumento está diseñado para ser diligenciado por los Enfermeros (as) con auxilio del entrevistador en un tiempo aproximado de 10 minutos.

La aplicabilidad de este instrumento puede influenciar en la mejora de la calidad en la atención a las personas con este tipo de trastorno, dado que existen evidencias de que las actitudes son precursoras de la cantidad y calidad del cuidado prestado. Adicionalmente este trabajo también puede beneficiar la investigación de Enfermería en el área de adicciones en alcohol y 
otras drogas, todavía incipiente en la mayoría de países de América Latina, especialmente en aquellos de habla hispana.

Usted es libre de expresar sus ideas y podrá realizar preguntas acerca del estudio y su participación. Si tiene alguna duda haremos lo posible por aclararla en cualquier momento de la investigación.

IV - Aclaraciones dadas por los responsables del estudio sobre las garantías de los (as) participantes del estudio:

1. Acceso en cualquier momento a la información sobre riesgos y beneficios relacionados a la investigación.

2. Libertad de retirar su consentimiento en cualquier momento y abandonar la participación en la investigación sin que esto le traiga algún perjuicio.

3. Salvaguardar la confidencialidad, sigilo e privacidad.

4. No sufrirá ningún perjuicio caso se niegue a participar del estudio.

Nota: Deberán ser firmadas dos copias de este documento, una quedará con el participante y otra con los investigadores.

\section{V - Consentimiento Informado:}

"Declaro que, después de las aclaraciones realizadas por el investigador y haber entendido lo que me fue explicado, estoy de acuerdo en participar del presente estudio".

Bogotá, de de 201 
Apêndice G. ALTERAÇÕES E RESOLUÇÃO DE CONFLITOS PARA OBTER VERSÃO S1.

\begin{tabular}{|c|c|c|c|c|}
\hline $\mathbf{N}$ & Item Versão Original & T1 & T2 & S1 \\
\hline 01 & $\begin{array}{l}\text { Eu tenho medo de abordar o problema do } \\
\text { álcool com meus pacientes. }\end{array}$ & $\begin{array}{l}\text { Tengo miedo de abordar el problema del } \\
\text { alcohol con mis pacientes. }\end{array}$ & $\begin{array}{l}\text { Tengo miedo de abordar el problema del } \\
\text { alcohol con mis pacientes }\end{array}$ & $\begin{array}{l}\text { Tengo miedo de abordar el problema del } \\
\text { alcohol con mis pacientes. }\end{array}$ \\
\hline 05 & $\begin{array}{l}\text { Eu tenho medo da agressividade de pacientes } \\
\text { com transtornos relacionados ao uso do álcool. }\end{array}$ & $\begin{array}{l}\text { Tengo miedo de la agresividad de mis } \\
\text { pacientes con trastornos relacionados al } \\
\text { consumo del alcohol. }\end{array}$ & $\begin{array}{l}\text { Tengo miedo de la agresividad del paciente } \\
\text { con trastornos relacionados al consumo de } \\
\text { alcohol }\end{array}$ & $\begin{array}{l}\text { Tengo miedo de la agresividad del paciente } \\
\text { con trastornos relacionados al consumo de } \\
\text { alcohol. }\end{array}$ \\
\hline 09 & $\begin{array}{l}\text { Sinto-me frustrado quando trabalho com } \\
\text { pacientes com transtornos relacionados ao uso } \\
\text { do álcool. }\end{array}$ & $\begin{array}{l}\text { Me siento frustrado cuando trabajo con } \\
\text { pacientes con trastornos relacionados al } \\
\text { consumo del alcohol. }\end{array}$ & $\begin{array}{l}\text { Me siento frustrado cuando trabajo con } \\
\text { pacientes con trastornos relacionados al } \\
\text { consumo de alcohol }\end{array}$ & $\begin{array}{l}\text { Me siento frustrado cuando trabajo con } \\
\text { pacientes con trastornos relacionados al } \\
\text { consumo de alcohol. }\end{array}$ \\
\hline 13 & $\begin{array}{l}\text { De todos os meus pacientes, o paciente com } \\
\text { transtornos relacionados ao uso do álcool é } \\
\text { aquele que do mais trabalho. }\end{array}$ & $\begin{array}{l}\text { De todos mis pacientes, el paciente con } \\
\text { trastornos relacionados al consumo de } \\
\text { alcohol es aquel que me cuesta más } \\
\text { trabajo. }\end{array}$ & $\begin{array}{l}\text { De todos mis pacientes, el con trastornos } \\
\text { relacionados al consumo de alcohol es el que } \\
\text { da más trabajo }\end{array}$ & $\begin{array}{l}\text { De todos mis pacientes, el que tiene } \\
\text { trastornos relacionados al consumo de } \\
\text { alcohol, es el que da más trabajo. }\end{array}$ \\
\hline 17 & $\begin{array}{l}\text { Devo cuidar do paciente com transtornos } \\
\text { relacionados ao uso do álcool, mesmo que ele } \\
\text { acredite não precisar de cuidado de saúde. }\end{array}$ & $\begin{array}{l}\text { Debo cuidar al paciente con trastornos } \\
\text { relacionados al consumo de alcohol, así el } \\
\text { crea no necesitar cuidar su salud. }\end{array}$ & $\begin{array}{l}\text { Debo cuidar al paciente con trastornos } \\
\text { relacionados al consumo de alcohol, de la } \\
\text { misma manera de aquel que crea no } \\
\text { necesitar del cuidado de su salud (o como } \\
\text { cualquier otro paciente, o como un paciente } \\
\text { más) (?) }\end{array}$ & $\begin{array}{l}\text { Debo cuidar al paciente con trastornos } \\
\text { relacionados al consumo de alcohol, así el } \\
\text { crea no necesitar cuidar de su salud. }\end{array}$ \\
\hline 21 & $\begin{array}{l}\text { Mesmo quando não intoxicado o paciente com } \\
\text { transtornos relacionados ao uso do álcool, é } \\
\text { desrespeitoso com os membros da equipe. }\end{array}$ & $\begin{array}{l}\text { Incluso, cuando el paciente con trastornos } \\
\text { relacionados con el consumo de alcohol no } \\
\text { esté intoxicado, es irrespetuoso con los } \\
\text { miembros del equipo. }\end{array}$ & No la entendo & $\begin{array}{l}\text { Incluso, cuando el paciente con trastornos } \\
\text { relacionados con el consumo de alcohol no } \\
\text { está intoxicado, es irrespetuoso con los } \\
\text { miembros del equipo. }\end{array}$ \\
\hline 25 & $\begin{array}{l}\text { Sinto raiva ao trabalhar com pacientes com } \\
\text { transtornos relacionados ao uso do álcool. }\end{array}$ & $\begin{array}{l}\text { Siento rabia al trabajar con pacientes con } \\
\text { trastornos relacionados al consumo de } \\
\text { alcohol. }\end{array}$ & $\begin{array}{l}\text { Siento rabia (o no me gusta trabajar) (?) al } \\
\text { trabajar con pacientes con trastornos } \\
\text { relacionados al consumo de alcohol }\end{array}$ & $\begin{array}{l}\text { Siento rabia al trabajar con pacientes con } \\
\text { trastornos relacionados al consumo de } \\
\text { alcohol. }\end{array}$ \\
\hline 29 & $\begin{array}{l}\text { Pacientes com transtornos relacionados ao uso } \\
\text { do álcool nunca aceitam o que os profissionais } \\
\text { de saúde falam sobre seus problemas com a } \\
\text { bebida. }\end{array}$ & $\begin{array}{l}\text { Los pacientes con trastornos relacionados } \\
\text { al consumo de alcohol nunca aceptan lo } \\
\text { que los profesionales de la salud hablan } \\
\text { sobre sus problemas con la bebida. }\end{array}$ & $\begin{array}{l}\text { Los pacientes con trastornos relacionados al } \\
\text { consumo de alcohol nunca aceptan que los } \\
\text { profesionales de la salud hablen sobre sus } \\
\text { problemas con la bebida }\end{array}$ & $\begin{array}{l}\text { Los pacientes con trastornos relacionados al } \\
\text { consumo de alcohol nunca aceptan lo que } \\
\text { los profesionales de la salud dicen sobre sus } \\
\text { problemas con la bebida. }\end{array}$ \\
\hline
\end{tabular}




\begin{tabular}{|c|c|c|c|c|}
\hline $\mathbf{N}$ & Ítem Versão Original & T1 & T2 & S1 \\
\hline 37 & $\begin{array}{l}\text { Abordar o problema do álcool com pacientes } \\
\text { com transtornos relacionados ao uso do álcool } \\
\text { significa menos tempo para os demais } \\
\text { pacientes. }\end{array}$ & $\begin{array}{l}\text { Abordar el problema del alcohol con } \\
\text { pacientes con trastornos relacionados al } \\
\text { consumo de alcohol significa menos tiempo } \\
\text { para los demás pacientes }\end{array}$ & $\begin{array}{l}\text { Abordar el problema del alcohol con pacientes } \\
\text { con trastornos relacionados a su consumo, } \\
\text { implica dedicar menos tiempo para otros } \\
\text { pacientes }\end{array}$ & $\begin{array}{l}\text { Abordar el problema del alcohol con } \\
\text { pacientes con trastornos relacionados a su } \\
\text { consumo, implica dedicar menos tiempo } \\
\text { para otros pacientes. }\end{array}$ \\
\hline 41 & $\begin{array}{l}\text { Eu prefiro trabalhar com pacientes com } \\
\text { transtornos relacionados ao uso do álcool a } \\
\text { trabalhar com outros pacientes. }\end{array}$ & $\begin{array}{l}\text { Prefiero trabajar con pacientes con } \\
\text { trastornos relacionados al consumo de } \\
\text { alcohol a trabajar con otros pacientes. }\end{array}$ & $\begin{array}{l}\text { Prefiero trabajar con pacientes con trastornos } \\
\text { relacionados al consumo de alcohol a trabajar } \\
\text { con otro tipo de pacientes }\end{array}$ & $\begin{array}{l}\text { Prefiero trabajar con pacientes con } \\
\text { trastornos relacionados al consumo de } \\
\text { alcohol a trabajar con otro tipo de pacientes }\end{array}$ \\
\hline 44 & $\begin{array}{l}\text { Eu considero difícil estabelecer um } \\
\text { relacionamento terapêutico com pacientes com } \\
\text { transtornos relacionados ao uso do álcool. }\end{array}$ & $\begin{array}{l}\text { Considero que es difícil establecer una } \\
\text { relación terapéutica con pacientes con } \\
\text { trastornos relacionados al consumo de } \\
\text { alcohol. }\end{array}$ & $\begin{array}{l}\text { Considero dificil establecer un relacionamiento } \\
\text { terapéutico (o una terapia) con pacientes con } \\
\text { trastornos relacionados al consumo de alcohol. }\end{array}$ & $\begin{array}{l}\text { Considero que es difícil establecer una } \\
\text { relación terapéutica con pacientes con } \\
\text { trastornos relacionados al consumo de } \\
\text { alcohol. }\end{array}$ \\
\hline 46 & $\begin{array}{l}\text { É preciso tomar cuidado para não ser agredido } \\
\text { ao trabalhar com pacientes com transtornos } \\
\text { relacionados ao uso do álcool. }\end{array}$ & $\begin{array}{l}\text { Es preciso tener cuidado para no ser } \\
\text { agredido al trabajar con pacientes con } \\
\text { trastornos relacionados al consumo de } \\
\text { alcohol }\end{array}$ & $\begin{array}{l}\text { Es preciso tomar cuidado para no ser agredido } \\
\text { al trabajar con pacientes con trastornos } \\
\text { relacionados al consumo de alcohol }\end{array}$ & $\begin{array}{l}\text { Es preciso tener cuidado para no ser } \\
\text { agredido al trabajar con pacientes con } \\
\text { trastornos relacionados al consumo de } \\
\text { alcohol. }\end{array}$ \\
\hline 48 & & $\begin{array}{l}\text { Cuando el paciente con trastornos } \\
\text { relacionados al consumo de alcohol no } \\
\text { acepta que tiene problemas relacionados al } \\
\text { consumo, la mejor decisión es desistir de } \\
\text { ayudar. }\end{array}$ & $\begin{array}{l}\text { Cuando el paciente con trastornos } \\
\text { relacionados al consumo de alcohol no acepta } \\
\text { que tiene problemas relacionados al consumo, } \\
\text { la mejor decisión es desistir de ayudar }\end{array}$ & $\begin{array}{l}\text { Cuando el paciente con trastornos } \\
\text { relacionados al consumo de alcohol no } \\
\text { acepta que tiene problemas relacionados al } \\
\text { consumo, la mejor decisión es desistir de } \\
\text { ayudar. }\end{array}$ \\
\hline 49 & $\begin{array}{l}\text { Quando trabalho com pacientes com } \\
\text { transtornos relacionados ao uso do álcool, não } \\
\text { sei como conduzir a situação. }\end{array}$ & $\begin{array}{l}\text { Cuando trabajo con pacientes con } \\
\text { trastornos relacionados al consumo de } \\
\text { alcohol, no sé cómo manejar la situación. }\end{array}$ & $\begin{array}{l}\text { Cuando trabajo con pacientes con trastornos } \\
\text { relacionados al consumo de alcohol, no sé } \\
\text { cómo conducir mi situación (o actuar, o } \\
\text { comportarme profesionalmente...) (?) Se } \\
\text { refiera a que al profesional le afecta, le molesta } \\
\text { el borracho, o que no tiene claro qué actitud } \\
\underline{\text { tomar, si a favor o en contra...? (no me queda }} \\
\text { claro el planteamiento). }\end{array}$ & $\begin{array}{l}\text { Cuando trabajo con pacientes con } \\
\text { trastornos relacionados al consumo de } \\
\text { alcohol, no sé cómo manejar la situación. }\end{array}$ \\
\hline
\end{tabular}




\begin{tabular}{|c|c|c|c|c|}
\hline $\mathbf{N}$ & Ítem Versão Original & T1 & T2 & S1 \\
\hline 50 & $\begin{array}{l}\text { Cuidar de pacientes com transtornos relacionados } \\
\text { ao uso do álcool não é gratificante para mim }\end{array}$ & $\begin{array}{l}\text { Cuidar pacientes con trastornos } \\
\text { relacionados al consumo de alcohol no } \\
\text { es gratificante para mí. }\end{array}$ & $\begin{array}{l}\text { Cuidar de pacientes con trastornos } \\
\text { relacionados al consumo de alcohol no es } \\
\text { gratificante para mí (o grato) (?) } \underline{0 \text { sea, no le }} \\
\text { gusta porque no ve resultados de sanación (?) }\end{array}$ & $\begin{array}{l}\text { Cuidar pacientes con trastornos } \\
\text { relacionados al consumo de alcohol no es } \\
\text { gratificante para mí. }\end{array}$ \\
\hline 02 & $\begin{array}{l}\text { Pessoas com transtornos relacionados ao uso do } \\
\text { álcool não têm bom senso. }\end{array}$ & $\begin{array}{l}\text { Las personas con trastornos } \\
\text { relacionados al consumo de alcohol no } \\
\text { tienen sentido común. }\end{array}$ & $\begin{array}{l}\text { Las personas con trastornos relacionados al } \\
\text { consumo de alcohol no razonan bien. }\end{array}$ & $\begin{array}{l}\text { Las personas con trastornos relacionados } \\
\text { al consumo de alcohol no tienen sentido } \\
\text { común. }\end{array}$ \\
\hline 06 & $\begin{array}{l}\text { Pessoas com transtornos relacionados ao uso do } \\
\text { álcool são mal-educadas. }\end{array}$ & $\begin{array}{l}\text { Las personas con trastornos } \\
\text { relacionados al consumo de alcohol } \\
\text { son maleducadas. }\end{array}$ & $\begin{array}{l}\text { Las personas con trastornos relacionados al } \\
\text { consumo de alcohol son mal educadas }\end{array}$ & $\begin{array}{l}\text { Las personas con trastornos relacionados } \\
\text { al consumo de alcohol son mal educadas. }\end{array}$ \\
\hline 10 & $\begin{array}{l}\text { Pessoas com transtornos relacionados ao uso do } \\
\text { álcool são irresponsáveis. }\end{array}$ & $\begin{array}{l}\text { Las personas con trastornos } \\
\text { relacionados al consumo de alcohol } \\
\text { son irresponsables. }\end{array}$ & $\begin{array}{l}\text { Las personas con trastornos relacionados al } \\
\text { consumo de alcohol son irresponsables }\end{array}$ & $\begin{array}{l}\text { Las personas con trastornos relacionados } \\
\text { al consumo de alcohol son irresponsables. }\end{array}$ \\
\hline 14 & $\begin{array}{l}\text { Pacientes com transtornos relacionados ao uso do } \\
\text { álcool tem maior probabilidade de se tornarem } \\
\text { violentos contra mim. }\end{array}$ & $\begin{array}{l}\text { Los pacientes con trastornos } \\
\text { relacionados al consumo de alcohol } \\
\text { tienen mayor probabilidad de volverse } \\
\text { violentos en contra mía. }\end{array}$ & $\begin{array}{l}\text { Pacientes con trastornos relacionados al } \\
\text { consumo de alcohol tienen mayores } \\
\text { probabilidades de reaccionar en forma violenta } \\
\text { contra mí }\end{array}$ & $\begin{array}{l}\text { Pacientes con trastornos relacionados al } \\
\text { consumo de alcohol tienen mayores } \\
\text { probabilidades de reaccionar en forma } \\
\text { violenta contra mí. }\end{array}$ \\
\hline 18 & $\begin{array}{l}\text { Penso que pessoas que desenvolvem o alcoolismo } \\
\text { são fracas. }\end{array}$ & $\begin{array}{l}\text { Pienso que las personas que } \\
\text { desarrollan alcoholismo son débiles. }\end{array}$ & $\begin{array}{l}\text { Creo que las personas con problemas de } \\
\text { alcoholismo son débiles }\end{array}$ & $\begin{array}{l}\text { Creo que las personas con problemas de } \\
\text { alcoholismo son débiles de carácter }\end{array}$ \\
\hline 22 & $\begin{array}{l}\text { Eu percebo que pacientes com transtornos } \\
\text { relacionados ao uso do álcool não querem se } \\
\text { cuidar. }\end{array}$ & $\begin{array}{l}\text { Percibo que los pacientes con } \\
\text { trastornos relacionados al consumo de } \\
\text { alcohol no se quieren cuidar. }\end{array}$ & $\begin{array}{l}\text { Percibo que los pacientes con trastornos } \\
\text { relacionados al consumo de alcohol no se } \\
\text { quieren cuidar o no se quieren sanar) (?) }\end{array}$ & $\begin{array}{l}\text { Percibo que los pacientes con trastornos } \\
\text { relacionados al consumo de alcohol no se } \\
\text { quieren cuidar. }\end{array}$ \\
\hline 26 & $\begin{array}{l}\text { Não confio nas informações que pacientes com } \\
\text { transtornos relacionados ao uso do álcool relatam }\end{array}$ & $\begin{array}{l}\text { No confío en las informaciones que } \\
\text { cuentan los pacientes con trastornos } \\
\text { relacionados al consumo de alcohol. }\end{array}$ & $\begin{array}{l}\text { No confío en las informaciones que relatan } \\
\text { pacientes con trastornos relacionados al } \\
\text { consumo de alcohol }\end{array}$ & $\begin{array}{l}\text { No confío en las informaciones que } \\
\text { cuentan los pacientes con trastornos } \\
\text { relacionados al consumo de alcohol. }\end{array}$ \\
\hline 30 & $\begin{array}{l}\text { Penso que a pessoa com transtornos relacionados } \\
\text { ao uso do álcool é culpada por seus problemas de } \\
\text { saúde. }\end{array}$ & $\begin{array}{l}\text { Pienso que una persona con trastornos } \\
\text { relacionados al consumo de alcohol es } \\
\text { culpable por sus problemas de salud. }\end{array}$ & $\begin{array}{l}\text { Creo que la persona con trastornos } \\
\text { relacionados al consumo de alcohol es } \\
\text { culpable de sus problemas de salud. }\end{array}$ & $\begin{array}{l}\text { Creo que la persona con trastornos } \\
\text { relacionados al consumo de alcohol es d. }\end{array}$ \\
\hline
\end{tabular}




\begin{tabular}{|c|c|c|c|c|}
\hline $\mathbf{N}$ & Ítem Versão Original & T1 & T2 & S1 \\
\hline 33 & & $\begin{array}{l}\text { Considero que el paciente con trastornos } \\
\text { relacionados al consumo de alcohol es un } \\
\text { caso perdido. }\end{array}$ & $\begin{array}{l}\text { Considero al paciente con trastornos relacionados al } \\
\text { consumo de alcohol como un caso perdido }\end{array}$ & $\begin{array}{l}\text { Considero al paciente con trastornos } \\
\text { relacionados al uso de alcohol como un } \\
\text { caso perdido. }\end{array}$ \\
\hline 34 & $\begin{array}{l}\text { A pessoa com transtornos relacionados ao uso do álcool } \\
\text { acaba sempre voltando ao serviço de saúde com o } \\
\text { mesmo problema }\end{array}$ & $\begin{array}{l}\text { Una persona con trastornos relacionados al } \\
\text { consumo de alcohol acaba siempre } \\
\text { volviendo al servicio de salud con el mismo } \\
\text { problema. }\end{array}$ & $\begin{array}{l}\text { La persona con trastornos relacionados al consumo } \\
\text { de alcohol acaba siempre volviendo al servicio de } \\
\text { salud por el mismo problema }\end{array}$ & $\begin{array}{l}\text { La persona con trastornos relacionados al } \\
\text { uso de alcohol acaba siempre volviendo al } \\
\text { servicio de salud por el mismo problema. }\end{array}$ \\
\hline 38 & $\begin{array}{l}\text { De todos os meus pacientes, o paciente com transtornos } \\
\text { relacionados ao uso do álcool é o mais difícil de lidar. }\end{array}$ & $\begin{array}{l}\text { De todos mis pacientes, el paciente con } \\
\text { trastornos relacionados al consumo de } \\
\text { alcohol es el más difícil de llevar. }\end{array}$ & $\begin{array}{l}\text { De todos mis pacientes, el con trastornos } \\
\text { relacionados al consumo de alcohol es el más difícil } \\
\text { de tratar }\end{array}$ & $\begin{array}{l}\text { De todos mis pacientes, el que posee } \\
\text { trastornos relacionados al consumo de } \\
\text { alcohol es el más difícil de tratar. }\end{array}$ \\
\hline 42 & $\begin{array}{l}\text { A pessoa com transtornos relacionados ao uso do } \\
\text { álcool é uma pessoa difícil de relacionar-se. }\end{array}$ & & $\begin{array}{l}\text { La persona con trastornos relacionados al } \\
\text { consumo de alcohol es una persona que le } \\
\text { cuesta relacionarse. }\end{array}$ & $\begin{array}{l}\text { La persona con trastornos relacionados al } \\
\text { uso de alcohol es una persona que le } \\
\text { cuesta relacionarse con los otros. }\end{array}$ \\
\hline 45 & $\begin{array}{l}\text { Pacientes com transtornos relacionados ao uso do } \\
\text { álcool são pacientes que cooperam com seu } \\
\text { tratamento. }\end{array}$ & $\begin{array}{l}\text { Los pacientes con trastornos } \\
\text { relacionados al consumo de alcohol } \\
\text { son pacientes que cooperan con su } \\
\text { tratamiento. }\end{array}$ & $\begin{array}{l}\text { Los pacientes con trastornos relacionados al } \\
\text { consumo de alcohol son personas que } \\
\text { cooperan en su tratamiento }\end{array}$ & $\begin{array}{l}\text { Los pacientes con trastornos relacionados } \\
\text { al consumo de alcohol son personas que } \\
\text { cooperan en su tratamiento. }\end{array}$ \\
\hline 47 & $\begin{array}{l}\text { Pessoas com transtornos relacionados ao uso do } \\
\text { álcool não levam o tratamento a sério. }\end{array}$ & $\begin{array}{l}\text { Las personas con trastornos } \\
\text { relacionados al consumo de alcohol no } \\
\text { llevan un tratamiento serio. }\end{array}$ & $\begin{array}{l}\text { Las persona con trastornos relacionados al } \\
\text { consumo de alcohol no toman en serio su } \\
\text { tratamiento }\end{array}$ & $\begin{array}{l}\text { Las personas con trastornos relacionados } \\
\text { al consumo de alcohol no toman en serio } \\
\text { su tratamiento. }\end{array}$ \\
\hline 03 & $\begin{array}{l}\text { Penso que passar por um desajuste familiar leva } \\
\text { ao alcoolismo }\end{array}$ & & $\begin{array}{l}\text { Creo que la disfunción familiar puede llevar al } \\
\text { alcoholismo }\end{array}$ & $\begin{array}{l}\text { Creo que la disfunción familiar puede llevar } \\
\text { al alcoholismo. }\end{array}$ \\
\hline 07 & $\begin{array}{l}\text { Pessoas tímidas ou inibidas têm maior chance de } \\
\text { desenvolver } 0 \text { alcoolismo. }\end{array}$ & $\begin{array}{l}\text { Las personas tímidas o inhibidas tienen } \\
\text { mayor tendencia a desarrollar } \\
\text { alcoholismo. }\end{array}$ & $\begin{array}{l}\text { Las personas tímidas o inhibidas tienen } \\
\text { mayores posibilidades de convertirse en } \\
\text { alcohólicas }\end{array}$ & $\begin{array}{l}\text { Las personas tímidas o inhibidas tienen } \\
\text { mayor tendencia a desarrollar alcoholismo. }\end{array}$ \\
\hline 11 & Penso que a depressão leva ao alcoolismo. & $\begin{array}{l}\text { Pienso que la depresión lleva al } \\
\text { alcoholismo. }\end{array}$ & $\begin{array}{l}\text { Creo que la depresión es causa del } \\
\text { alcoholismo una de las causas, } i\end{array}$ & $\begin{array}{l}\text { Creo que la depresión puede provocar } \\
\text { alcoholismo. }\end{array}$ \\
\hline 19 & As questões sociais levam o indivíduo a beber. & $\begin{array}{l}\text { Las problemáticas sociales llevan a un } \\
\text { individuo a beber. }\end{array}$ & $\begin{array}{l}\text { Las cuestiones de tipo sociales llevan al } \\
\text { individuo a beber. }\end{array}$ & $\begin{array}{l}\text { Las problemáticas sociales llevan a un } \\
\text { individuo a beber }\end{array}$ \\
\hline 23 & Predisposições hereditárias levam ao alcoolismo. & $\begin{array}{l}\text { Las predisposiciones hereditarias } \\
\text { llevan al alcoholismo. }\end{array}$ & $\begin{array}{l}\text { Predisposiciones (o las condiciones } \\
\text { hereditarias, o factores hereditarios) conducen } \\
\text { al alcoholismo (?) }\end{array}$ & $\begin{array}{l}\text { Factores hereditarios conducen al } \\
\text { alcoholismo. }\end{array}$ \\
\hline 27 & Pessoas insatisfeitas abusam do álcool. & $\begin{array}{l}\text { Las personas insatisfechas abusan del } \\
\text { alcohol }\end{array}$ & $\begin{array}{l}\text { Las personas insatisfechas abusan del } \\
\text { consumo de alcohol }\end{array}$ & $\begin{array}{l}\text { Las personas insatisfechas abusan del } \\
\text { consumo de alcohol. }\end{array}$ \\
\hline
\end{tabular}




\begin{tabular}{|c|c|c|c|c|}
\hline $\mathbf{N}$ & Ítem Versão Original & T1 & T2 & S1 \\
\hline 31 & $\begin{array}{l}\text { As pessoas que desenvolvem o alcoolismo } \\
\text { têm baixa autoestima. }\end{array}$ & $\begin{array}{l}\text { Las personas que desarrollan } \\
\text { alcoholismo tienen baja autoestima. }\end{array}$ & $\begin{array}{l}\text { Las personas alcohólicas tienen baja la } \\
\text { autoestima }\end{array}$ & $\begin{array}{l}\text { Las personas que desarrollan alcoholismo } \\
\text { tienen baja autoestima. }\end{array}$ \\
\hline 35 & $\begin{array}{l}\text { As pessoas com transtornos relacionados ao } \\
\text { uso do álcool são psicologicamente } \\
\text { abaladas. }\end{array}$ & $\begin{array}{l}\text { Las personas con trastornos } \\
\text { relacionados al consumo de alcohol } \\
\text { son psicológicamente inestables. }\end{array}$ & $\begin{array}{l}\text { Las personas con trastornos relacionados al } \\
\text { consumo de alcohol son sicológicamente } \\
\text { inestables }\end{array}$ & $\begin{array}{l}\text { Las personas con trastornos relacionados } \\
\text { al consumo de alcohol son } \\
\text { psicológicamente inestables }\end{array}$ \\
\hline 39 & $\begin{array}{l}\text { As pessoas bebem para se sentirem mais } \\
\text { sociáveis. }\end{array}$ & $\begin{array}{l}\text { Las personas beben para sentirse más } \\
\text { sociables. }\end{array}$ & $\begin{array}{l}\text { Las personas beben para sentirse (o hacerse) } \\
\text { más sociables (?) }\end{array}$ & $\begin{array}{l}\text { Las personas beben para sentirse más } \\
\text { sociables. }\end{array}$ \\
\hline 43 & $\begin{array}{l}\text { A pessoa com transtornos relacionados ao } \\
\text { uso do álcool bebe porque não consegue } \\
\text { enfrentar a sua realidade. }\end{array}$ & $\begin{array}{l}\text { La persona con trastornos relacionados } \\
\text { al consumo de alcohol bebe porque no } \\
\text { consigue enfrentar su realidad. }\end{array}$ & $\begin{array}{l}\text { La persona con trastornos relacionados al } \\
\text { consumo de alcohol bebe porque no es capaz } \\
\text { de enfrentar (o asumir) su propia realidad (?) }\end{array}$ & $\begin{array}{l}\text { La persona con trastornos relacionados al } \\
\text { consumo de alcohol bebe porque no es } \\
\text { capaz de enfrentar su propia realidad. }\end{array}$ \\
\hline 04 & $\begin{array}{l}\text { Penso que as pessoas têm o direito de beber } \\
\text { se elas quiserem. }\end{array}$ & $\begin{array}{l}\text { Pienso que las personas tienen el } \\
\text { derecho a beber si ellas quieren. }\end{array}$ & $\begin{array}{l}\text { Creo que las personas tienen derecho a beber } \\
\text { si eso quieren (o si así lo desean) (?) }\end{array}$ & $\begin{array}{l}\text { Creo que las personas tienen derecho a } \\
\text { beber si así lo desean. }\end{array}$ \\
\hline 08 & $\begin{array}{l}\text { A bebida alcoólica é agradável e proporciona } \\
\text { bem-estar ao usuário }\end{array}$ & $\begin{array}{l}\text { La bebida alcohólica es agradable y } \\
\text { proporciona bien-estar al usuario }\end{array}$ & $\begin{array}{l}\text { La bebida alcohólica es agradable y } \\
\text { proporciona bienestar a quien la consume }\end{array}$ & $\begin{array}{l}\text { La bebida alcohólica es agradable y } \\
\text { proporciona bienestar a quien la consume. }\end{array}$ \\
\hline 12 & O uso da bebida alcoólica é algo normal & $\begin{array}{l}\text { El consumo de bebida alcohólica es } \\
\text { algo normal }\end{array}$ & Consumir alcohol es algo normal & $\begin{array}{l}\text { El consumo de bebida alcohólica es algo } \\
\text { normal }\end{array}$ \\
\hline 16 & $\begin{array}{l}\text { A bebida em qualquer quantidade vai deixar } \\
\text { o indivíduo dependente. }\end{array}$ & $\begin{array}{l}\text { La bebida en cualquier cantidad va } \\
\text { dejar al individuo dependiente. }\end{array}$ & $\begin{array}{l}\text { Beber alcohol en cualquier cantidad causará } \\
\text { (siempre) dependencia (?) }\end{array}$ & $\begin{array}{l}\text { Beber alcohol en cualquier cantidad } \\
\text { causará siempre dependencia. }\end{array}$ \\
\hline 20 & Beber com moderação não é prejudicial. & $\begin{array}{l}\text { Beber con moderación no es } \\
\text { perjudicial. }\end{array}$ & Beber con moderación no es perjudicial & Beber con moderación no es perjudicial. \\
\hline 24 & $\begin{array}{l}\text { Eu sou contra o uso de álcool em qualquer } \\
\text { momento. }\end{array}$ & $\begin{array}{l}\text { Estoy en contra del uso del alcohol en } \\
\text { cualquier momento. }\end{array}$ & $\begin{array}{l}\text { Estoy en contra del uso del alcohol en } \\
\text { cualquier circunstancia }\end{array}$ & $\begin{array}{l}\text { Estoy en contra del uso del alcohol en } \\
\text { cualquier circunstancia }\end{array}$ \\
\hline 28 & Eu sou favorável ao beber moderado. & $\begin{array}{l}\text { Estoy a favor de beber con } \\
\text { moderación. }\end{array}$ & $\begin{array}{l}\text { Soy favorable a beber (pero) en forma } \\
\text { moderada (?) }\end{array}$ & Estoy a favor de beber con moderación. \\
\hline 32 & $\begin{array}{l}\text { Doses pequenas de álcool são capazes de } \\
\text { causar dependência. }\end{array}$ & $\begin{array}{l}\text { Dosis pequeñas de alcohol son } \\
\text { capaces de causar dependencia. }\end{array}$ & $\begin{array}{l}\text { Dosis pequeñas de alcohol pueden causar } \\
\text { dependencia }\end{array}$ & $\begin{array}{l}\text { Dosis pequeñas de alcohol pueden causar } \\
\text { dependencia. }\end{array}$ \\
\hline 36 & $\begin{array}{l}\text { O álcool em quantidades reduzidas é } \\
\text { benéfico. }\end{array}$ & $\begin{array}{l}\text { El alcohol en cantidades reducidas es } \\
\text { benéfico }\end{array}$ & $\begin{array}{l}\text { El alcohol en cantidades reducidas es } \\
\text { saludable }\end{array}$ & $\begin{array}{l}\text { El alcohol en cantidades reducidas es } \\
\text { benéfico }\end{array}$ \\
\hline 40 & $\begin{array}{l}\text { As pessoas podem beber desde saibam se } \\
\text { controlar. }\end{array}$ & $\begin{array}{l}\text { Las personas pueden beber desde que } \\
\text { sepan controlarse. }\end{array}$ & $\begin{array}{l}\text { Las personas pueden beber alcohol si son } \\
\text { capaces de controlar su consumo (o si saben } \\
\text { controlarse) (?) }\end{array}$ & $\begin{array}{l}\text { Las personas pueden beber desde que } \\
\text { sepan controlarse. }\end{array}$ \\
\hline
\end{tabular}




\section{APÉNDICE H. AVALIAÇÃO QUALITATIVA DO COMITÊ DE JUÍZES PARA EQUIVALÊNCIA SEMÂNTICA, CONCEITUAL E} IDIOMÁTICA- MODIFICAÇÕES REALIZADAS POR ITEM

\begin{tabular}{|c|c|c|c|c|c|c|c|c|c|}
\hline ID & Item Inicial & JUIZ 1 & JUIZ 2 & JUIZ 3 & JUIZ 4 & JUIZ 5 & JUIZ 6 & Modificações & Item Final \\
\hline 1 & $\begin{array}{c}\text { Tengo miedo de abordar el problema } \\
\text { del alcohol con mis pacientes }\end{array}$ & Adequado & Adequado & $\begin{array}{c}\text { clarificar si usted planteará } \\
\text { el uso del alcohol como } \\
\text { un problema. }\end{array}$ & \begin{tabular}{|c|} 
sugiero revisar conceptos \\
utilizados tales como: \\
usuario o paciente o \\
persona o individuo, creo \\
importante que sea usado \\
el mismo termino en todos \\
los ittems \\
\end{tabular} & Adequado & Adequado & $\begin{array}{c}\text { Mudou a palavra "problema de } \\
\text { alcohol" por "problemas } \\
\text { relacionados al uso de bebidas } \\
\text { alcohólicas"- "mis pacientes" por "los } \\
\text { pacientes" }\end{array}$ & $\begin{array}{c}\text { Tengo miedo de abordar los problemas } \\
\text { relacionados al uso de bebidas alcohólicas } \\
\text { con los pacientes. }\end{array}$ \\
\hline 5 & $\begin{array}{c}\text { Tengo miedo de la agresividad del } \\
\text { paciente con trastornos relacionados al } \\
\text { consumo de alcohol. }\end{array}$ & Adequado & $\begin{array}{l}\text { Podemos cambiar miedo } \\
\text { por inseguridad, en la } \\
\text { anterior ya se manifiesta } \\
\text { esta emoción }\end{array}$ & \begin{tabular}{|c|} 
Sugiero cambiar la \\
palabra consumo por uso \\
y que sea utilizado el \\
mismo termino em todos \\
los items.
\end{tabular} & Adequado & Adequado & Adequado & \begin{tabular}{|c|} 
Mudou a expressão "tengo miedo" \\
por "Me siento inseguro " - mudou a \\
palavra "consumo de alcohol" por \\
"uso de bebida alcoholica"
\end{tabular} & $\begin{array}{c}\text { Me siento inseguro ante la agresividad de } \\
\text { una persona con trastornos relacionados al } \\
\text { uso de bebidas alcohólicas }\end{array}$ \\
\hline 9 & $\begin{array}{c}\text { Me siento frustrado cuando trabajo con } \\
\text { pacientes con trastornos relacionados } \\
\text { al uso de alcohol. }\end{array}$ & Adequado & $\begin{array}{l}\text { Utilizar la diferenciación } \\
\text { de genero }\end{array}$ & Adequado & Adequado & Adequado & Adequado & \begin{tabular}{|c|} 
Acresentou-se a diferença de \\
genero (a)à palavra "frustrado" - \\
Mudou -se as palavras "paciente" \\
por "persona" e "alcohol" por \\
"bebida alcoholica" \\
\end{tabular} & $\begin{array}{c}\text { Me siento frustrado (a) cuando trabajo con } \\
\text { personas con trastornos relacionados al uso } \\
\text { de bebidas alcohólicas. }\end{array}$ \\
\hline 13 & $\begin{array}{l}\text { De todos mis pacientes, el que tiene } \\
\text { trastornos relacionados al uso de } \\
\text { alcohol, es el que da más trabajo. }\end{array}$ & Adequado & Sugiere la respuesta & Adequado & Adequado & Adequado & Adequado & $\begin{array}{c}\text { Mudou -se a palavra "paciente" por } \\
\text { "persona" }\end{array}$ & $\begin{array}{l}\text { De todas las personas, las que tienen } \\
\text { trastornos relacionados al uso de bebidas } \\
\text { alcohólicas, son las que dan más trabajo. }\end{array}$ \\
\hline 17 & $\begin{array}{l}\text { Debo cuidar al paciente con trastornos } \\
\text { relacionados al uso de alcohol, así el } \\
\text { crea no necesitar cuidar de su salud. }\end{array}$ & Adequado & $\begin{array}{c}\text { Mejorar la redacción, la } \\
\text { segunda parte de la } \\
\text { pregunta corresponde al } \\
\text { Factor } 2\end{array}$ & Adequado & $\begin{array}{l}\text { Aunque el crea que no } \\
\text { necesita... }\end{array}$ & Adequado & $\begin{array}{l}\text { Sugerencia para evitar } \\
\text { cuidado impuesto. } \\
\text { Ofrecer ayuda y } \\
\text { orientaciones }\end{array}$ & $\begin{array}{c}\text { Para melhorar a redação e a } \\
\text { equivalência semantica mudou-se a } \\
\text { expressão " Debo cuidar al } \\
\text { paciente" por " Debo ofrecer ayuda } \\
\text { y orientaciones a la persona". Além } \\
\text { disso mudou-se a expressão "asíel } \\
\text { crea " por "aunque ella crea" como o } \\
\text { intuito de melhorar a comprensão } \\
\text { para a população alvo. Optou-se } \\
\text { por manter esse item nesse fator ja } \\
\text { que faz referencia á relaçâo } \\
\text { Enfermeiro - Usuário. } \\
\end{array}$ & $\begin{array}{c}\text { Debo offecer ayuda y orientaciones a la } \\
\text { persona con trastornos relacionados al uso } \\
\text { de alcohol, aunque ella crea que no } \\
\text { necesita cuidar de su salud. }\end{array}$ \\
\hline 21 & $\begin{array}{c}\text { Incluso, cuando el paciente con } \\
\text { trastornos relacionados con el uso de } \\
\text { alcohol no está intoxicado, es } \\
\text { irrespetuoso con los miembros del } \\
\text { equipo. }\end{array}$ & Adequado & corresponde al Factor 2 & Adequado & Sem Alterações & Adequado & $\begin{array}{c}\text { Suena como } \\
\text { característica personal }\end{array}$ & $\begin{array}{l}\text { Após discussão com o autor do } \\
\text { instrumento optou-se por não aceitar } \\
\text { as sugestōes dos juizes já que esse } \\
\text { item refere-se à relação do usuário } \\
\text { com a equipe de saúde e não às } \\
\text { caracterisitcas pessoais do usuário. }\end{array}$ & $\begin{array}{l}\text { Incluso, cuando la persona con trastornos } \\
\text { relacionados con el uso de bebidas } \\
\text { alcohólicas no está intoxicada, es } \\
\text { irrespetuosa con los miembros del equipo de } \\
\text { salud. }\end{array}$ \\
\hline 25 & $\begin{array}{c}\begin{array}{c}\text { Siento rabia al trabajar con pacientes } \\
\text { con trastornos relacionados al uso de } \\
\text { alcohol. }\end{array} \\
\end{array}$ & Adequado & Adequado & Adequado & $\begin{array}{c}\text { Se sugiere utilizar los } \\
\text { mismos terminos para } \\
\text { todos los items. }\end{array}$ & Adequado & Sem Alterações & $\begin{array}{c}\text { Segue-se o padrão de usar a } \\
\text { palavra " persona" no lugar de " } \\
\text { paciente" }\end{array}$ & $\begin{array}{c}\begin{array}{c}\text { Siento rabia al trabajar con personas con } \\
\text { trastornos relacionados al uso de bebidas } \\
\text { alcohólicas. }\end{array} \\
\end{array}$ \\
\hline 29 & \begin{tabular}{|c|} 
Los pacientes con trastornos \\
relacionados al uso de alcohol nunca \\
aceptan lo que los profesionales de la \\
salud dicen sobre sus problemas con la \\
bebida.
\end{tabular} & Adequado & $\begin{array}{l}\text { Este ftem debería ser } \\
\text { mejorado. Quizás } \\
\text { corresponde al Factor } 2\end{array}$ & Adequado & Adequado & Adequado & $\begin{array}{c}\text { Suena como } \\
\text { característica personal }\end{array}$ & $\begin{array}{c}\text { Após discussão com o autor do } \\
\text { instrumento optou-se por não aceitar } \\
\text { as sugestōes dos juizes já que esse } \\
\text { item refere-se à relaçăo do usuário } \\
\text { coma equipe de saúde e não às } \\
\text { caracterisitcas pessoais do usuário. } \\
\text { Segue-se o padrão de usar a } \\
\text { palavra " persona" no lugar de " } \\
\text { paciente" } \\
\end{array}$ & $\begin{array}{c}\text { Los personas con trastornos relacionados al } \\
\text { uso de alcohol nunca aceptan lo que los } \\
\text { profesionales de la salud dicen sobre sus } \\
\text { problemas con la bebida. }\end{array}$ \\
\hline 37 & \begin{tabular}{|c|} 
Abordar el problema del alcohol con \\
pacientes con trastornos relacionados a \\
su uso, implica dedicar menos tiempo \\
para otros pacientes.
\end{tabular} & Adequado & Adequado & Adequado & Adequado & Adequado & Adequado & $\begin{array}{c}\text { Segue-se o padrão de usar a } \\
\text { palavra " persona" no lugar de " } \\
\text { paciente" }\end{array}$ & $\begin{array}{c}\text { Abordar el problema del alcohol con } \\
\text { personas con trastornos relacionados a su } \\
\text { uso, implica dedicar menos tiempo para otros } \\
\text { pacientes. }\end{array}$ \\
\hline
\end{tabular}


APÊNDICES.

97

\begin{tabular}{|c|c|c|c|c|c|c|c|c|c|}
\hline ID & Item Inicial & JUIZ 1 & JUIZ 2 & JUIZ 3 & JUIZ 4 & JUIZ 5 & JUIZ 6 & Modificações & Item Final \\
\hline 41 & $\begin{array}{l}\text { Prefiero trabajar con pacientes con } \\
\text { trastornos relacionados al uso de } \\
\text { alcohol a trabajar con otro tipo de } \\
\text { pacientes }\end{array}$ & Adequado & Adequado & $\begin{array}{l}\text { Se da por hecho que } \\
\text { existen "tipos de } \\
\text { pacientes" }\end{array}$ & Adequado & Adequado & Adequado & $\begin{array}{l}\text { Eliminou-se a expressão "tipo de } \\
\text { pacientes" }\end{array}$ & $\begin{array}{l}\text { Prefiero trabajar con pacientes con } \\
\text { trastornos relacionados al uso de bebidas } \\
\text { alcohólicas que trabajar con otros pacientes }\end{array}$ \\
\hline 42 & \begin{tabular}{|c|} 
La persona con trastornos \\
relacionados al uso de alcohol es una \\
persona que le cuesta relacionarse con \\
los otros.
\end{tabular} & Adequado & $\begin{array}{l}\text { Yo lo eliminaría y dejaría } \\
\text { el siguiente (44) }\end{array}$ & $\begin{array}{l}\text { Creo que pertence al } \\
\text { factor } 2\end{array}$ & Factor 2 & Adequado & $\begin{array}{c}\text { Característica personal, } \\
\text { pertenece al factor } 2\end{array}$ & \begin{tabular}{|c|} 
Após discussaõ com o autor do \\
instrumento optou-se por mudar o \\
item para o fator 2 já que no seu \\
conteúdo faz referência ás \\
caracteristicas pessoais do usuário; \\
em concordância com as sugestōes \\
dos juizes. \\
\end{tabular} & $\begin{array}{l}\text { El paciente con trastornos relacionados al } \\
\text { uso de alcohol es una persona que le cuesta } \\
\text { relacionarse con los otros. }\end{array}$ \\
\hline 44 & $\begin{array}{c}\text { Considero que es dificil establecer una } \\
\text { relación terapéutica con pacientes con } \\
\text { trastornos relacionados al uso de } \\
\text { alcohol. }\end{array}$ & Adequado & Adequado & Adequado & Adequado & Adequado & \begin{tabular}{|c|} 
Mantener la forma \\
afirmativa y personal
\end{tabular} & \begin{tabular}{|c|}
\multicolumn{2}{|c}{ Modificou-se a expressão } \\
"Considero que" por "Es dificil para \\
mi" $\quad$ Segue-se o \\
padrão de usar a palavra " \\
persona" no lugar de " paciente"
\end{tabular} & $\begin{array}{l}\text { Es diffil para mi establecer una relación } \\
\text { terapéutica con personas que tienen } \\
\text { trastornos relacionados al uso de bebidas } \\
\text { alcohólicas. }\end{array}$ \\
\hline 46 & $\begin{array}{c}\text { Es preciso tener cuidado para no ser } \\
\text { agredido al trabajar con pacientes con } \\
\text { trastornos relacionados al consumo de } \\
\text { alcohol. }\end{array}$ & Adequado & $\begin{array}{c}\text { Mejorar la redacción, } \\
\text { inferir en la preparación } \\
\text { para manejar este tipo de } \\
\text { pacientes }\end{array}$ & \begin{tabular}{|c|} 
Usaria una palabra \\
diferente a “ terner \\
cuidado", pues ha usado \\
el cuidado con otro \\
sentido anteriormente, \\
sugiero es preciso tener \\
precaución... \\
\end{tabular} & Adequado & Adequado & \begin{tabular}{|c|} 
Mantener la forma \\
afirmativa y personal
\end{tabular} & $\begin{array}{l}\text { Modificou-se a expressão "Es } \\
\text { preciso tener cuidado" por "Debo } \\
\text { tener precaución" } \\
\text { Segue-se o padrão de usar a } \\
\text { palavra " persona" no lugar de " } \\
\text { paciente" } \\
\end{array}$ & $\begin{array}{l}\text { Debo tener precaución para no ser } \\
\text { agredido (a) al trabajar con personas que } \\
\text { teenen trastornos relacionados al uso de } \\
\text { bebidas alcohólicas. }\end{array}$ \\
\hline 48 & $\begin{array}{l}\text { Cuando el paciente con trastornos } \\
\text { relacionados al uso de alcohol no } \\
\text { acepta que tiene problemas } \\
\text { relacionados al consumo, la mejor } \\
\text { decisión es desistir de ayudar. }\end{array}$ & Adequado & $\begin{array}{c}\text { La pregunta se refiere al } \\
\text { paciente en su primera } \\
\text { parte corresponde al } \\
\text { Factor } 2\end{array}$ & Adequado & Adequado & Adequado & Adequado & $\begin{array}{l}\text { Após discussão com o autor do } \\
\text { instrumento optou-se por não aceitar } \\
\text { as sugestôes dos juizes já que esse } \\
\text { item refere-se à relação do usuário } \\
\text { com a equipe de saúde e não às } \\
\text { caracterisitcas pessoais do usuário. }\end{array}$ & $\begin{array}{c}\text { Cuando el paciente con trastornos } \\
\text { relacionados al uso de bebidas alcohólicas } \\
\text { no acepta que tiene problemas relacionados } \\
\text { al consumo, la mejor decisión es desistir de } \\
\text { ayudar. }\end{array}$ \\
\hline 49 & $\begin{array}{c}\text { Cuando trabajo con pacientes con } \\
\text { trastornos relacionados al uso de } \\
\text { alcohol, no sé cómo manejar la } \\
\text { situación. }\end{array}$ & Adequado & Adequado & Adequado & Adequado & Adequado & Adequado & $\mathrm{O}$ item conservou-se igual & $\begin{array}{c}\text { Cuando trabajo con pacientes con trastornos } \\
\text { relacionados al uso de bebidas alcohólicas, } \\
\text { no sé cómo manejar la situación. }\end{array}$ \\
\hline 50 & \begin{tabular}{|c|} 
Cuidar pacientes con trastornos \\
relacionados al uso de alcohol no es \\
gratificante para mí.
\end{tabular} & Adequado & Adequado & Adequado & Adequado & Adequado & Adequado & $\mathrm{O}$ item conservou-se igual & $\begin{array}{l}\text { Cuidar pacientes con trastornos relacionados } \\
\text { al uso de alcohol no es gratificante para mí. }\end{array}$ \\
\hline 2 & $\begin{array}{l}\text { Las personas con trastornos } \\
\text { relacionados al uso de alcohol no } \\
\text { tienen sentido común. }\end{array}$ & Adequado & $\begin{array}{c}\text { Utilizar un solo trato, } \\
\text { paciente o persona, } \\
\text { debemos ser consistentes }\end{array}$ & Adequado & Adequado & Adequado & \begin{tabular}{|l|} 
La expresión sentido \\
comum es muy amplia, \\
sugiero cambiarla por \\
"critica de la realidad" \\
\end{tabular} & $\begin{array}{c}\text { Optou-se por aceitar as sugestões } \\
\text { dos juizes mudando a expressão } \\
\text { "sentido comun" por "critica de la } \\
\text { realidad" } \\
\end{array}$ & $\begin{array}{l}\text { Las personas con trastornos relacionados al } \\
\text { uso de bebidas alcohólicas no tienen critica } \\
\text { de la realidad. }\end{array}$ \\
\hline 6 & \begin{tabular}{|c|} 
Las personas con trastornos \\
relacionados al uso de alcohol son mal \\
educadas.
\end{tabular} & Adequado & \begin{tabular}{|c|} 
Utilizar un solo trato, \\
paciente o persona, \\
debemos ser consistentes
\end{tabular} & Adequado & Adequado & Adequado & Adequado & $\mathrm{O}$ item conservou-se igual & \begin{tabular}{|c|}
$\begin{array}{c}\text { Las personas con trastornos relacionados al } \\
\text { uso de bebidas alcoholicas son mal } \\
\text { educadas. }\end{array}$ \\
\end{tabular} \\
\hline 10 & \begin{tabular}{|c|} 
Las personas con trastornos \\
relacionados al uso de alcohol son \\
irresponsables.
\end{tabular} & Adequado & $\begin{array}{c}\text { Utilizar un solo trato, } \\
\text { paciente o persona, } \\
\text { debemos ser consistentes }\end{array}$ & Adequado & Adequado & Adequado & Adequado & $\mathrm{O}$ item conservou-se igual & \begin{tabular}{|c} 
Las personas con trastornos relacionados al \\
uso de alcohol son irresponsables.
\end{tabular} \\
\hline 14 & $\begin{array}{c}\text { Pacientes con trastornos relacionados } \\
\text { al uso de alcohol tienen mayores } \\
\text { probabilidades de reaccionar en forma } \\
\text { violenta contra mí. }\end{array}$ & Adequado & Adequado & $\begin{array}{c}\text { Creo que pertenece al } \\
\text { Factor } 1 \text {, pues habla de la } \\
\text { relación }\end{array}$ & Adequado & Adequado & \begin{tabular}{|c|} 
El aspecto relativo al \\
profesional ya está \\
incluido en el factor 1
\end{tabular} & \begin{tabular}{|c|} 
Opotu-se por aceitar as sugestôes \\
dos juizes e mudar esse item para o \\
Fator 1 já que faz referência à \\
relaçăo interpessoal Enfermeiro - \\
Usuário, além disso o IVC para esse \\
item apresentou valores inferiores a \\
0,80 o que indica que deve ser \\
refirado do fator atual. \\
\end{tabular} & $\begin{array}{l}\text { Personas con trastornos relacionados al uso } \\
\text { de bebidas alcoholicas tienen mayores } \\
\text { probabilidades de reaccionar en forma } \\
\text { violenta contra mí. }\end{array}$ \\
\hline
\end{tabular}




\begin{tabular}{|c|c|c|c|c|c|c|c|c|c|}
\hline \multicolumn{10}{|c|}{ APÊNDICES. } \\
\hline ID & Item Inicial & JUIZ 1 & JUIZ 2 & JUIZ 3 & JUIZ 4 & JUIZ 5 & JUIZ 6 & Modificações & Item Final \\
\hline 18 & $\begin{array}{l}\text { Creo que las personas con problemas } \\
\text { de alcoholismo son débiles de carácter. }\end{array}$ & Adequado & Adequado & Adequado & Adequado & Adequado & $\begin{array}{c}\text { Mantener la } \\
\text { uniformidad de la } \\
\text { redacción }\end{array}$ & $\begin{array}{c}\text { Aceitaram-se as sugestões dos } \\
\text { juizes e retirou-se a expresão } \\
\text { "Creo" } \\
\end{array}$ & $\begin{array}{c}\text { Las personas con problemas de alcoholismo } \\
\text { son débiles de carácter. }\end{array}$ \\
\hline 22 & $\begin{array}{l}\text { Percibo que los pacientes con } \\
\text { trastornos relacionados al uso de } \\
\text { alcohol no se quieren cuidar. }\end{array}$ & Adequado & Corresponde al factor 1 & Adequado & Adequado & Adequado & $\begin{array}{l}\text { Mantener la } \\
\text { uniformidad de la } \\
\text { redacción }\end{array}$ & $\begin{array}{c}\text { Aceitou-se a sugestão do juiz } 6 \text { e } \\
\text { retirou-se a expresão "Percibo que " } \\
\text { em relação à sugestão do juiz } 2 \text { não } \\
\text { foi aceita já que esse item refere-se } \\
\text { às caracterisitcas pessoais do } \\
\text { usuário e não à relação do usuário } \\
\text { com a equipe de saúde. }\end{array}$ & $\begin{array}{l}\text { Los pacientes con trastornos relacionados al } \\
\text { uso de alcohol no se quieren cuidar. }\end{array}$ \\
\hline 26 & $\begin{array}{l}\text { No confio en las informaciones que } \\
\text { cuentan los pacientes con trastornos } \\
\text { relacionados al consumo de alcohol. }\end{array}$ & Adequado & Adequado & \begin{tabular}{|c|} 
La frase: "las \\
informaciones" no me \\
queda a claro a que se \\
refiere
\end{tabular} & Adequado & Adequado & \begin{tabular}{|c|} 
Mantener la \\
uniformidad de la \\
redacción, sugiero \\
retirar la expresión "no \\
confio"
\end{tabular} & $\begin{array}{c}\text { Aceitaram-se as sugestões dos } \\
\text { juizes e retirou-se a expresão "No } \\
\text { confio" }\end{array}$ & $\begin{array}{l}\text { Los relatos de las personas con trastornos } \\
\text { relacionados al consumo de alcohol no son } \\
\text { confiables. }\end{array}$ \\
\hline 30 & $\begin{array}{l}\text { Creo que la persona con trastornos } \\
\text { relacionados al uso de alcohol es } \\
\text { culpable de sus problemas de salud. }\end{array}$ & Adequado & Adequado & Adequado & Adequado & Adequado & $\begin{array}{l}\text { Mantener la } \\
\text { uniformidad de la } \\
\text { redacción }\end{array}$ & $\begin{array}{c}\text { Aceitaram-se as sugestōes dos } \\
\text { juizes e retirou-se a expresão "Creo } \\
\text { que " }\end{array}$ & $\begin{array}{l}\text { La persona con trastornos relacionados al } \\
\text { uso de alcohol es culpable de sus } \\
\text { problemas de salud. }\end{array}$ \\
\hline 33 & $\begin{array}{c}\text { Considero al paciente con trastornos } \\
\text { relacionados al uso de alcohol como } \\
\text { un caso perdido. }\end{array}$ & Adequado & Mejorar la redacción & Adequado & Adequado & Adequado & $\begin{array}{c}\text { Mantener la } \\
\text { uniformidad de la } \\
\text { redacción }\end{array}$ & $\begin{array}{c}\text { Aceitaram-se as sugestões dos } \\
\text { juizes e retirou-se a expresão } \\
\text { "Considero" }\end{array}$ & \begin{tabular}{|c}
$\begin{array}{c}\text { La persona con trastornos relacionados al } \\
\text { uso de bebidas alcoholicas es un caso } \\
\text { perdido. }\end{array}$ \\
\end{tabular} \\
\hline 34 & \begin{tabular}{|c|} 
La persona con trastornos \\
relacionados al uso de alcohol acaba \\
siempre volviendo al servicio de salud \\
por el mismo problema.
\end{tabular} & Adequado & Corresponde al factor 1 & Adequado & Adequado & Adequado & Adequado & \begin{tabular}{|c|} 
Após discussão com o autor do \\
instrumento optou-se por não aceitar \\
as sugestôes do juiz 2 já que esse \\
item refere-se netamente às \\
caracterisitcas pessoais do usuário e \\
não à relação do usuário com a \\
equipe de saúdes. \\
\end{tabular} & $\begin{array}{l}\text { La persona con trastornos relacionados al } \\
\text { uso de bebida alcohólica acaba siempre } \\
\text { volviendo al servicio de salud por el mismo } \\
\text { problema. }\end{array}$ \\
\hline 38 & $\begin{array}{l}\text { De todos mis pacientes, el que posee } \\
\text { trastornos relacionados al uso de } \\
\text { alcohol es el más dificil de cuidar. }\end{array}$ & Adequado & $\begin{array}{c}\text { Corresponde al factor } 1, \\
\text { de hecho la pregunta esta } \\
\text { en este factor (Item 13) }\end{array}$ & $\begin{array}{l}\text { Creo que es factor } 1 \\
\quad \text { alude al hecho } \\
\text { interpersonal de cuidar }\end{array}$ & $\begin{array}{l}\text { Se sugiere cambiar la } \\
\text { palabra "posee" por } \\
\text { "tiene" }\end{array}$ & Adequado & $\begin{array}{l}\text { El aspecto relativo al } \\
\text { profesional ya está } \\
\text { incluido en el factor } 1\end{array}$ & \begin{tabular}{|c|} 
Adoptaram-se as sugestões dos \\
juizes, muda-se o item para o fator 1 \\
(Relações interpessoais Enfermeiro- \\
Usuário) e muda-se a palavra \\
"posee" por "tiene". \\
\end{tabular} & $\begin{array}{l}\text { De todas las personas, las que tienen } \\
\text { trastornos relacionados al uso de bebidas } \\
\text { alcohólicas son las más dificiles de cuidar. }\end{array}$ \\
\hline 45 & $\begin{array}{c}\text { Los pacientes con trastornos } \\
\text { relacionados al uso de alcohol son } \\
\text { personas que cooperan en su } \\
\text { tratamiento. }\end{array}$ & Adequado & Adequado & Adequado & Adequado & Adequado & Adequado & $\begin{array}{l}\text { Padronizou-se a mudança da } \\
\text { palavra "paciente " por "pessoas" }\end{array}$ & $\begin{array}{l}\begin{array}{l}\text { Las personas con trastornos relacionados al } \\
\text { uso de bebidas alcohólicas cooperan en su } \\
\text { tratamiento. }\end{array} \\
\end{array}$ \\
\hline 47 & $\begin{array}{c}\text { Las personas con trastornos } \\
\text { relacionados al consumo de alcohol no } \\
\text { toman en serio su tratamiento. }\end{array}$ & Adequado & Adequado & Adequado & Adequado & Adequado & Adequado & $\mathrm{O}$ item conservou-se igual & $\begin{array}{l}\text { Las personas con trastornos relacionados al } \\
\text { consumo de alcohol no toman en serio su } \\
\text { tratamiento. }\end{array}$ \\
\hline 3 & $\begin{array}{l}\text { Creo que la disffunción familiar puede } \\
\text { llevar al alcoholismo. }\end{array}$ & Adequado & $\begin{array}{l}\text { Sugiero eliminar la } \\
\text { palabra "CREO" }\end{array}$ & Adequado & Adequado & Adequado & $\begin{array}{c}\text { Mantener la } \\
\text { uniformidad de la } \\
\text { redacción Sugiero } \\
\text { eliminar la palabra } \\
\text { "CREO" } \\
\end{array}$ & $\begin{array}{l}\text { Adoptaram-se as sugestöes dos } \\
\text { juizes, elimina-se a palavra "creo". }\end{array}$ & $\begin{array}{l}\text { La disfunción familiar puede llevar al } \\
\text { alcoholismo. }\end{array}$ \\
\hline 7 & $\begin{array}{c}\text { Las personas timidas o inhibidas tienen } \\
\text { mayor tendencia a desarrollar } \\
\text { alcoholismo. }\end{array}$ & Adequado & Adequado & Adequado & Adequado & Adequado & Adequado & $\mathrm{O}$ item conservou-se igual & $\begin{array}{l}\text { Las personas timidas o inhibidas tienen } \\
\text { mayor tendencia a desarrollar alcoholismo. }\end{array}$ \\
\hline 11 & $\begin{array}{c}\text { Creo que la depresión puede provocar } \\
\text { alcoholismo. }\end{array}$ & Adequado & $\begin{array}{l}\text { Sugiero eliminar la } \\
\text { palabra "CREO" }\end{array}$ & Adequado & Adequado & Adequado & $\begin{array}{c}\text { Mantener la } \\
\text { uniformidad de la } \\
\text { redacción Sugiero } \\
\text { eliminar la palabra } \\
\text { "CREO" } \\
\end{array}$ & $\begin{array}{l}\text { Adoptaram-se as sugestöes dos } \\
\text { juizes, elimina-se a palavra "creo". }\end{array}$ & La depresión puede provocar alcoholismo. \\
\hline 15 & $\begin{array}{l}\text { Lo que falta en una persona con } \\
\text { trastornos relacionados al uso de } \\
\text { alcohol es fuerza de voluntad. }\end{array}$ & Adequado & $\begin{array}{c}\text { Mejorar la redacción } \\
\text { sugiero mudar para el } \\
\text { factor } 2\end{array}$ & $\begin{array}{l}\text { Me parece que es Factor } \\
\text { 2, pues da cuenta de una } \\
\text { percepción sobre la } \\
\text { persona que usa alcohol }\end{array}$ & Pertenece al factor 2 & Adequado & Adequado & $\begin{array}{l}\text { Adoptaram-se as sugestões dos } \\
\text { juizes, muda-se o item para o fator } 2 \\
\text { (caracteristicas pessoais do usuário). }\end{array}$ & $\begin{array}{c}\text { Lo que falta en una persona con trastornos } \\
\text { relacionados al uso de alcohol es fuerza de } \\
\text { voluntad. }\end{array}$ \\
\hline
\end{tabular}


APÊNDICES.

99

\begin{tabular}{|c|c|c|c|c|c|c|c|c|c|}
\hline ID & Item Inicial & JUIZ 1 & JUIZ 2 & JUIZ 3 & JUIZ 4 & JUIZ 5 & JUIZ 6 & Modificações & Item Final \\
\hline 19 & $\begin{array}{l}\text { Las problemáticas sociales llevan a un } \\
\text { individuo a beber. }\end{array}$ & Adequado & Adequado & Adequado & Adequado & Adequado & Adequado & O item conservou-se igual & $\begin{array}{l}\text { Las problemáticas sociales llevan a uma } \\
\text { persona a beber. }\end{array}$ \\
\hline 23 & $\begin{array}{c}\text { Factores hereditarios conducen al } \\
\text { alcoholismo. }\end{array}$ & Adequado & Adequado & Adequado & Adequado & Adequado & Adequado & $\mathrm{O}$ item conservou-se igual & $\begin{array}{l}\text { Factores hereditarios conducen al } \\
\text { alcoholismo. }\end{array}$ \\
\hline 27 & $\begin{array}{c}\text { Las personas insatisfechas abusan del } \\
\text { alcohol. }\end{array}$ & Adequado & Adequado & Adequado & Adequado & Adequado & Adequado & $\mathrm{O}$ item conservou-se igual & $\begin{array}{c}\text { Las personas insatisfechas abusan de las } \\
\text { bebidas alcoholicas. }\end{array}$ \\
\hline 31 & $\begin{array}{l}\text { Las personas que desarrollan } \\
\text { alcoholismo tienen baja autoestima. }\end{array}$ & Adequado & Adequado & Adequado & Adequado & Adequado & Adequado & $\mathrm{O}$ item conservou-se igual & $\begin{array}{c}\text { Las personas que desarrollan alcoholismo } \\
\text { tenen baja autoestima. }\end{array}$ \\
\hline 35 & $\begin{array}{c}\text { Las personas con trastornos } \\
\text { relacionados al uso de alcohol son } \\
\text { psicológicamente inestables }\end{array}$ & Adequado & Adequado & Adequado & Adequado & Adequado & $\begin{array}{l}\text { Ver el termino más } \\
\text { claro para el lector } \\
\text { "psicologicamente" } \\
\text { "psiquicamente" ou } \\
\text { "emocionalmente" } \\
\end{array}$ & $\mathrm{O}$ item conservou-se igual & $\begin{array}{l}\text { Las personas con trastornos relacionados al } \\
\text { uso de alcohol son psicológicamente } \\
\text { inestables }\end{array}$ \\
\hline 39 & $\begin{array}{l}\text { Las personas beben para sentirse más } \\
\text { sociables. }\end{array}$ & Adequado & Adequado & Adequado & Adequado & Adequado & Adequado & O item conservou-se igual & $\begin{array}{l}\text { Las personas beben para sentirse más } \\
\text { sociables. }\end{array}$ \\
\hline 43 & \begin{tabular}{|c|} 
La persona con trastornos \\
$\begin{array}{c}\text { relacionados al uso de alcohol bebe } \\
\text { porque no es capaz de enfrentar su } \\
\text { propia realidad. }\end{array}$ \\
\end{tabular} & Adequado & Adequado & Adequado & Adequado & Adequado & Adequado & $\mathrm{O}$ item conservou-se igual & $\begin{array}{l}\text { La persona con trastornos relacionados al } \\
\text { uso de alcohol bebe porque no es capaz de } \\
\text { enfrentar su propia realidad. }\end{array}$ \\
\hline 4 & $\begin{array}{c}\text { Creo que las personas tienen derecho } \\
\text { a beber si asi lo desean. }\end{array}$ & Adequado & Adequado & Adequado & Adequado & Adequado & $\begin{array}{c}\text { Mantener la } \\
\text { uniformidad de la } \\
\text { redacción Sugiero } \\
\text { eliminar la palabra } \\
\text { "CREO" } \\
\end{array}$ & $\begin{array}{l}\text { Adoptaram-se as sugestões dos } \\
\text { juizes, elimina-se a palavra "creo". }\end{array}$ & $\begin{array}{l}\text { Las personas tienen derecho a beber si así } \\
\text { lo desean. }\end{array}$ \\
\hline 8 & $\begin{array}{c}\text { La bebida alcohólica es agradable y } \\
\text { proporciona bienestar a quien la } \\
\text { consume. }\end{array}$ & Adequado & Adequado & Adequado & Adequado & Adequado & Adequado & $\mathrm{O}$ item conservou-se igual & $\begin{array}{l}\text { La bebida alcohólica es agradable y } \\
\text { proporciona bienestar a quien la usa. }\end{array}$ \\
\hline 12 & $\begin{array}{c}\text { El uso de bebida alcohólica es algo } \\
\text { normal }\end{array}$ & Adequado & Adequado & Adequado & Adequado & Adequado & Adequado & O item conservou-se igual & El uso de bebida alcohólica es algo normal \\
\hline 16 & $\begin{array}{l}\text { Beber alcohol en cualquier cantidad } \\
\text { causará siempre dependencia. }\end{array}$ & Adequado & Adequado & Adequado & Adequado & Adequado & Adequado & O item conservou-se igual & $\begin{array}{c}\text { Beber alcohol en cualquier cantidad causará } \\
\text { siempre dependencia. }\end{array}$ \\
\hline 20 & $\begin{array}{l}\text { Beber con moderación no es } \\
\text { perjudicial. }\end{array}$ & Adequado & Adequado & Adequado & Adequado & Adequado & $\begin{array}{l}\text { Definir cantidad sino } \\
\text { queda dificil de } \\
\text { evaluar, que es } \\
\text { moderación? }\end{array}$ & $\begin{array}{l}\text { Após analise em conjunto com o } \\
\text { orientador do estudo define-se e } \\
\text { conforme as sugestōes dos juizes } \\
\text { elimina-se este item por estar } \\
\text { representado em outras questões } \\
\text { presentes neste fator. }\end{array}$ & Eliminado \\
\hline 24 & $\begin{array}{c}\text { Estoy en contra del uso del alcohol en } \\
\text { cualquier circunstancia }\end{array}$ & Adequado & Adequado & Adequado & Adequado & Adequado & \begin{tabular}{|c|}
$\begin{array}{c}\text { No haría la colocación } \\
\text { personal }\end{array}$ \\
\end{tabular} & $\begin{array}{l}\text { Atendendo às sugestões do juiz } 6 \\
\text { elimina-se a colocação pessoal }\end{array}$ & $\begin{array}{c}\text { El uso de bebidas alcohólicas es perjudicial } \\
\text { en cualquier circunstancia }\end{array}$ \\
\hline 28 & $\begin{array}{l}\text { Estoy a favor de beber con } \\
\text { moderación. }\end{array}$ & Adequado & Adequado & Adequado & Adequado & Adequado & \begin{tabular}{|c|} 
Va a repetir el item 12 \\
y el 20 . No haría \\
colocación personal
\end{tabular} & $\begin{array}{l}\text { Em vista da eliminação do iten } 20 \text {, } \\
\text { atendeu-se a sugestão do juiz } 6, \mathrm{e} \\
\text { porcedeu-se à definir o beber } \\
\text { moderado e as doses segundo a } \\
\text { literatura especializada na area. }\end{array}$ & $\begin{array}{c}\text { Estoy a favor de beber con } \\
\text { moderación.(Hombres menos de cinco dosis } \\
\text { em uma ocasion y Mujeres menos de } 4 \\
\text { dosis em uma ocasion.) Dose } 11 \text { lata de } \\
\text { cerveza } 350 \mathrm{ml}, 1 \text { copa de vino } 140 \mathrm{ml}, 1 \\
\text { trago de destlado } 10 \mathrm{ml}, 1 \text { trago de aperibvo } \\
40 \mathrm{ml} . \\
\end{array}$ \\
\hline 32 & $\begin{array}{l}\text { Dosis pequeñas de alcohol pueden } \\
\text { causar dependencia. }\end{array}$ & Adequado & Adequado & Adequado & Adequado & Adequado & $\begin{array}{c}\text { Definir la dosis de } \\
\text { acuerdo con la } \\
\text { literatura }\end{array}$ & $\begin{array}{l}0 \text { item conservou-se igual já que as } \\
\text { doses foram definidas no item } \\
\text { anterior. } \\
\end{array}$ & \\
\hline 36 & $\begin{array}{c}\text { El alcohol en cantidades reducidas es } \\
\text { benéfico }\end{array}$ & Adequado & Adequado & Adequado & Adequado & Adequado & Adequado & O item conservou-se igual & $\begin{array}{l}\text { Las bebidas alcohólicas en cantidades } \\
\text { reducidas son benéficas }\end{array}$ \\
\hline 40 & $\begin{array}{l}\text { Las personas pueden beber desde } \\
\text { que sepan controlarse. }\end{array}$ & Adequado & Adequado & Adequado & $\begin{array}{l}\text { Mudar a expresão } \\
\text { "desde que sepan" por } \\
\text { "Con tal que" }\end{array}$ & Adequado & $\begin{array}{c}\text { Que es controlarse? } \\
\text { Mudar a expresão por } \\
\text { control sobre su uso }\end{array}$ & $\begin{array}{l}\text { Atendendo às sugestões dos jizes } \\
\text { elimina-se a expresão "desde que } \\
\text { sepan controlarse" }\end{array}$ & $\begin{array}{l}\text { Las personas pueden beber con tal que } \\
\text { mantengan el control sobre su uso.. }\end{array}$ \\
\hline
\end{tabular}


ANEXOS 


\section{ANEXOS}

Anexo I.

\section{Questionário baseado no Nursing Education in alcohol and Drug Education}

(NEADA) (Vásquez 2005):

\section{Proyecto Cicad/Oea}

Solicitamos su colaboración para realizar el presente estudio:

La Formación de Enfermeras y el Fenómeno de las Drogas en Brasil y Colombia: la realidad colombiana

Esta evaluación no supone respuestas acertadas o erradas. Estamos interesados apenas en conocer su opinión y experiencia teórica - práctica, así como su percepción y creencias frente al alcohol y las drogas.

No es Necesario su identificación

Gracias por su participación

Marque con una $\mathrm{X}$ el dato que corresponda

Escala sobre Creencias y Actitudes

\section{Parte III. Actitudes y Creencias - NAEDA FACULTY Y SURVEY}

En la escala siguiente responda sobre el uso de alcohol y Drogas, según sus experiencias y conocimientos

\begin{tabular}{|l|l|l|l|l|l|}
\hline \multicolumn{1}{|c|}{ Pregunta } & $\begin{array}{c}\text { Sí, } \\
\text { mucho }\end{array}$ & Suficiente & Algo & $\begin{array}{c}\text { Muy } \\
\text { poco }\end{array}$ & Nada \\
\hline $\begin{array}{l}\text { Mi educación básica en el alcoholismo es } \\
\text { adecuada }\end{array}$ & & & & & \\
\hline $\begin{array}{l}\text { Mi educación básica sobre el abuso de las drogas } \\
\text { es adecuada }\end{array}$ & & & & & \\
\hline $\begin{array}{l}\text { Aun cuando se sabe que el alcohol está } \\
\text { contribuyendo a los problemas de salud de los } \\
\text { pacientes es reconocido que no es competencia } \\
\text { del profesional de enfermería hablar a los } \\
\text { pacientes acerca de beber }\end{array}$ & & & & & \\
\hline No es fácil para las enfermeras hablar a los & & & & & \\
\hline
\end{tabular}




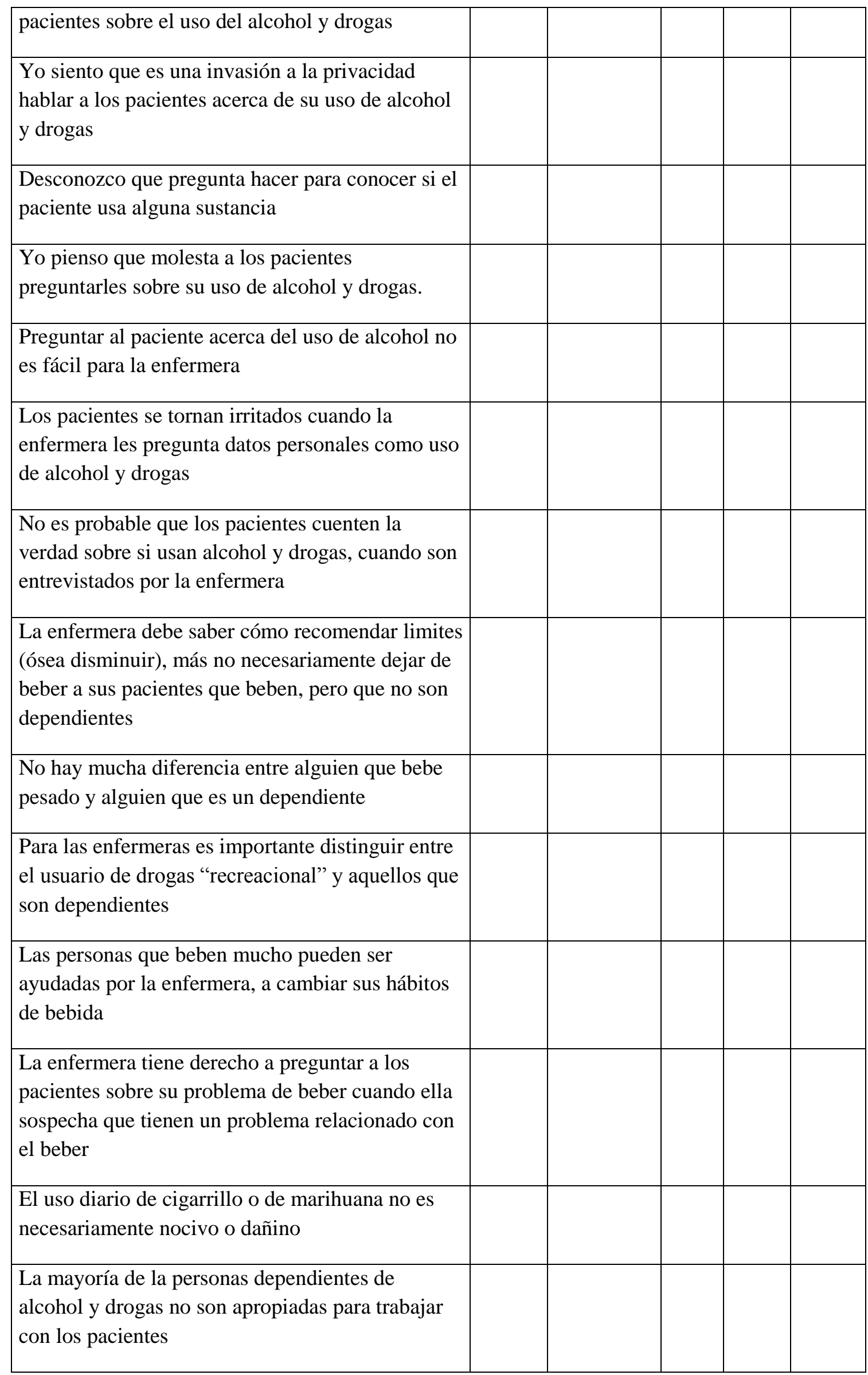




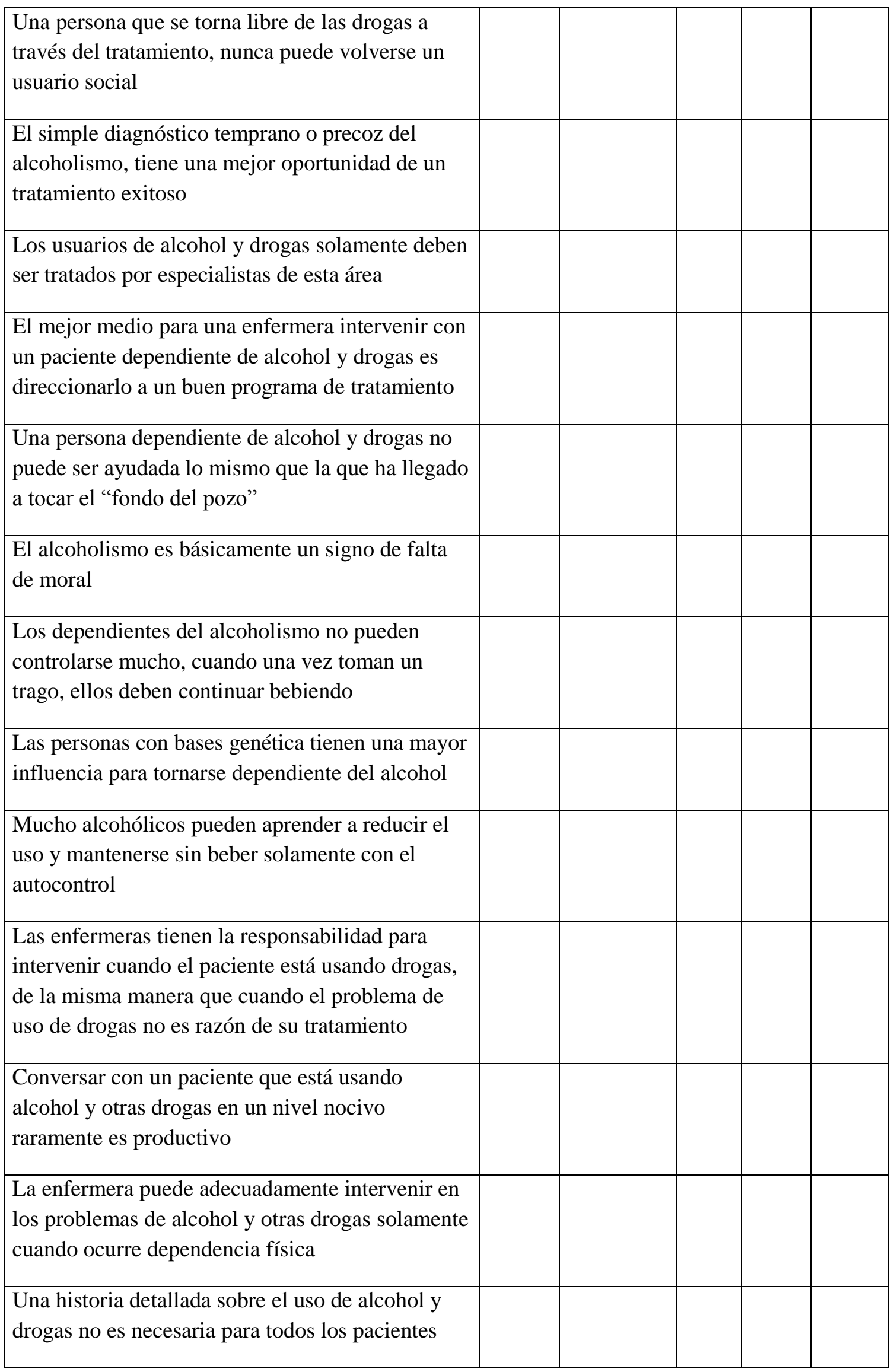


Anexo II

ESCALA SEMAN E MANELLO VERSÃO ESPANHOL.(Navarrete 2004)

\begin{tabular}{|c|c|c|c|}
\hline \multirow{2}{*}{$\begin{array}{c}\text { Escala Seaman e Mannello } / \text { Escala Likert }^{\star *} \\
\text { Sub-Escala I: Inclinación con relación al caso: terapia vs castigo }\end{array}$} & $|1| 2$ & \begin{tabular}{l|l}
3 \\
2
\end{tabular} & \\
\hline & & & \\
\hline 01. La vida de un alcohólico no es agradable & & & \\
\hline 06. Los alcohólicos tienen por lo general una pobre salud física & & & \\
\hline $\begin{array}{l}\text { 11. Pienso que es muy penoso que los alcohólicos sufran a menudo } \\
\text { por delirium tremens }\end{array}$ & & & \\
\hline 16. Los pacientes alcohólicos necesitan ayuda psiquiátrica & & & \\
\hline 21. Los alcohólicos deberían recibir tratamiento médico & & & \\
\hline 26. El alcoholismo es una enfermedad & & & \\
\hline $\begin{array}{l}\text { Sub-Escala II: Satisfacción personal/profesional en su trabajo con } \\
\text { alcohólicos }\end{array}$ & & & \\
\hline 02. Siento que trabajo mejor con pacientes alcohólicos & & & \\
\hline 07. Prefiero trabajar con alcohólicos en vez de otros pacientes & & & \\
\hline $\begin{array}{l}\text { 12. Los alcohólicos merecen un lugar en el hospital al igual que } \\
\text { cualquier otro paciente }\end{array}$ & & & \\
\hline $\begin{array}{l}\text { 17. No pienso que mis pacientes se enojen si discuto su problema de } \\
\text { consumo excesivo con ellos }\end{array}$ & & & \\
\hline 22. Me siento cómodo al trabajar con alcohólicos & & & \\
\hline $\begin{array}{l}\text { Sub-escala III: Inclinación a identificarse: habilidad para ayudar a } \\
\text { pacientes alcohólicos }\end{array}$ & & & \\
\hline 03. Los alcohólicos no se preocupan solamente por su felicidad & & & \\
\hline 08. Los alcohólicos respetan sus familias & & & \\
\hline 13. Los alcohólicos quieren dejar de tomar & & & \\
\hline $\begin{array}{l}\text { 18. Los alcohólicos que no obedecen las órdenes de las enfermeras } \\
\text { también deben ser tratados }\end{array}$ & & & \\
\hline 23. La mayoría de los alcohólicos no quiere ser alcohólico & & & \\
\hline 28. Puedo ayudar a un alcohólico aún si él o ella no deja de tomar & & & \\
\hline $\begin{array}{l}\text { Sub-Escala IV: Percepciones de características personales de } \\
\text { personas alcohólicas }\end{array}$ & & & \\
\hline 04. Los alcohólicos son gente muy sensible & & & \\
\hline 09. Los alcohólicos tienen complejo de inferioridad & & & \\
\hline $\begin{array}{l}\text { 14. Los alcohólicos fueron conducidos a la bebida debido a otros } \\
\text { problemas }\end{array}$ & & & \\
\hline $\begin{array}{l}\text { 19. Los alcohólicos sienten que no son malas personas debido a su } \\
\text { consumo de bebidas }\end{array}$ & & & \\
\hline 14. Un alcohólico es solitario & & & \\
\hline $\begin{array}{l}\text { 29. Los alcohólicos tienen usualmente dificultades emocionales } \\
\text { severas }\end{array}$ & & & \\
\hline Sub-Escala V: Actitudes personales hacia la bebida & & & \\
\hline $\begin{array}{l}\text { 05. El alcohol en cantidad moderada puede de hecho ser beneficioso } \\
\text { para la salud de las personas }\end{array}$ & & & \\
\hline 10. No hay nada malo en tomar cantidades moderadas de alcohol & & & \\
\hline $\begin{array}{l}\text { 15. Las bebidas alcohólicas son inofensivas si son usadas con } \\
\text { moderación }\end{array}$ & & & \\
\hline 20. La gente debería tomar bebidas alcohólicas si lo desea & & & \\
\hline $\begin{array}{l}\text { 25. Si son usadas con sabiduría, las bebidas alcohólicas no son más } \\
\text { dañinas para los adultos normales que las bebidas sin alcohol }\end{array}$ & & & \\
\hline $\begin{array}{l}\text { 30. El consumo de bebidas alcohólicas no convierte a las personas } \\
\text { normales en débiles y tontas }\end{array}$ & & & \\
\hline
\end{tabular}

"Extraído de: Navarrete PR, Luis MAV. Actitud de la enfermera de un complejo hospitalario en relación al paciente alcohólico. Rev Latino-Am Enfermagem. 2004; 12(número especial):420-426. 


\section{Escala de Atitudes Frente ao Álcool e ao Alcoolismo EAFAA (Vargas 2014)}

\begin{tabular}{|c|c|c|c|c|c|}
\hline $\mathbf{N}$ & Ítem & 1 & 2 & 3 & 4 \\
\hline 01 & Eu tenho medo de abordar o problema do álcool com meus pacientes. & & & & \\
\hline 05 & $\begin{array}{l}\text { Eu tenho medo da agressividade de pacientes com transtornos } \\
\text { relacionados ao uso do álcool. }\end{array}$ & & & & \\
\hline 09 & $\begin{array}{l}\text { Sinto-me frustrado quando trabalho com pacientes com transtornos } \\
\text { relacionados ao uso do álcool. }\end{array}$ & & & & \\
\hline 13 & $\begin{array}{l}\text { De todos os meus pacientes, o paciente com transtornos relacionados } \\
\text { ao uso do álcool é aquele que do mais trabalho. }\end{array}$ & & & & \\
\hline 17 & $\begin{array}{l}\text { Devo cuidar do paciente com transtornos relacionados ao uso do } \\
\text { álcool, mesmo que ele acredite não precisar de cuidado de saúde. }\end{array}$ & & & & \\
\hline 21 & $\begin{array}{l}\text { Mesmo quando não intoxicado o paciente com transtornos } \\
\text { relacionados ao uso do álcool, é desrespeitoso com os membros da } \\
\text { equipe. }\end{array}$ & & & & \\
\hline 25 & $\begin{array}{l}\text { Sinto raiva ao trabalhar com pacientes com transtornos relacionados } \\
\text { ao uso do álcool. }\end{array}$ & & & & \\
\hline 29 & $\begin{array}{l}\text { Pacientes com transtornos relacionados ao uso do álcool nunca } \\
\text { aceitam o que os profissionais de saúde falam sobre seus problemas } \\
\text { com a bebida. }\end{array}$ & & & & \\
\hline 33 & $\begin{array}{l}\text { Considero o paciente com transtornos relacionados ao uso do álcool } \\
\text { como um caso perdido. }\end{array}$ & & & & \\
\hline 37 & $\begin{array}{l}\text { Abordar o problema do álcool com pacientes com transtornos } \\
\text { relacionados ao uso do álcool significa menos tempo para os demais } \\
\text { pacientes. }\end{array}$ & & & & \\
\hline 41 & $\begin{array}{l}\text { Eu prefiro trabalhar com pacientes com transtornos relacionados ao } \\
\text { uso do álcool a trabalhar com outros pacientes. }\end{array}$ & & & & \\
\hline 44 & $\begin{array}{l}\text { Eu considero difícil estabelecer um relacionamento terapêutico com } \\
\text { pacientes com transtornos relacionados ao uso do álcool. }\end{array}$ & & & & \\
\hline 46 & $\begin{array}{l}\text { É preciso tomar cuidado para não ser agredido ao trabalhar com } \\
\text { pacientes com transtornos relacionados ao uso do álcool. }\end{array}$ & & & & \\
\hline 49 & $\begin{array}{l}\text { Quando trabalho com pacientes com transtornos relacionados ao uso } \\
\text { do álcool, não sei como conduzir a situação. }\end{array}$ & & & & \\
\hline 50 & $\begin{array}{l}\text { Cuidar de pacientes com transtornos relacionados ao uso do álcool não } \\
\text { é gratificante para mim }\end{array}$ & & & & \\
\hline 02 & $\begin{array}{l}\text { Pessoas com transtornos relacionados ao uso do álcool não têm bom } \\
\text { senso. }\end{array}$ & & & & \\
\hline 06 & $\begin{array}{l}\text { Pessoas com transtornos relacionados ao uso do álcool são mal- } \\
\text { educadas. }\end{array}$ & & & & \\
\hline 10 & $\begin{array}{l}\text { Pessoas com transtornos relacionados ao uso do álcool são } \\
\text { irresponsáveis. }\end{array}$ & & & & \\
\hline 14 & $\begin{array}{l}\text { Pacientes com transtornos relacionados ao uso do álcool tem maior } \\
\text { probabilidade de se tornarem violentos contra mim. }\end{array}$ & & & & \\
\hline 18 & Penso que pessoas que desenvolvem o alcoolismo são fracas. & & & & \\
\hline 22 & Eu percebo que pacientes com transtornos relacionados ao uso do & & & & \\
\hline
\end{tabular}




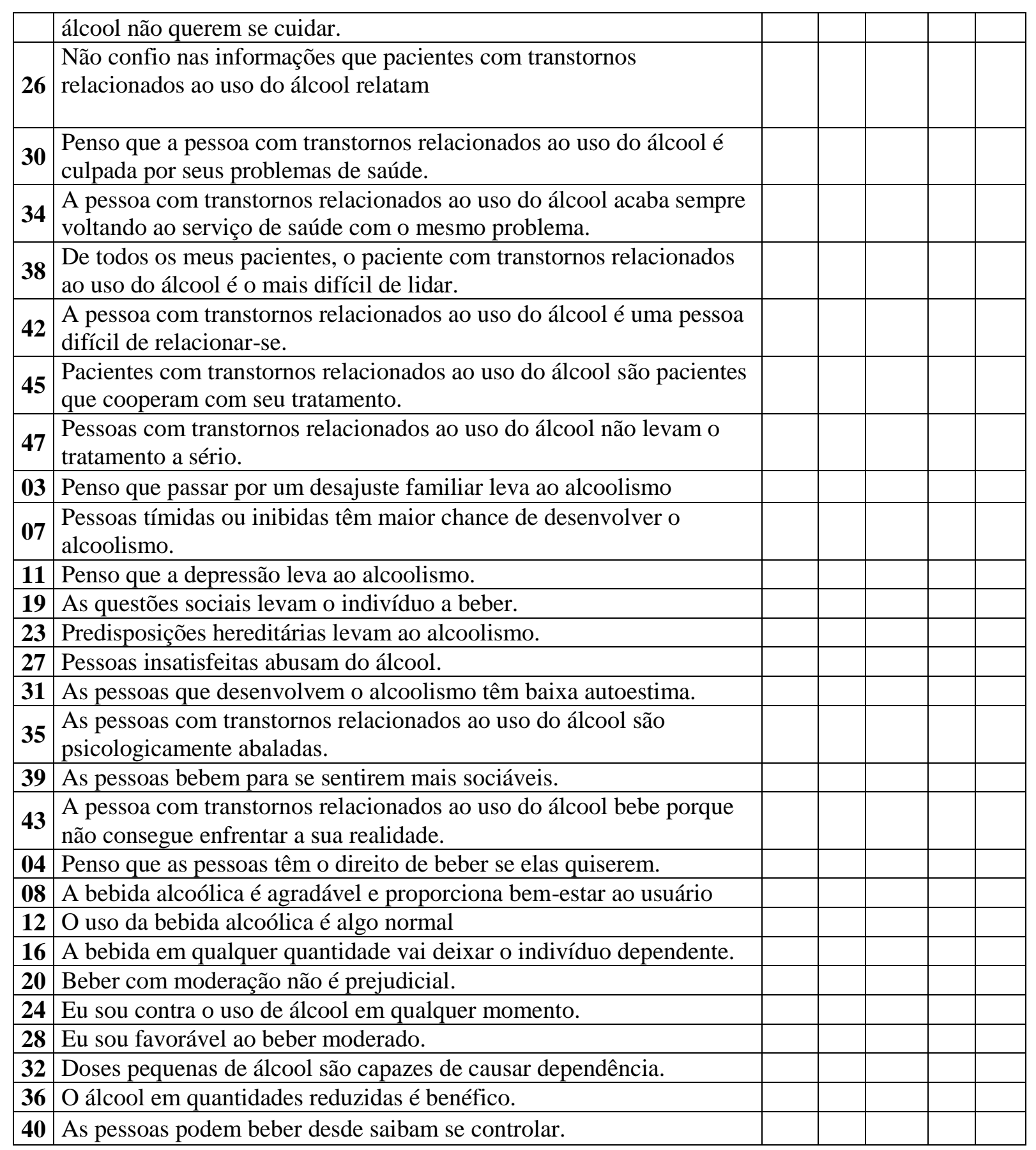




\section{Anexo IV}

\section{Aprovação comitê de ética em pesquisa da Escola de Enfermagem da Universidade} de São Paulo

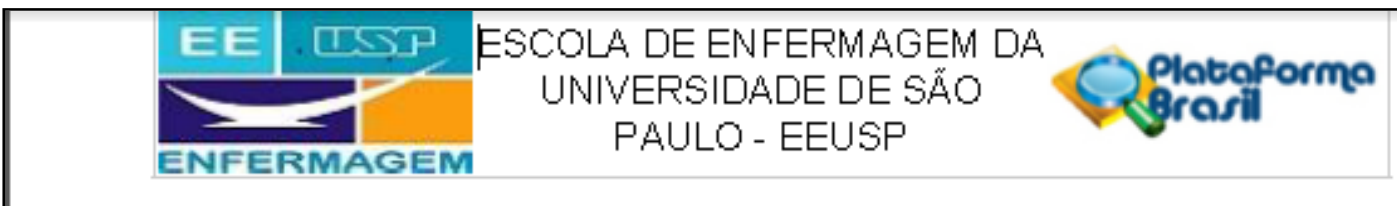

\section{PARECER CONSUBSTANCIADO DO CEP}

DADOS DO PROJET ODE PESQUISA

Título da Pesquis: TRADUÇÃ̃o, ADAPTAÇÃO CULTURAL E VALIDAÇÃ̃O DA ESCALA DE ATITUDES FRENTE AO ÁLC OOL, AO ALC OOLISMO E AO ALC OOLISTA.

EAFAVERSÄO ESPANHOL

Pesquisador: DNANE DE VARGAS

Área Temática:

Vers̃̃o: 3

CAAE: 33481214.60000 .5392

Instituição Proponente: Escola de Enfermagem da Universidade de São Paulo - EEUSP

Parocinador Principal: Financiamento Próprio

DADOS DO PARECER

Nú mero do Parecer: 843.965

Data da Relatoria: 20/10/2014

Apresentaç引o do Projeto:

Trata-se de um estudo do tipo metodológico em que o instrumento Escala de Aditudes Frente ao Álcool, ao Alcoolismo e ao Alcoolista (EAFA), elaborado no Brasil por um dos pes quisadores deste projeto, será traduzido, adaptado culturalmente e validado para o idioma Espanhol. Para isto, o instrumento será adaptado para a cultura colombiana seguindo as etapas sugeridas pela literatura sobre as diretrizes de tradução e adaptação de irs trumentos: tradução, retro tradução, avaliação da vers âo por um comitê de juizes, e préteste daversão final. Para aualiar as propriedades psicométricas do instrumento na versâo em espanhol, ou seja, para verificar se as característic as do instrumento original for am mantidas, a escala será aplicada em uma amost a de, no mínimo, 500 sujeitos, que serẫo enfermeiros nascidos em países his panoamericanos cuja língua nativa s eja o es panhol e que estejam vinculados a instituiçốes de saúde credenciadas pelo Ministério de Proteçâo Social da Colômbia e que aceitam participar do estudo. 


\section{EE TSTP ESCOLADE ENFERMAGEM DA UNIVERSIDADE DE SÄO \\ PAULO - EEUSP \\ ENFERMAGEM}

Con thiaça do Pare oer: 8 13.955

Alcoolista-EAFA para o idioma Espanhol.

\section{Aualiação dos Risc os e Benefícios:}

Nấo há riscos nem benetícios diretos aos participantes da pesquisa.

\section{Comentários e Considerações sobre a Pesquisa:}

O projeto contempla as etapas de um projeto de cunho metodológico que visa a adaptaçấo cultural e a validaçẫo de um instrumento para determinada línguaicultura. Tem coerência e está bem fundamentado.

\section{Considerações sobre os Temmos de apresentação obrigatória:}

O TCLE é adequadam ente apresentado.

\section{Recomendaçōes:}

Nẫo há.

Conclusóes ou Pendências e Lista de Inadequações:

Projeto aprovado.

\section{Situação do Parecer:}

Aprovado

\section{Necessita Apreciação da CONEP:}

Nẫo

\section{Considerações Finais a critério do CEP:}

A aprovaçẫo do Comitê de Ética em Pesquisa da EEUSP nẫo substitui a autorizaçẫo da instituiçẫo coparticipante para o início da pesquisa.

O CEP EEUSP informa que há necessidade de registro dos relatórios: parcial e final da pesquisa, na Plataforma Brasil. 


\section{Anexo V \\ QUESTIONARIO ANÁLISE SEMANTICA DA VERSÃO PRELIMINAR}

Escala de actitudes frente al alcohol, al alcoholismo y a la persona con transtornos relacionado al uso de bebidas alcohólicas.

1. ¿Para usted los items de la escala fueron claros? Por favor marque com uma X segun corresponda.

$\mathrm{SI} \square \quad \mathrm{NO} \square$

En caso de que su respuesta sea NO, porfavor especifique el número del item y una breve descripción que defina las razones por las que no fue claro.

2. ¿Tuvo alguna dificultad al diligenciar el instrumento? Por favor marque com uma $\mathrm{X}$ segun corresponda.

SI

NO

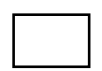

En caso de que su respuesta sea SI, porfavor haga uma breve descripción que defina las dificultades presentadas. 